\author{
UNIVERSITY OF SÃO PAULO \\ Faculty of Pharmaceutical Sciences \\ Graduate Program in Food Science \\ Area: Food Science
}

Carlos Mario Donado-Pestana

Polyphenols from cagaita (Eugenia dysenterica DC.) and cambuci (Campomanesia phaea Berg.): bioactivities in dietinduced obesity and their metabolic alterations

SÃO PAULO

2016 

Carlos Mario Donado-Pestana

Polyphenols from cagaita (Eugenia dysenterica DC.) and cambuci (Campomanesia phaea Berg.): bioactivities in diet-induced obesity and their metabolic alterations

Original version

Thesis presented for the degree of

DOCTOR IN SCIENCE

Adviser: Prof. Dr. Maria Inés Genovese 
Ficha Catalográfica

Elaborada pela Divisão de Biblioteca e Documentação do Conjunto das Químicas da USP.

Donado-Pestana, Carlos Mario

D674p Polyphenols from cagaita (Eugénia dysenterica DC.) and cambuci (Campomanesia phaea Berg.): bioactivities in diet-induced obesity and their metabolic alterations / Carlos Mario DonadoPestana. -- São Paulo, 2016.

$157 \mathrm{p}$.

Thesis (doctorate) - Faculty of Pharmaceutical Sciences of the University of São Paulo. Department of Food and Experimental Nutrition.

Orientador: Genovese Rodriguez, Maria Inés

1. Alimento: Composto fenólico: Ciência dos alimentos 2. Diabetes mellitus 3. Obesidade 4. Frutas tropicais I. T. II Genovese Roplriguez, Maria Inés, orientador.

$641 \quad \mathrm{CDD}$ 


\title{
Carlos Mario Donado-Pestana
}

Polyphenols from cagaita (Eugenia dysenterica DC.) and cambuci (Campomanesia phaea Berg.): bioactivities in diet-induced obesity and their metabolic alterations

Thesis presented to the Graduate Program in Food Science for the degree of Doctor in Science

\author{
Examining committee
}

Prof. Dr. Maria Inés Genovese

Adviser/Chair

$1^{\mathrm{o}}$ Member

$2^{\circ}$ Member

$3^{\mathrm{o}}$ Member

$4^{\mathrm{O}}$ Member

São Paulo, of 

To my beloved wife, Priscila, and my entire family for their continuous support and encouragement 



\section{ACKNOWLEDGEMENTS}

Throughout my educational formation, I have had the opportunity of receiving the orientation and support of innumerable people and institutions. I would like to express my most sincere gratitude to each and every one of them, being certain that each person and each institution made it possible for this objective to be conquered.

I wish to express my sincere gratitude:

To University of São Paulo, to Faculty of Pharmaceutical Sciences and to the Department of Food and Experimental Nutrition, for the opportunity and the honor of being a part of this highly regarded academic universe.

To the Coordenação de Aperfeiçoamento de Pessoal de Nível Superior (CAPES) for the vital support received through the Programa Estudante Convênio da Pós-graduação (PEC-PG, processo No. 5554-11-0).

To professor Dr. María Inés Genovese Rodríguez, for opening the doors of this institution and giving me the opportunity and the honor of having been guided by her. It was a very productive educational process and in both academic and personal arenas, I will carry your orientations and your teachings with me, forever.

To the Group of Bioactive Compounds in Foods, students and former students, graduates and undergraduates who have been or are a part of it, for your friendship and for the knowledge generated throughout this academic journey. I esteem each and every one of you highly and wish you great personal and professional success, always.

To professor Dr. William Tadeu Festuccia for the contributions in the revisions of this document and to Dr. Thiago Belchior de Oliveira, both who have accompanied and given support for the realization of the activities, which were programmed for this research. 
To the Department of Food and Experimental Nutrition, professors, students, and to the workers for your professional and human virtues, and for the contributions in making the development of this work viable.

To Wendel Saboia da Silva for the grammatical revisions of the English language in this document. 
"As the Philosopher says at the beginning of the Metaphysics, all men and women naturally desire to possess knowledge. This can, and should, be traced to the fact that every being has a drive inherent in its own nature directing it towards its own perfection. Since knowledge is the

highest perfection of our soul, in which our supreme happiness is found, we are all by our very nature driven by the desire to attain this"

Banquet, Dante Alighieri 



\begin{abstract}
DONADO-PESTANA, C. M. Polyphenols from cagaita (Eugenia dysenterica DC.) and cambuci (Campomanesia phaea Berg.): bioactivities in diet-induced obesity and their metabolic alterations. 2016. Doctoral thesis - Faculty of Pharmaceutical Sciences, University of São Paulo, São Paulo.
\end{abstract}

Obesity and overweight have reached epidemic proportions and their prevalence has increased dramatically in the last decades worldwide. This has resulted in a dramatic increase in the incidence of obesity-associated metabolic alterations including type 2 diabetes, cardiovascular complications, and certain types of cancer. Evidences suggest that bioactive compounds present in fruit and vegetables, including polyphenols (or phenolic compounds), may exert beneficial effects against the development of obesity and associated alterations. Brazil is the world's third largest fruit producer and the seventh largest producer of tropical fresh fruits; however, only a few of them are being exploited commercially, perhaps due to the limited amount of information available about their chemical composition, and biochemical, nutritional and functional properties. Cagaita (Eugenia dysenterica DC.) and cambuci (Campomanesia phaea Berg.) are fruit species of the Myrtaceae family growing in the regions of the Brazilian Cerrado and Atlantic Coastal Forest biomes, respectively. Cagaita and cambuci fruits are used in various typical preparations, mainly jams, jellies, ice-cream, and liqueurs; whereas both fruit and leaves are used as popular alternative medicine by local communities to treat various disturbs such as diarrhea, diabetes, and jaundice. Previous studies have demonstrated the antioxidant and antidiabetic potential from cagaita and cambuci polyphenols in in vitro assays. Thus, in the present study, we investigated whether the administration of polyphenol-rich extracts from cagaita and cambuci, at two different doses, protect mice from diet-induced obesity and associated alterations. Two biological models, preventive and therapeutic, were designed for cagaita, and preventive for cambuci. For the preventive protocols, C57BL/6J mice fed either with a chow or a high-fat, high-sucrose (HFHS) diets were daily treated by gavage with water or polyphenols-rich extracts at two doses for 8 weeks. The findings demonstrate that polyphenols from cagaita prevented body weight and fat mass gains, attenuated fasting hyperglycemia and dyslipidemia, and reduced hepatic lipid accumulation. On the other hand, polyphenols from cambuci showed absence of changes in body weight and adiposity; however, an attenuation of adipose tissue inflammation 
was observed for both doses tested. Additionally, polyphenols from cambuci were effective in ameliorating glucose tolerance, as well as reducing fasting hyperglycemia, and improving dyslipidemia. For the therapeutic protocol, C57BL/6J obese mice induced by the intake of a HFHS diet for six weeks were treated with polyphenols from cagaita at two doses by oral gavage for further 8 weeks. Polyphenols from cagaita improved glucose homeostasis and attenuated dyslipidemia in obese mice, without affecting body weight and adiposity. Mechanistically, these beneficial actions seem to be mediated, at least in part, through a reduction in hepatic inflammation. In conclusion, polyphenols from cagaita and cambuci have a potential protective role in diet-induced obesity and their metabolic alterations.

Keywords: cagateira, cambucizeiro, Brazilian Cerrado, Atlantic Coastal Forest, Myrtaceae, phenolic compounds, diabetes. 


\section{RESUMO}

DONADO-PESTANA, C. M. Polifenóis de cagaita (Eugenia dysenterica DC.) e cambuci (Campomanesia phaea Berg.): bioatividades na obesidade induzida por dieta e suas alterações metabólicas. 2016. Tese (Doutorado) - Faculdade de Ciências Farmacêuticas, Universidade de São Paulo, São Paulo.

A obesidade é considerada uma das grandes epidemias do século XXI, devido ao aumento de sua prevalência nos últimos anos e às diversas co-morbidades decorrentes destas alterações metabólicas como diabetes mellitus tipo 2, doenças cardiovasculares e alguns tipos de câncer. Evidências sugerem que compostos bioativos presentes em frutas e vegetais, incluindo os

polifenóis (ou compostos fenólicos), podem exercer efeitos benéficos contra o desenvolvimento de obesidade e suas alterações associadas. O Brasil é o terceiro produtor mundial de frutas e o sétimo na produção de frutas tropicais, no entanto, um grande número de espécies frutíferas nativas permanece inexplorado em relação a seu potencial nutricional e funcional. Cagaita (Eugenia dysenterica DC.) e cambuci (Campomanesia phaea Berg.) são espécies frutíferas originárias das regiões do Cerrado e da Mata Atlântica, respectivamente, cujos frutos são usados na elaboração de diversos produtos alimentícios, e frutos e folhas de cagaita são usados na medicina popular. Estudos prévios têm demonstrado o potencial antioxidante e antidiabético in vitro dos polifenóis de ambas as frutas. Neste contexto, no presente estudo, foi investigado se a administração de extratos ricos em polifenóis de cagaita e cambuci, em duas doses diferentes, protegem camundongos de obesidade induzida por dieta a suas alterações associadas. Dois modelos biológicos, preventivo e terapêutico, foram desenvolvidos para cagaita, e preventivo para cambuci. Para os protocolos preventivos, foram usados camundongos da linhagem C57BL/6J alimentados com dieta rica em gorduras e sacarose (high-fat high-sucrose diet, HFHS), aos quais foram administrados água (controle) ou extratos ricos em polifenóis por gavagem em duas doses por 8 semanas. Os resultados demonstraram diferentes efeitos para os dois extratos. Os polifenóis de cagaita preveniram ganho de peso corporal e adiposidade, atenuaram hiperglicemia de jejum e dislipidemia, e reduziram acumulação de lipídeos hepáticos. Por outro lado, polifenóis de cambuci não contribuíram na prevenção do ganho de peso corporal e adiposidade, no entanto, foi observada uma atenuação na inflamação do tecido adiposo, em ambas as doses avaliadas. Adicionalmente, polifenóis de cambuci melhoraram a tolerância à glicose, assim como 
reduziram a hiperglicemia de jejum e atenuaram a dislipidemia. Para o protocolo terapêutico, camundongos da linhagem C57BL/6J foram induzidos à obesidade pela ingestão da dieta alta em gorduras e sacarose por 6 semanas e posteriormente foram tratados com polifenóis de cagaita, em duas doses, por gavagem por 8 semanas. Os polifenóis de cagaita melhoraram a homeostase glicêmica e atenuaram a dislipidemia em camundongos obesos, sem afetar peso corporal e adiposidade. Estes benefícios aparentam ser mediados, ao menos em parte, através da uma redução da inflamação hepática. Em conclusão, polifenóis de cagaita e cambuci têm um papel protetor potencial em obesidade induzida por dieta e suas alterações metabólicas.

Palavras chaves: cagateira, cambucizeiro, Cerrado, Mata Atlântica, Myrtaceae, compostos fenólicos, diabetes. 


\section{LIST OF ABBREVIATIONS}

$\begin{array}{ll}\text { ANOVA } & \text { Analysis of variance } \\ \text { AUC } & \text { Area under the curve } \\ \text { BMI } & \text { Body mass index } \\ \text { BSA } & \text { Bovine serum albumin } \\ \text { CBC } & \text { Phenolic-rich extract from cambuci } \\ \text { CD11b } & \text { Integrin alpha M } \\ \text { CD86 } & \text { CD86 antigen }\end{array}$

CEUA/FCF Ethical Committee for Animal Research of the Faculty of Pharmaceutical Science of University of São Paulo

CGT Phenolic-rich extract from cagaita

CVD Cardiovascular disease

DPPH 2,2-diphenyl-1-picrylhydrazyl (DPPH) radical-scavenging

ERK Extracellular signal-regulated kinases

F4/80 EGF-like module containing, mucin-like, hormone receptor-like sequence 1

FAO Food and Agriculture Organization of the United Nations

FDA Food and Drug Administration

FRAP Ferric reducing antioxidant power, plasma

G6Pase Glucose-6-phosphatase

GAE Gallic acid equivalent

GLUT Glucose transporter

GTT Glucose tolerance test

HDL High-density lipoprotein

HF/HS High-fat, high-sucrose diet

HFHS High-fat, high-sucrose diet

HFS High-fat, high-sucrose diet

HMGR 3-hydroxy-3-methylglutaryl-CoA reductase

HPLC High-performance liquid chromatography

$\mathrm{IC}_{50} \quad$ Half maximal inhibitory concentration

IKK I $\quad$ I B kinase

IL Interleukin 
IRS Insulin receptor substrate

JNK, c-Jun N-terminal kinases

LDL Low-density lipoprotein

LSD Fisher's least significant difference

LTB4 Leukotriene B4

M1 Classically active macrophages

M2 Alternatively active macrophages

MCP-1 Monocyte chemotatic protein-1

NEFA Non-esterified fatty acid

NFאB Nuclear factor kappa-light-chain-enhancer of activated B cells

OGTT Oral glucose tolerance test

ORAC Oxygen radical absorbance capacity

PCE Polyphenol-rich cagaita extract

PCX Pyruvate carboxylase

PEPCK Phosphoenolpyruvate carboxykinase

PPAR $\gamma \quad$ Peroxisome proliferator-activated receptor gamma

PTFE Polytetrafluoroethylene

QTE Quebracho tannin equivalent.

RER Respiratory exchange ratio

ROS Reactive oxygen species

RPL19 Ribosomal protein L19

RPL3 Ribosomal protein L3

SD Standard deviation

SEM Standard error

SGLT1 Sodium-dependent glucose transporter 1

SPE Solid-phase extraction

TAG Triacylglycerol

TNF- $\alpha \quad$ Tumor necrosis factor-alpha

WHO World Health Organization 


\section{LIST OF FIGURES}

Figure 1. Global prevalence of overweight and obesity (A) and obesity alone (B), ages $\geq 20$ years, by sex.

Figure 2. Evolution of inflammation in obesity accompanied with the progression of insulin resistance and cardiovascular disease. Obese adipose tissue is characterized by inflammation and progressive macrophage infiltration in the development of obesity. Adipocyte hypertrophy promotes physical changes in the surrounding area and modifications of the paracrine function of the adipocyte.

Figure 3. Representative histological illustration of inflamed adipose tissue. Macrophages (brown color) are organized into two separate 'crown-like structures' (indicated by arrows) surrounding individual adipocytes.

Figure 4. Regulation of macrophage polarity in both lean and obese adipose tissue and paracrine interaction between adipocytes and macrophages (A). Both M1 and M2 macrophages express myeloid cell surface markers F4/80 and CD11b. However, only M1 population expresses marker CD11c (B).

Figure 5. Cagaita or cagaiteira (Eugenia dysenterica DC.) and derivative products

Figure 6. Cambuci or cambucizeiro (Campomanesia phaea Berg.) and derivative products 36 



\section{TABLE OF CONTENTS}

ABSTRACT

RESUMO

LIST OF ABBREVIATIONS

LIST OF FIGURES

1. INTRODUCTION

1.1 Prevalence of obesity and overweight

1.2 Obesity and inflammation

1.3 Polyphenols as bioactive compounds

1.4 Cagaita (Eugenia dysenterica DC.) and cambuci (Campomanesia phaea Berg.) and their potential functional role

1.4.1 Cagaita (Eugenia dysenterica DC.)

1.4.2 Cambuci (Campomanesia phaea Berg.)

2 OBJECTIVES

2.1 General objective

2.2 Specific objectives

3.1 Preventive protocol for cagaita

3.1.1 Preparation and characterization of phenolic-rich extract from cagaita 
3.1.5 Fecal lipids determination 44

3.1.6 Liver glycogen, triacylglycerol, and total cholesterol determination 44

3.1.7 Statistical analysis $\quad 45$

3.2 Preventive protocol for cambuci $\quad 46$

3.2.1 Preparation and characterization of phenolic-rich extract from cambuci $\quad 46$

3.2.2 Animals and experimental design 47

3.2.3 Glucose tolerance test (GTT) $\quad 48$

3.2.4 Plasma biochemical parameters $\quad 48$

3.2.5 Gene expression analysis by quantitative PCR 48

3.2.6. Statistical analysis $\quad 49$

3.3 Therapeutic protocol for cagaita 49

3.3.1 Preparation of polyphenol-rich cagaita extracts (PCE) 49

3.3.2 Animals and experimental design $\quad 50$

3.3.3 Oral glucose tolerance test (OGTT)

3.3.4 Oxygen consumption and respiratory exchange ratio (RER) determination 51

3.3.5 Lipolysis and isolation from epididymal adipocytes $\quad 51$

3.3.6 Serum biochemical parameters $\quad 52$

3.3.7 Fecal energy determination $\quad 52$

3.3.8 Gene expression analysis by quantitative PCR 52

3.3.9 Protein analysis by immunoblotting 53

3.3.10 Statistical analysis $\quad 53$ 
4.1 Phenolic compounds from cagaita (Eugenia dysenterica DC.) fruit prevent body weight and fat mass gain induced by a high-fat, high-sucrose diet ${ }^{1}$

4.2 Phenolic compounds from cambuci (Campomanesia phaea Berg.) fruit attenuate glucose intolerance and adipose tissue inflammation induced by high-fat, high-sucrose $\operatorname{diet}^{2}$

4.3 Polyphenols from cagaita (Eugenia dysenterica DC.) improve glucose homeostasis and reduce hepatic inflammation in high-fat/high-sucrose-diet-induced obesity

5. CONCLUSIONS

6. REFERÊNCIAS

ANEXOS 



\section{INTRODUCTION}

Obesity is defined as a condition of excessive body fat accumulation with a characteristic etiology, an imbalance between energy intake and expenditure (TURCONI, CENA, 2007; BRAY, 2004). The obesity condition is associated with a state of chronic, low-grade inflammation, and is a major risk factor for the development of obesity-induced metabolic alterations, such as diabetes and cardiovascular diseases (ITOH et al., 2011).

The prevalence of obesity is a serious health issue threatening modern society and has markedly increased in the last decades. According to a recent study developed by NCD Risk Factor Collaboration, the global prevalence of obesity increased from 3.2\% in 1975 to $10.8 \%$ in 2014 in men, and from $6.4 \%$ to $14.9 \%$ in women (NCD RISK FACTOR COLLABORATION, 2016). This study also reported that if the post-2000 trends continue, by 2025 , global obesity prevalence will reach $18 \%$ in men and surpass $21 \%$ in women. The yearly increase in the prevalence rate of obesity and its associated co-morbidities has generated a substantial impact on the public health burden. Despite the global strategies and health policies to counter this problem, the growing trend remains unaltered.

Several factors are associated with obesity and obesity-related chronic diseases, including gender, race, and socioeconomic condition (PAERATAKUL et al., 2002). However, there are also environmental factors which influence this condition, including the frequency of physical activity and type of diet. It has been suggested that the fundamental cause of obesity is an imbalance between the amount of energy intake as food and the energy expenditure by the body in daily activities, making the analogy with the first law of thermodynamic, which suggests that the energy of a system is determined by the difference between the heat that enters that system and the heat that leaves (BRAY, 2004).

Dietary factors are important to obesity management. High energy intake from consumption of processed foods, which are usually high in carbohydrates (mainly simple carbohydrates) and fats, contributes to obesity development. In contrast, diets rich in fruits and vegetables may exert beneficial physiological effects against obesity and obesity-related abnormalities. There are evidences that high intake of fruit and vegetables results in reduced risk of chronic non-communicable diseases (NAKAMURA et al., 2008; AUNE et al., 2012). Although the mechanisms by which fruits and vegetables exert those protective actions are not yet completely elucidated, they may be related to antioxidant and anti-inflammatory 
properties featured in the chemical components of these crops (CARTER et al., 2010; CHERNIACK, 2011). These benefits have been partially attributed to the bioactive compounds that are present in these foods. Bioactive compounds vary widely in chemical structure and function, which are regularly involved in the plant secondary metabolism. Polyphenols (also known as phenolic compounds) are the most abundant bioactive compounds in the diet and are widespread components of fruits, vegetables, cereals, legumes, chocolate, and beverages, such as tea, coffee, and wine (SCALBERT et al., 2005).

Due to its area, geographic location, climate, and soil conditions, Brazil has a natural abundance of native fruits, being the world's third largest fruit producer and the seventh largest producer of tropical fresh fruit (FAOSTAT, 2016); however, only a few of them are being exploited commercially, perhaps due to the limited amount of information available about their chemical composition, and biochemical and nutritional properties. These native fruits are used in various typical preparations (jams, jellies, liqueurs, etc.), and as popular alternative medicine by local communities to treat diverse diseases, including diarrhea, diabetes, jaundice, among others.

Most of the drugs used by modern medicine such as aspirin, and anti-cancer and antidiabetic drugs are originated from plants. Medicinal plants have a potential effectiveness against deleterious metabolic alterations and bioactive compounds play a major role in their management (PRABHAKAR, DOBLE, 2008). In this context, this work describes the functional properties of polyphenols obtained from cagaita (Eugenia dysenterica DC.) and cambuci (Campomanesia phaea Berg.) fruits of the plant family Myrtaceae. We have investigated whether the administration of polyphenol-rich extracts from both fruits at two different doses protects male mice C57BL/6J from diet-induced obesity and their metabolic alterations.

\subsection{Prevalence of obesity and overweight}

The prevalence of obesity (body mass index, BMI > 30) and overweight (BMI, 25-30) has increased dramatically in the last decades worldwide. According to current estimates of the World Health Organization (WHO), in 2014, more than 1.9 billion adults, 18 years and older, were overweight; of these, over 600 million were obese. About 42 million children under the age of five years were overweight or obese in 2013 (WHO, 2016). 
Until relatively recently, obesity was considered a condition associated with the developed world. In the $20^{\text {th }}$ century, most countries in which obesity became a public health problem were, mainly, United States and European countries. However, in more recent decades, available information shows that the most dramatic increases in obesity are in developing countries, specifically in their urban areas (CABALLERO, 2007).

In Brazil, obesity is a problem which affects the population of children and adults of both sexes. WHO estimated that, in 2015 , the prevalence of overweight was $67.2 \%$ and $73.6 \%$ in Brazilian men and women, respectively; and obesity was $21.6 \%$ and $39.7 \%$, respectively (WHO, 2016). In a recent study, it was shown that Brazil along with nine other countries (United States, China, India, Russia, Mexico, Egypt, Germany, Pakistan, and Indonesia) have more than $50 \%$ of the obese individuals in the world (NG et al., 2014). This study also appointed that no countries had significantly decreased obesity in the past 30 years. Comparison between countries suggests that in developed countries more men than women were overweight or obese, whereas in developing countries, overweight and obesity was more prevalent in women (Figure 1) (NG et al., 2014).

Type 2 diabetes mellitus is a chronic metabolic disorder, which corresponds to $80 \%$ of the overall incidence of diabetes, and is strongly associated with both obesity and insulin resistance (BIDEN et al., 2014; DEFRONZO, 1999). In 2011, diabetes mellitus affected 366 million people, and the prevalence is expected to rise to 552 million by 2030. Most individuals with diabetes live in developing countries, and these countries will have the greatest increase over the next two decades (WHITING et al., 2011). In 2012, WHO estimated that 1.5 million deaths were directly caused by diabetes and another 2.2 million deaths were attributed to high blood glucose (characteristic of pre- or diabetes). The WHO also projected that diabetes will be the $7^{\text {th }}$ leading cause of death in 2030 (WHO, 2016). The study by Whithing et al. (2011) highlights the demographic changes in countries with large populations as Brazil, China and India, which can affect the total numbers of diabetes in the future. In Brazil, it was estimated that in 2011, 12.4 million Brazilians were diabetic and estimates for 2030 indicate an increase to 19.6 millions, ranking the country in the fourth among the "top 10" countries with the largest numbers of people with diabetes (WHITING et al., 2011). 

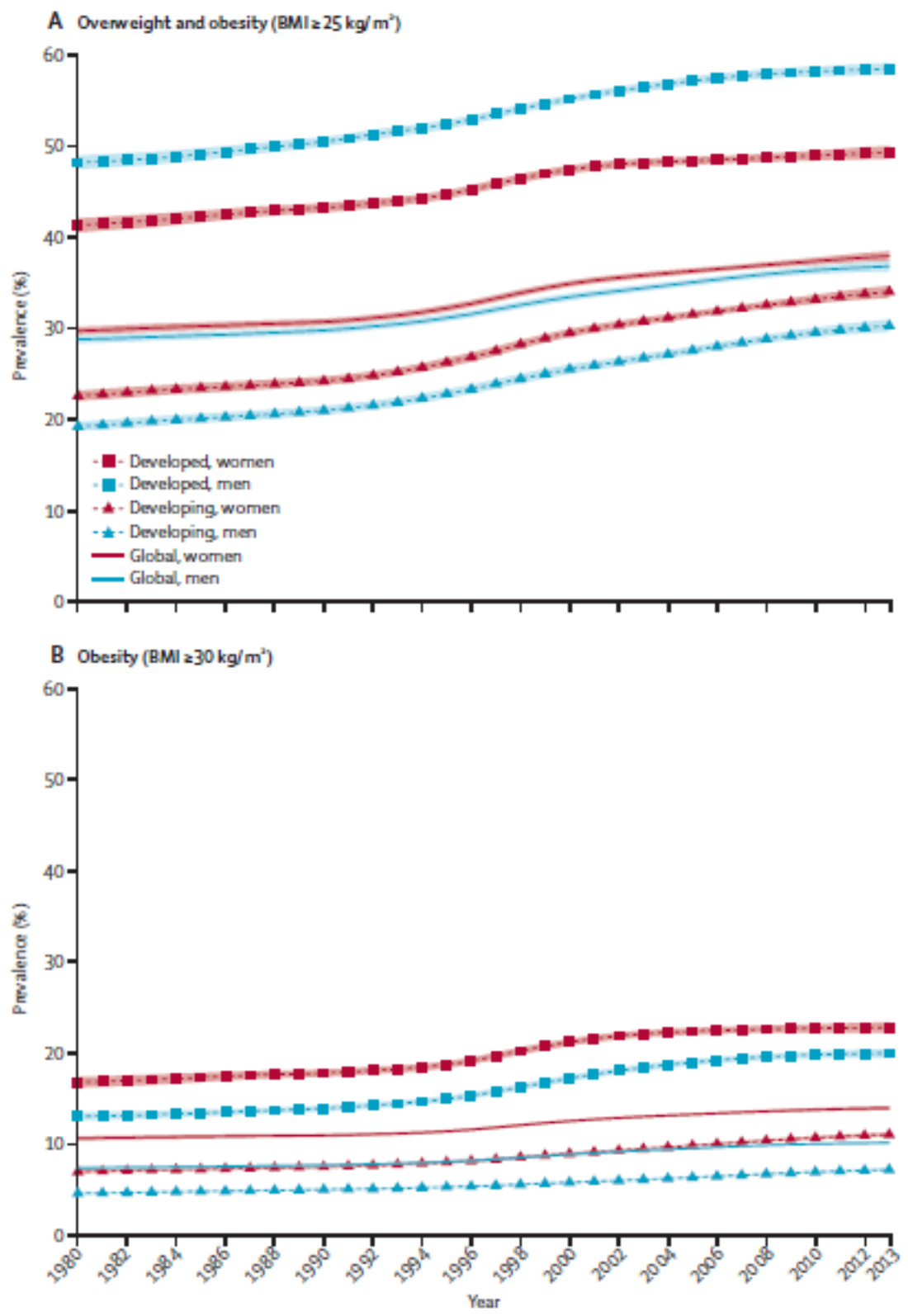

Figure 1. Global prevalence of overweight and obesity (A) and obesity alone (B), ages $\geq 20$ years, by sex. BMI: Body mass index.

Source - NG et al. 2014

\subsection{Obesity and inflammation}

For many years, the adipose tissue was classically viewed only as an organ playing a passive role as a storage depot for excess calories (CYPESS; KAHN, 2013). However, adipose tissue is now recognized as a highly active metabolic and endocrine organ, regulating physiologic and pathologic processes, including immunity and inflammation (FRAYN et al., 2003; FANTUZZI, 2005). 
During the development of obesity, the adipose tissue is characterized by adipocyte hypertrophy, an increase in angiogenesis, immune cell accumulation (such as macrophages), and extracellular matrix overproduction, favoring the adipose tissue remodeling (ITOH et al., 2011). These changes in adipocyte and fat pad size lead to a physical changes in the surrounding areas and modifications of the paracrine function of the adipocyte associated with a chronic inflammatory response characterized by an abnormal cytokine production and the activation of the inflammatory signaling pathways (Figure 2) (WELLEN, HOTAMISLIGIL, 2003). The accumulation of macrophages in the adipose tissue can contribute to enhance the 'low-grade' chronic inflammation associated with obesity, since macrophages and adipocytes are secretory cells. It has been suggested that the 'low-grade' inflammatory state is associated with metabolic complications of obesity including, diabetes and cardiovascular diseases (CANCELLO; CLÉMENT, 2006).

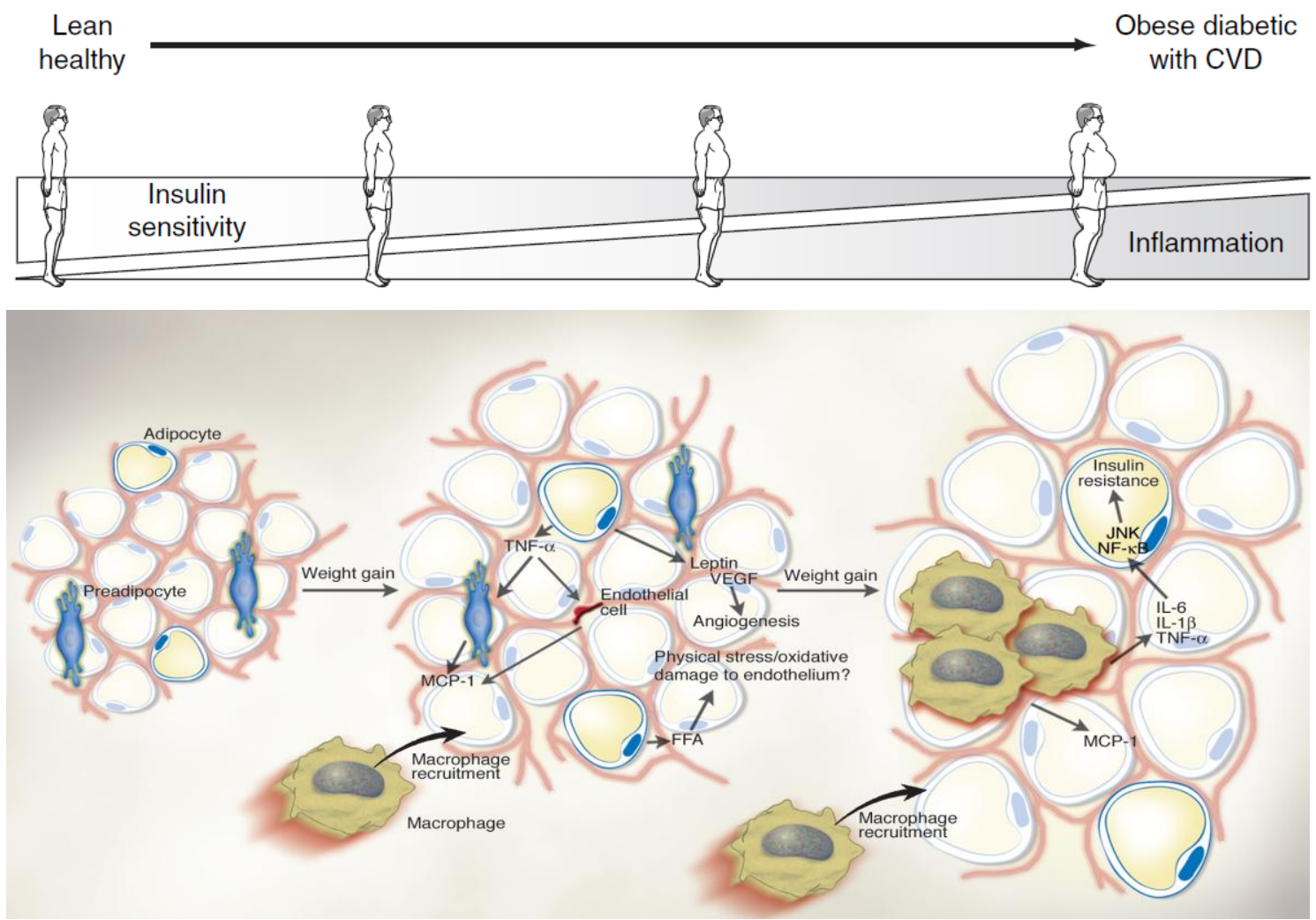

Figure 2. Evolution of inflammation in obesity accompanied with the progression of insulin resistance and cardiovascular disease (CVD). Obese adipose tissue is characterized by inflammation and progressive macrophage infiltration in the development of obesity. Adipocyte hypertrophy promotes physical changes in the surrounding area and modifications of the paracrine function of the adipocyte. Source - WELLEN; HOTAMISLIGIL, 2003; WHITE; MARETTE, 2005 
The excessive and prolonged energy intake and the low energy expenditure develop obesity, storing the positive energy balance and nutrient excess in the adipose tissue through adipocyte hypertrophy and hyperplasia (EMANUELA et al., 2012). Evidence suggests that in the obese state, apoptosis induced by the adipocyte hypertrophy is increased. The nutrient excess and hypertrophy induce secretion of cytokines by adipocytes that attract monocytes to the adipose tissue, including monocyte chemotatic protein-1 (MCP-1), leukotriene B4 (LTB4) and others; in turn, these monocytes become macrophages. Enlarged adipocytes undergo necrotic cell death and become surrounded by macrophages in crown-like structures (Figure 3) (OSBORN; OLEFSKY, 2012).
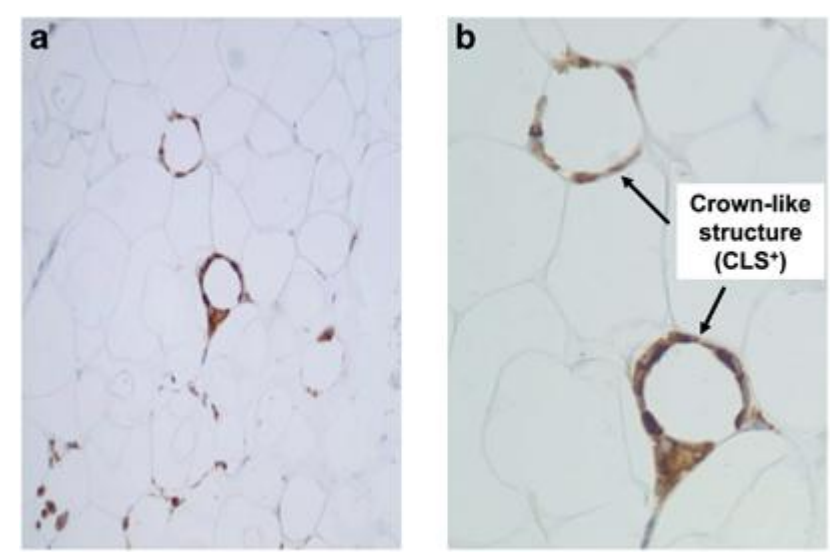

Figure 3. Representative histological illustration of inflamed adipose tissue. Macrophages (brown color) are organized into two separate 'crown-like structures' (indicated by arrows) surrounding individual adipocytes.

Source - BIGORNIA et al., 2012

Evidence has pointed to the heterogeneity of macrophages in the adipose tissue and they were classified into two major groups based on their distinct polarization states: M1 or classically activated (pro-inflammatory) macrophages, which are induced by proinflammatory mediators, and M2 or alternatively active (anti-inflammatory) macrophages (SUGANAMI; OGAWA, 2010). The phenotypic changes of macrophages are associated with the condition from either a lean or an obese adipose tissue. Adipocytes in adipose tissue from a lean individual produce humoral factors that induce activation of M2 macrophages such as interleukin-4 (IL-4) and interleukin-13 (IL-13), in turn, M-2 alternatively active macrophages secrete anti-inflammatory mediators including interleukin-10 (IL-10). In contrast, hypertrophied adipocytes in obese individuals secrete pro-inflammatory cytokines and saturated fatty acids that induce M1 polarization of macrophages. In sequence, classically activated M1 macrophages secrete pro-inflammatory cytokines, thereby accelerating the 
adipose tissue inflammation (Figure 4) (ITOH et al., 2011). Both macrophages types express myeloid cell surface markers (i.e. F4/80 and CD11b), but M1 macrophages express unique markers, including CD86 and CD11c (Figure 5) (KADL et al., 2010; PATEL, PAYAL S; BURAS, 2013).

A)

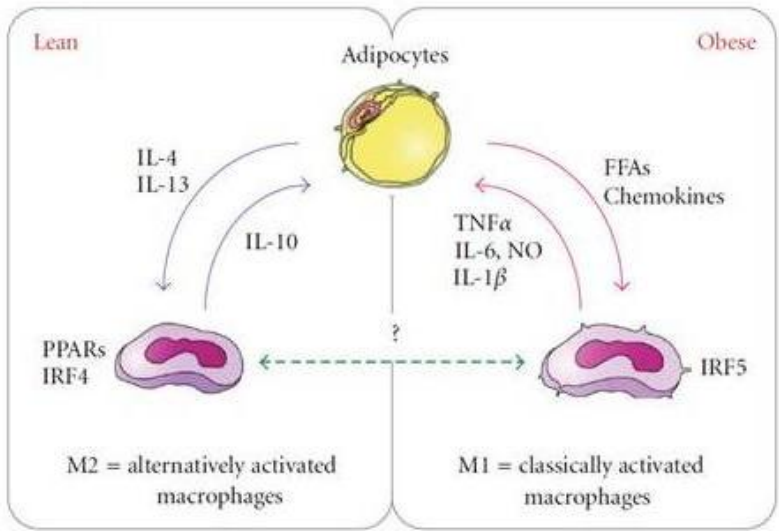

B)

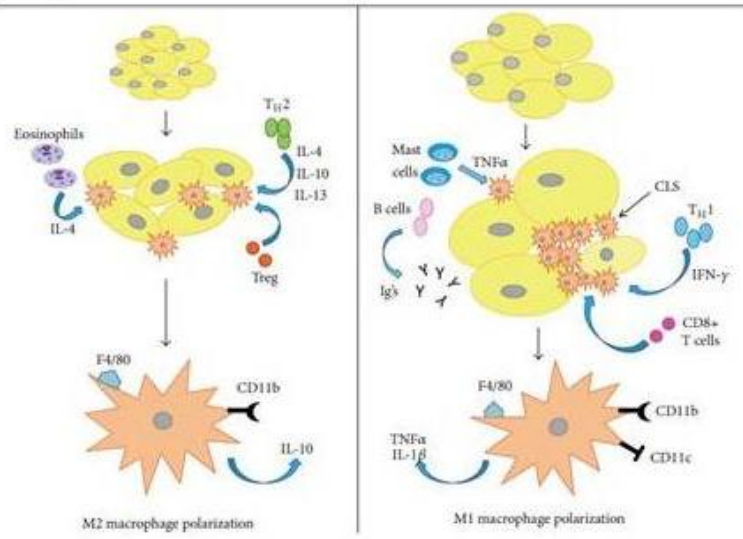

Figure 4. Regulation of macrophage polarity in both lean and obese adipose tissue, and paracrine interaction between adipocytes and macrophages (A). Both M1 and M2 macrophages express myeloid cell surface markers F4/80 and CD11b. However, only M1 population expresses marker CD11c (B).

Source - ITOH et al., 2011; PATEL, BURAS, BALASUBRAMANYAM, 2013

\subsection{Polyphenols as bioactive compounds}

Clinical and epidemiological evidence suggest that regular consumption of fruit and vegetables is one of the factors that contributes to the prevention and reduction of disease risks (HUANG, CAI, ZHANG, 2010; LIU, 2003; ROSSI et al., 2010; SAMMAN, 2004). The functionality of these foods is attributed to the presence of phytochemicals such as polyphenols, carotenoids, phytosterols, and other bioactive compounds that help in the cell and tissue protection against metabolic alterations and oxidative stress, reducing the risk of cardiovascular and neurodegenerative diseases, diabetes and cancer (BASTIANETTO, QUIRION, 2008; KOH, MITCHELL, 2008; FUHRMAN; AVIRAM, 2002).

Plants produce structurally diverse chemicals, which are traditionally know as secondary metabolites, because many of them are not directly involved in the central metabolism (primary metabolism, i.e. enzymes, proteins, RNA-DNA, etc.). Unlike primary metabolites required for central metabolism, secondary metabolites are specialized compounds which are 
biosynthesized in response to environmental cues or as a consequence of plant growth and development (WENG; PHILIPPE; NOEL, 2012). Polyphenols (or phenolic compounds) are secondary metabolites derived mainly from phenylalanine, and, to a lesser extent in some plant, from tyrosine obtained through the shikimate pathway (SHAHIDI; NACZK, 2006), which is the metabolic route used by bacteria, algae, and plants for the biosynthesis of aromatic amino acids. The shikimic acid that acts as a precursor for polyphenols is formed by phosphoenolpyruvate and erythrose-4-phosphate, which are molecules formed during the carbohydrate metabolism in plants.

Structurally, polyphenols contain an aromatic ring bearing one or more hydroxyl groups, including their functional derivatives (SHAHIDI; NACZK, 2006). Depending on their structural diversity (simple molecules to highly polymerized), polyphenols can be classified into phenolic acids, flavonoids and tannins, flavonoids being the most abundant polyphenols in the human diet (DAI; MUMPER, 2010). These various substances are essential for the plant growth and development acting as anti-pathogens, against stress, attractants for pollinators, protective agents against ultraviolet light, and contributors to the pigmentation of plant foods (SHAHIDI; NACZK, 2006).

The protective properties against stress and infection in plants are related to the antioxidant properties of polyphenols, which in turn, may play an important role in the cell and tissue protection against oxidative stress and other metabolic alterations associated with chronic diseases in animals and humans. However, polyphenols can have diverse pleiotropic biological activities, although they are most widely known as antioxidants and therefore protectors against oxidative damage (GORLACH; FICHNA; LEWANDOWSKA, 2015). Because obesity-associated chronic inflammation induces excessive production of reactive oxygen species (ROS), polyphenols may have health benefits by their ability to act as antioxidants and singlet oxygen quenchers, therefore inhibiting the destructive effects of ROS and suppressing inflammation in the development of obesity (WANG et al., 2014). However, polyphenols exhibit far more activities than antioxidatives (GORLACH; FICHNA; LEWANDOWSKA, 2015), in addition, there is evidence that polyphenols and their metabolites exert modulatory effects in cells through selective actions on different components of the intracellular signaling cascades, which is vital for cellular functions, such as growth, proliferation and apoptosis (CROZIER; JAGANATH; CLIFFORD, 2009). In this context, it has been reported that consumption of fruit and vegetables, and their bioactive compounds, can reduce the risk of obesity, diabetes mellitus and cardiovascular disease 
(BAZZANO et al., 2008; MONTONEN et al., 2005; FORD \& MOKDAD, 2001; KRISETHERTON et al., 2002).

Polyphenols are the most abundant bioactive compounds present in the diet, with an average consumption of approximately $1 \mathrm{~g}$ per day. The main dietary sources of polyphenols are fruits and beverages including apple, grape, pear, berries, wine, tea, chocolate, and coffee (SCALBERT et al., 2005), and the contents vary considerably depending on genetic and environmental factors, such as growing conditions and harvest time (OZKAN, BAYDAR, ERBAS, 2010; REYES \& CISNEROS-ZEVALLOS, 2003).

Although there are large knowledge gaps in science's current understanding of polyphenols and their effects on obesity and type 2 diabetes mellitus, evidence suggests that these compounds may influence the metabolism through several mechanisms, modulating metabolic disease risk, especially cardiovascular disease, diabetes, obesity, and Alzheimer disease (BURTON-FREEMAN; SANDHU; EDIRISINGHE, 2016). As an example, in a revision, HANHIEVA (2010) appointed that dietary polyphenols may influence carbohydrate metabolism in diverse pathways including inhibition of carbohydrate digestion and glucose absorption in the gut, stimulation of insulin secretion from the pancreatic $\beta$-cells, modulation of glucose release from the liver, activation of insulin receptors and glucose uptake in the insulin-sensitive tissue, and modulation of intracellular signaling pathways and gene expression. Additionally, polyphenols may also exert beneficial effects against obesity and obesity-associated inflammation reducing the viability of adipocytes and proliferation of preadipocytes, suppressing adipocyte differentiation and triglyceride accumulation, stimulating lipolysis and fatty acid $\beta$-oxidation, enhancing energy expenditure and fat utilization, modulating signaling pathways that regulate adipogenesis, and antioxidant and antiinflammatory responses (WANG et al., 2014).

There is an extensive literature demonstrating the beneficial effects of polyphenols from food and beverages commonly consumed, such as green tea, chocolate, red wine, berries, apple, orange, and coffee. However, whether polyphenols from native fruits also exert functional properties remains unexplored, and limited information is available. DEVALARAJA, JAIN \& YADAV (2011) suggested that native fruits such as litchi (Litchi chinensis), mangosteen (Garcina mangostana), and mango (Mangifera indica), have a variety of bioactive compounds with potential health benefits, including antidiabetic, anti-obesity, anti-inflammatory and antioxidant properties. According to the authors, native fruits and their constituents can act on various pathophysiological targets of obesity and diabetes. 


\subsection{Cagaita (Eugenia dysenterica DC.) and cambuci (Campomanesia phaea Berg.) and their potential functional role}

The Brazilian flora is characterized by a wide biodiversity, where several edible fruits produced by the species of the Myrtaceae family have an ecological importance. Species, including Eugenia dysenterica D.C. (cagaita), Myrciaria cauliflora Berg. (jabuticaba), Campomanesia phaea Berg. (cambuci), Myrciaria dubia Mc. Vaugh (camu-camu), Eugenia brasiliensis Lam. (grumixama), and others, are scattered by different Brazilian biomes, such as Cerrado, Atlantic Coastal Forest, Caatinga, Amazon, Pampa, and Pantanal. The edible fruits from the Myrtaceae family are a rich source of biologically active polyphenols, similar to temperate berries (REYNERTSON et al., 2008). Polyphenols protect against lipid peroxidation and ultraviolet damage, which can affect tropical and sub-tropical Myrtaceae fruits growing under severe conditions from intense sunlight and heat (LEE, GOULD, 2002; REYNERTSON; BASILE; KENNELLY, 2005).

\subsubsection{Cagaita (Eugenia dysenterica DC.)}

Cagaita or cagaiteira (Eugenia dysenterica DC.) owes its name to the laxative properties from their fruits when consumed in excess or after sun-drying and fermented. The cagaita is a Brazilian Cerrado biome tree, belonging to the Myrtaceae family, that grows in red-yellow latosoil types and in regions with temperatures between 21 to $25^{\circ} \mathrm{C}$ and at altitudes from 380 to $1100 \mathrm{~m}$ above sea level (MARTINOTTO et al., 2008). Cagaita is a half-height tree (4 to 10 m) with crooked trunk and branches, and axillary inflorescence. The flowers are fasciculated panicles, white and with four petals each. The fruit is a yellow-orange roughly spherical berry with a diameter of approximately $3-4 \mathrm{~cm}$ and mass varying between 15 and $37 \mathrm{~g}$ that has a sweet-sour and slightly astringent taste (CARDOSO et al., 2011; CLOVEGARDEN, 2015). The fructification period occurs mostly between October and December (OLIVEIRA et al., 2011). Because fruits have attractive sensorial properties, they are used in various regional preparations, such as jams, ice-cream, liqueurs, and juices. Cagaita is considered to be a lowenergy fruit and a source of vitamin C, vitamin A, and folate (CARDOSO et al., 2011; SILVA et al., 2008).

The cagaiteira plant is used by many local communities to control diverse diseases and metabolic disorders. The tea made from its leaves and flowers are regularly used to treat 
diarrhea, diabetes, jaundice, and kidney and bladder infections. The fruits are used as laxative, but, in contrast, leaf extracts were found to have anti-diarrheal properties by inhibiting gastrointestinal motility in rats with induced diarrhea (LIMA et al., 2011).

Cagaita pulp has been characterized as having ellagic acid, and flavonoids including quercetin and kaempferol derivatives (GONÇALVES; LAJOLO; GENOVESE, 2010). This study also suggested that cagaita exhibits high inhibitory activity against enzymes involved in the carbohydrate metabolism, such as $\alpha$-amylase and $\alpha$-glucosidase in in vitro enzymatic assays. These properties may be one therapeutic approach in obesity and diabetes management, to decrease postprandial hyperglycemia by suppressing carbohydrate hydrolysis and consequently glucose absorption in the digestive tract (GONÇALVES; LAJOLO; GENOVESE, 2010).

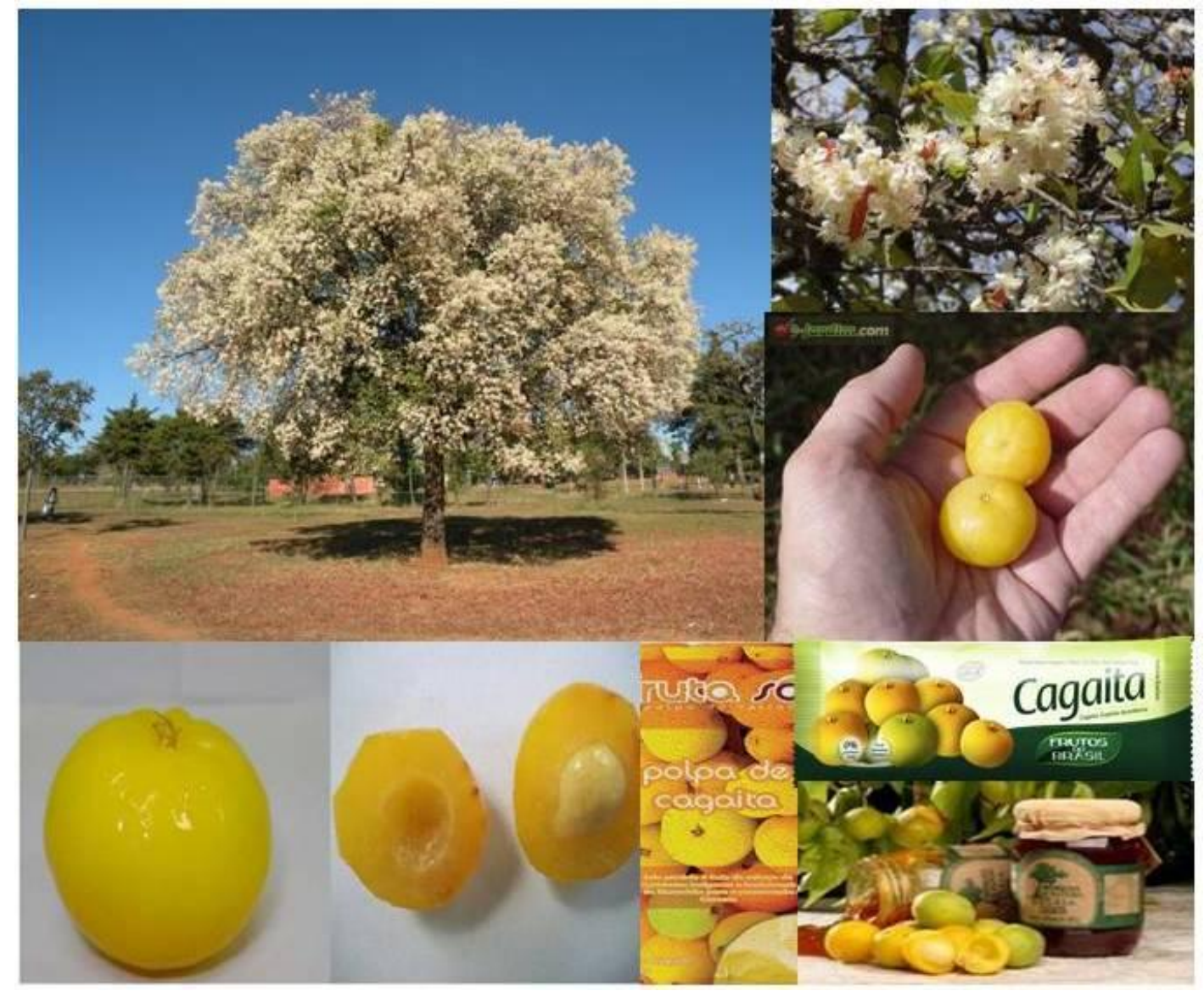

Figure 6. Cagaita or cagaiteira (Eugenia dysenterica DC.) and derivative products Source - CARDOSO et al., 2011; ceandf.wordpress.com;wikipedia.com

\subsubsection{Cambuci (Campomanesia phaea Berg.)}

Cambuci or cambucizeiro (Campomanesia phaea Berg.) is an Atlantic Coastal Forest tree belonging to the several Brazilian species of Myrtaceae. Historical evidence suggests that the 
name "cambuci" is derived from the Tupi-Guarani language for clay pot, because of the similarity between the rhomboid fruit and clay pots made by the Indians (KAWASAKI \& LANDRUM, 1997).

The cambucizeiro occurs mainly in the Brazilian states of Minas Gerais and São Paulo. The tree height varies from 3 to $5 \mathrm{~m}$ and trunk diameter from 20 to $30 \mathrm{~cm}$. The white flowering occurs from August to November, and the fruiting occurs from January to February (VALLILO et al., 2005). The fruit is unique in the genus, featuring an ovoid-rhomboidal structure with a horizontal ridge along with a strong sweet scent, but tasting extremely sour like lemons. These fruits are used in various typical preparations, mainly in jams, jellies, icecream, and liqueurs (KAWASAKI \& LANDRUM, 1997). The fruit is 5-6 cm in diameter and 4.1-4.5 cm long, with a high moisture content (85-89\%), acidity ( $\mathrm{pH} 2.4-3.0)$, and fiber content (4\%) when compared to other species of the same botanical family (AZEVEDO et al., 2016; VALLILO et al., 2005).

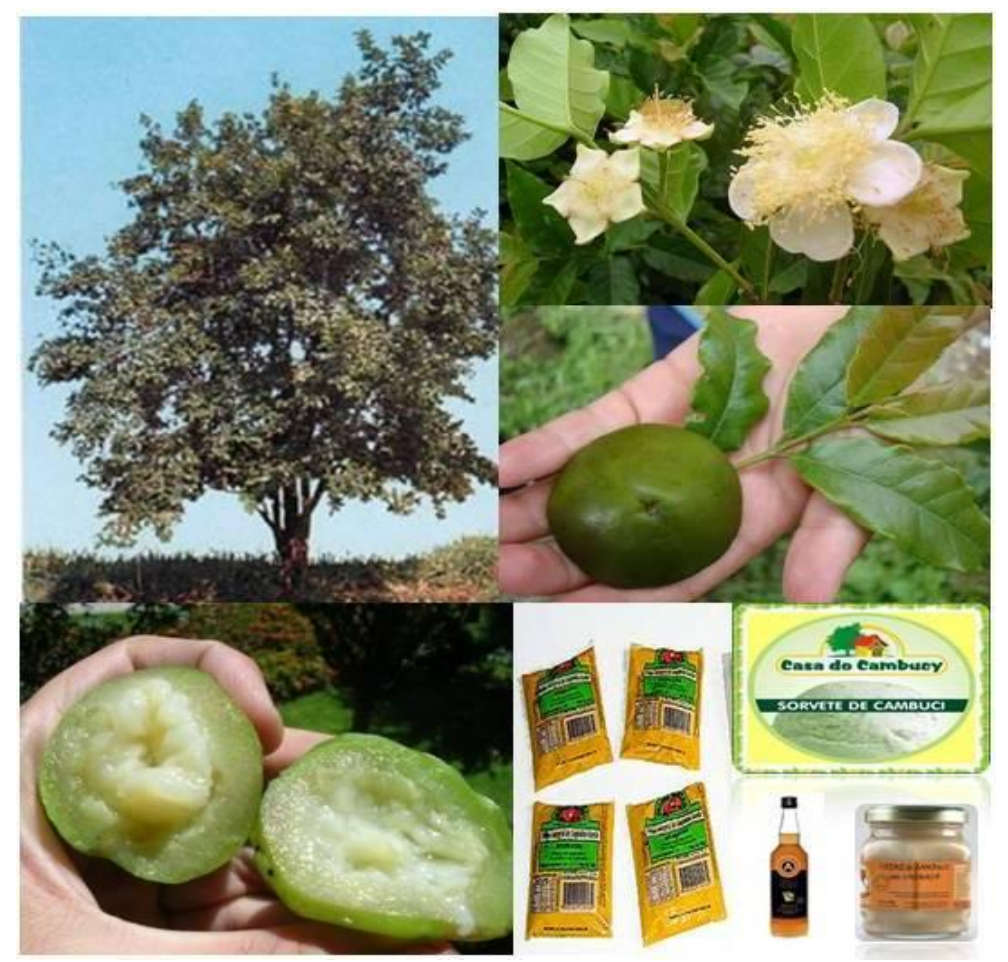

Figure 7. Cambuci or cambucizeiro (Campomanesia phaea Berg.) and derivative products Source - fazendacitra.com.br; wikipedia.com; arvoresdesaopaulo.wordpress.com

Cambuci is source of vitamin $\mathrm{C}$, sodium, potassium, phosphorus, magnesium, and calcium (VALLILO et al., 2005). However, the fruit is not commonly marketed and consumed in Brazil, but diverse initiatives and strategies are being implemented promoting its production, commercialization and consumption (i.e. rotadocambuci.org.br). 
The cambuci leaves have essential oils such as linalool, caryophyllene oxide, $\beta$ caryophyllene, among other constituents, which can be viewed as compounds with high commercial value for the cosmetic and pharmaceutical industry. Additionally, leaves also possess bioactive compounds such as flavonoids, tannins and saponins (ADATI, 2001). In turn, cambuci fruit has a high ellagic acid content, mainly in the form of ellagitannins, and quercetin derivatives (ABE; LAJOLO; GENOVESE, 2012; GONÇALVES; LAJOLO; GENOVESE, 2010; GENOVESE et al., 2008).

In a previous study evaluating ethanolic extracts of seven fruits from the Brazilian Atlantic Coastal Forest, cambuci featured the highest concentration of polyphenols (HAMINIUK et al., 2011). In addition, the commercial frozen pulp of cambuci also showed high concentration of polyphenols, when compared to diverse pulps from exotic fruits (GENOVESE et al., 2008). Polyphenols from cambuci were also found to be potent inhibitors of carbohydrate-hydrolyzing enzymes ( $\alpha$-amylase and $\alpha$-glucosidase) in in vitro enzymatic assays (GONÇALVES; LAJOLO; GENOVESE, 2010). 


\section{OBJECTIVES}

\subsection{General objective}

To evaluate the potential protective effect of polyphenols from cagaita and cambuci fruits in obesity and their metabolic alterations associated.

\subsection{Specific objectives}

To evaluate the effects of the administration of polyphenol-rich extracts from cagaita and cambuci, at two different doses, to C57BL/6J mice fed on a high-fat, high-sucrose diet, on:

- Body weight, adiposity, energy balance,

- Glucose homeostasis,

- Dyslipidemia,

- Inflammatory markers associated to obesity. 


\section{MATERIAL AND METHODS}

This section was divided into three parts according to the studies.

\subsection{Preventive protocol for cagaita}

\subsubsection{Preparation and characterization of phenolic-rich extract from cagaita}

The commercial frozen pulp of cagaita was obtained from Central do Cerrado, Urucuia ${ }^{\circledR}$ (Brasília DF, Brazil). Frozen samples were thawed at room temperature before extraction. A representative sample equivalent to $5.0 \mathrm{~g}$ of dry matter was homogenized and extracted in 100 $\mathrm{mL}$ of $80 \%$ aqueous methanol using a Turratec TE-102 (Tecnal) at $4000 \mathrm{rpm}$ for $1 \mathrm{~min}$, three times with intervals of $30 \mathrm{~s}$, in an ice-bath, followed by rotation using a magnetic stirrer (200 $\mathrm{rpm}$ ) at $5{ }^{\circ} \mathrm{C}$ for $30 \mathrm{~min}$. The extract was separated by centrifugation at $5000 \mathrm{~g}$ for $30 \mathrm{~min}$ and filtered through a Whatman No. 3 filter paper. The precipitate was resuspended twice in the aqueous alcoholic solution for additional extraction steps and then centrifuged and filtered as described above. The pooled filtrates were concentrated at $39{ }^{\circ} \mathrm{C}$ to remove methanol on a rotary evaporator (Rotavapor R-210; Büchi, Sweden), and $40 \mathrm{~mL}$ of extract was made with distilled water.

The aqueous extract was added onto a preconditioned $(100 \mathrm{~mL}$ of methanol, $150 \mathrm{~mL}$ of water) LC-18 SPE tube (10 g of LC-18 SPE, Supelclean ${ }^{\mathrm{TM}}$ LC-18, Supelco). After washing with water, the phenolic compounds were eluted with $200 \mathrm{~mL}$ of methanol. The eluate was evaporated to dryness and the residue resuspended in $70 \mathrm{~mL}$ of water, for CGT7 extract, or 35 $\mathrm{mL}$ of water, for CGT14 extract.

The extract was characterized regarding total phenolics (SINGLETON, ORTHOFER, LAMUELA-RAVENTOS, 1999) and proanthocyanidin contents (PORTER, HRSTICH, CHAN, 1985), antioxidant capacity by the oxygen radical absorbance capacity (ORAC) assay (DÁVALOS, GÓMEZ-CORDOVÉS, BARTOLOMÉ, 2004), the 2,2-diphenyl-1picrylhydrazyl (DPPH) radical-scavenging assay (BRAND-WILLIAMS, CUVELIER, BERSET, 1995), the ferric reducing antioxidant power (FRAP) assay (BENZIE; STRAIN, 1996), and the pancreatic lipase inhibitory activity (NAKAI et al., 2005). 
The identification and quantification of the main flavonoids and phenolic acids in cagaita were performed as described previously (ARABBI, GENOVESE, LAJOLO, 2004), adding the aqueous extract onto a preconditioned $(20 \mathrm{~mL}$ of methanol, $60 \mathrm{~mL}$ of water) polyamide SC6 SPE tube (1 g, Macherey-Nagel GmbH and Co., Düren, Germany). After washing with water, phenolic compounds were eluted with $50 \mathrm{~mL}$ of methanol to elute neutral phenolics, and with $50 \mathrm{~mL}$ of methanol:ammonia (99.5:0.5) to elute acidic phenolics. These two fractions were pooled and evaporated to dryness under reduced pressure at $39{ }^{\circ} \mathrm{C}$, re-dissolved in HPLC grade methanol $(1 \mathrm{~mL})$, and filtered through a $0.22 \mu \mathrm{m}$ PTFE (polytetrafluoroethylene) filter (Millipore Ltd, Bedford, MA). Identification and quantification were performed using a Prodigy ODS3 reversed phase silica column $(5 \mu \mathrm{m}$, $250 \times 4.6 \mathrm{~mm}$, Phenomenex Ltd, Torrance, CA), in an analytical reversed-phase HPLC (Hewlett-Packard 1100) system with an autosampler and a quaternary pump coupled to a diode array detector. Pure standards of quercetin, kaempferol, and ellagic acid dissolved in methanol (HPLC grade) were used to calibrate the standard curves and retention times. Calibration was performed by injecting the standards three times at five different concentrations. Peak identification was performed by comparing retention times and diode array spectral characteristics with the standards and the library spectra. Quantification of phenolic compounds was performed by comparing the peak area of the sample with that of the standards' peak area injected, and effected on the basis of external standard curves $(r \geq 0.998)$ for peaks detected and identified at $270 \mathrm{~nm}$ with spectral characteristics similar to the their respective standard. In the case of quercetin and kaempferol derivatives, results were expressed as $\mu \mathrm{g}$ of aglycone. The results were expressed by $\mathrm{mL}$ of extract.

Total ellagic acid was determined after acid hydrolysis according to Pinto, Lajolo and Genovese (2008). An aliquot of $0.5 \mathrm{~mL}$ of extract was dried under nitrogen and $2 \mathrm{~mL}$ of $2 \mathrm{~N}$ trifluoroacetic acid was added, and hydrolysis was performed at $120{ }^{\circ} \mathrm{C}$ for $90 \mathrm{~min}$. The hydrolyzed samples were evaporated to dryness under nitrogen, redissolved in methanol and filtered for HPLC analysis.

\subsubsection{Animals and experimental design}

All animal procedures performed had been previously approved by the Ethical Committee for Animal Research of the Faculty of Pharmaceutical Science of University of São Paulo (CEUA/FCF/378). Forty 8-week old male C57BL/6J mice of approximately $23 \mathrm{~g}$ 
were used in this study. The mice were matched by weight and kept at $22 \pm 1{ }^{\circ} \mathrm{C}$ under a 12 hour light/12-hour dark cycle. All mice were fed a low-fat chow diet (NUVILAB CR-1 ${ }^{\circledR}$ Sogorb Inc., São Paulo - SP, Brazil) ad libitum for one week before beginning the experiment.

The animals were randomly divided into four groups of ten mice each, as follows: 1) a chow fed group that received a daily water administration by gavage (Chow); 2) an HF/HS fed group that received a daily water administration by gavage (HF/HS); 3) an HF/HS fed group that received a daily administration of phenolic-rich extract from cagaita by gavage ( 7 mg GAE/kg body weight, CGT7); and 4) an HF/HS fed group that received a daily administration of phenolic-rich extract from cagaita by gavage (14 mg GAE/kg body weight, CGT14).

According to the manufacturer, the chow diet provided $12.5 \mathrm{~kJ} / \mathrm{g}$ of energy, of which, $63 \%$ was from carbohydrate, $25 \%$ from protein, and $12 \%$ from fat. The HF/HS diet provided $19.4 \mathrm{~kJ} / \mathrm{g}, 41 \%$ of calories from sucrose, $20 \%$ from protein, and $39 \%$ from fat, as previously described (LEMIEUX, PICARD, LABRIE, RICHARD, DESHAIES, 2003). The chemical composition - excluding fiber and carbohydrates values - of the diets used in this study was as follows (in grams per 100 grams of diet): protein, 23.3; lipids, 4.6; ash, 7.0; and moisture, 9.2 for chow diet; and 19.3; 19.6; 4.0; 4.6 for the HF/HS diet respectively. Diets and water were available ad libitum during the experimental period of 8 weeks. Body weight and food intake were recorded every two days, and fasting blood glucose $(6 \mathrm{~h})$ was measured from the caudal vein weekly throughout the study by using Accu-Chek Performa ${ }^{\circledR}$ (Roche, Mannheim, Germany).

After 8 weeks, the mice were anesthetized with isoflurane and immediately euthanized by decapitation. Blood was collected from the trunk and plasma separated by centrifugation at $3000 \mathrm{~g}$ for $20 \mathrm{~min}$ at $4{ }^{\circ} \mathrm{C}$. Tissues, including heart, liver, gastrocnemius muscle, and adipose tissues (inguinal, retroperitoneal, epididymal and brown) were removed, separated, weighed, and immediately frozen under liquid nitrogen and stored at $-80^{\circ} \mathrm{C}$.

\subsubsection{Glucose tolerance test (GTT)}

At the $7^{\text {th }}$ week, the mice were fasted for $6 \mathrm{~h}$ and injected intraperitoneally with a glucose solution ( $1 \mathrm{~g} / \mathrm{kg}$ body weight), and the glucose concentration was determined in tail blood collected at the baseline (prior to injection) and at 15, 30, 45, 60 and 90 min post-injection, using the Accu-Chek Performa ${ }^{\circledR}$ glucometer (Roche, Mannheim, Germany). 


\subsubsection{Plasma biochemical parameters}

A LabMax $240^{\circledR}$ clinical chemistry analyzer and appropriated kits were used to determine plasma levels of total cholesterol, HDL-cholesterol, LDL-cholesterol, triacylglycerol, urea and creatinine, following manufacturer's instructions (LABTEST, Lagoa Santa, MG, Brazil). Plasma antioxidant capacity was measured by ORAC (Dávalos et al., 2004) and ferric reducing ability of plasma (FRAP) assays (Benzie \& Strain, 1996). Both methods were performed on a Synergy H1 Hybrid Multi-Mode microplate reader (BioTek Instruments, Winooski, VT). The antioxidant capacity was calculated from a standard curve made with known concentrations of Trolox (6-hydroxy-2,5,7,8-tetramethylchroman-2-carboxylic acid; Sigma Chemical Co., St. Louis, MO, USA) and expressed in terms of $\mu$ mol Trolox equivalent per $\mathrm{mL}$ of plasma for both assays.

\subsubsection{Fecal lipids determination}

Feces collected from the cages at the final of the experimental period (last 3 days) were pooled per group and dried in an oven $\left(50{ }^{\circ} \mathrm{C}\right)$ for $36 \mathrm{~h}$. Feces were ground to a uniformly fine powder using a mortar and pestle and stored at $-20{ }^{\circ} \mathrm{C}$ until analysis. A representative sample of $0.5 \mathrm{~g}$ of the dried material was used for lipid extraction according to Folch, Lees, and Stanley (1957), using $7.5 \mathrm{~mL}$ of chloroform:methanol (2:1) and Ultra-Turrax ${ }^{\circledR}$ (T25, IKA) at $8000 \mathrm{rpm}$ for $3 \mathrm{~min}$. The lipids were filtered through a Whatman No. 3 filter paper and the residue was resuspended twice in the chloroform:methanol solution for additional extraction steps and then filtered as described above. The pooled filtrates were washed in two stages by using potassium chloride $(0.88 \%)$ and methanol:water (1:1) solution, respectively. Finally, the extract was dried in a nitrogen flow, weighted, and resuspended in isopropanol for the determination of total cholesterol and triglycerides concentrations using commercial kits (Labtest). The results were normalized to the weight of the sample and expressed in terms of mg per g of dry feces.

\subsubsection{Liver glycogen, triacylglycerol, and total cholesterol determination}


For liver glycogen determination, $50 \mathrm{mg}$ of tissue was digested for $10 \mathrm{~min}$ in $0.5 \mathrm{~mL} \mathrm{30 \%}$ $\mathrm{KOH}$ solution, at $100{ }^{\circ} \mathrm{C}$, and its extraction was performed in two stages of precipitation by using ethanol and $70 \%$ ethanol solution and centrifugation at $840 \mathrm{~g}$ for $30 \mathrm{~min}$ and $3000 \mathrm{~g}$ for 5 min at $4{ }^{\circ} \mathrm{C}$. The resultant glycogen precipitate was ressuspended in $0.5 \mathrm{~mL} 4 \mathrm{~N} \mathrm{H}_{2} \mathrm{SO}_{4}$ and heated at $100{ }^{\circ} \mathrm{C}$ for $10 \mathrm{~min}$, followed by dissolution in $0.5 \mathrm{~mL} 4 \mathrm{~N} \mathrm{NaOH}$. The resulting glucose solution was then measured spectrophotometrically with a Labtest kit (BioTek Instruments). Finally, the liver glycogen content was calculated using the formula proposed by Carroll, Longley, and Roe (1956) with a factor of 0.9 for converting glucose value to glycogen levels. On the other hand, liver triacylglycerol and total cholesterol content were analyzed by using an adapted Folch method (1957). Briefly, $50 \mathrm{mg}$ of tissue was used for lipid extraction and homogenized in $0.9 \mathrm{~mL}$ chloroform:methanol (2:1). After homogenization, $0.3 \mathrm{~mL}$ of methanol was added and centrifuged at $11000 \mathrm{rpm}$ for $15 \mathrm{~min}$. After the removal of the upper phase, washing in two stages by using $0.4 \mathrm{~mL}$ Folch solution, and conversion of the infranatant to a uniform phase with methanol, lipids were dried in a nitrogen flow, and resuspended in isopropanol for determination of total cholesterol and triglycerides concentrations by using commercial kits (Labtest). The results were normalized to the weight of the sample and expressed in terms of mg per $\mathrm{g}$ of tissue.

\subsubsection{Statistical analysis}

The results are presented as mean \pm SEM for groups based on nine to ten mice in each group for body and tissue weight, fasting blood glucose, blood glucose in GTT, and plasma biochemical. For fecal lipids excretion, data were processed based on four to five repetitions in each group. The data for characterization of the extracts were presented as mean \pm SD for three replicates. The effects of the phenolic compounds from cagaita at two doses on the studied parameters were analyzed using a one-way (treatment) analysis of variance (ANOVA). Significant effects were analyzed using Tukey's studentized range or post hoc Fisher's least significant difference (LSD) test when the main treatment or interaction effects were significant (statistical significance was determined at $p<0.05$ ). The statistical analysis was performed using the SAS 9.3 package (SAS Institute, Inc., Cary, NC). 


\subsection{Preventive protocol for cambuci}

\subsubsection{Preparation and characterization of phenolic-rich extract from cambuci}

The commercial frozen pulp of cambuci was obtained from Sítio do Bello (Paraibuna São Paulo, Brazil). Frozen samples were thawed at room temperature before extraction was performed. A representative sample equivalent to $5.0 \mathrm{~g}$ of dry matter was homogenized and extracted in $100 \mathrm{~mL}$ of $80 \%$ aqueous methanol using a Turratec TE-102 (Tecnal) at $4000 \mathrm{rpm}$ for $1 \mathrm{~min}$, three times with intervals of $30 \mathrm{~s}$, in an ice-bath, followed by rotation using a magnetic stirrer $(200 \mathrm{rpm})$ at $5{ }^{\circ} \mathrm{C}$ for $30 \mathrm{~min}$. The extract was separated by centrifuging for $30 \mathrm{~min}$ at $5000 \mathrm{~g}$ and filtered through a Whatman No. 3 filter paper. The precipitated was resuspended twice in the aqueous alcoholic solution for additional extraction steps and then centrifuged and filtered as described above. The pooled filtrates were concentrated at $39{ }^{\circ} \mathrm{C}$ to remove methanol on a rotary evaporator (Rotavapor R-210; Büchi, Sweden). The extract was made up to $40 \mathrm{~mL}$ with distilled water.

The aqueous extract was added onto a preconditioned $(100 \mathrm{~mL}$ of methanol, $150 \mathrm{~mL}$ of water) LC-18 SPE tube (10 g of LC-18 SPE, Supelclean ${ }^{\mathrm{TM}}$ LC-18, Supelco). After washing with water, the phenolic compounds were eluted with $200 \mathrm{~mL}$ of methanol. The eluate was evaporated to dryness and the residue ressuspended in $70 \mathrm{~mL}$ of water, for CBC18 extract, or $35 \mathrm{~mL}$ of water, for CBC32 extract.

The extract was characterized in relation to total phenolics (SINGLETON, ORTHOFER, LAMUELA-RAVENTOS, 1999), and proanthocyanidin contents (PORTER, HRSTICH, CHAN, 1985), antioxidant capacity by the oxygen radical absorbance capacity (ORAC) assay (DÁVALOS, GÓMEZ-CORDOVÉS, BARTOLOMÉ, 2004), the 2,2- diphenyl-1picrylhydrazyl (DPPH) radical-scavenging assay (BRAND-WILLIAMS, CUVELIER, BERSET, 1995), and the ferric reducing antioxidant power (FRAP) assay (BENZIE, STRAIN, 1996), and pancreatic lipase inhibitory activity (NAKAI et al., 2005).

The identification and quantification of the main flavonoids and phenolic acids in cambuci was performed as described previously (ARABBI, GENOVESE, LAJOLO, 2004), adding the aqueous extract onto a preconditioned $(20 \mathrm{~mL}$ of methanol, $60 \mathrm{~mL}$ of water) polyamide SC6 SPE tube (1 g, Macherey-Nagel GmbH and Co., Düren, Germany). After washing with water, phenolic compounds were eluted with $50 \mathrm{~mL}$ of methanol to elute neutral phenolics, and with $50 \mathrm{~mL}$ of methanol:ammonia (99.5:0.5) to elute acidic phenolics. These 
two fractions were evaporated to dryness under reduced pressure at $39{ }^{\circ} \mathrm{C}$, redissolved in HPLC grade methanol ( $1 \mathrm{~mL}$ ) and filtered through $0.22 \mu \mathrm{m}$ PTFE (polytetrafluoroethylene) filters (Millipore Ltd, Bedford, MA). The identification and quantification was performed using a Prodigy ODS3 reversed phase silica column $(5 \mu \mathrm{m}, 250$ x $4.6 \mathrm{~mm}$, Phenomenex Ltd, Torrance, CA), in an analytical reversed-phase HPLC (Hewlett-Packard 1100) system with autosampler and quaternary pump coupled to a diode array detector. Total ellagic acid was determined after acid hydrolysis according to Pinto, Lajolo and Genovese (2008). An aliquot of $2 \mathrm{~mL}$ of extract was dried under nitrogen, $2 \mathrm{~mL}$ of $2 \mathrm{~N}$ trifluoroacetic acid were added, and the hydrolysis was performed at $120{ }^{\circ} \mathrm{C}$ for $90 \mathrm{~min}$. The hydrolyzed samples were evaporated to dryness under nitrogen, redissolved in methanol and filtered for HPLC analysis.

\subsubsection{Animals and experimental design}

All animal procedures performed were previously approved by the Ethical Committee for Animals Research of the Faculty of Pharmaceutical Science of University of São Paulo (No. CEUA/FCF/378).

Forty 8-week old male C57BL/6J mice, weighting approximately $24 \mathrm{~g}$, were used in this study. The mice were matched by weight and kept at $22 \pm 1{ }^{\circ} \mathrm{C}$ and under a 12-hour light/12hour dark cycle. All mice were fed a chow low-fat diet (NUVILAB CR-1 ${ }^{\circledR}$ Sogorb Inc., São Paulo - SP, Brazil) ad libitum for one week before beginning the experiment.

The animals were randomly divided into four groups of ten mice each, as follows: 1) Chow group received the chow low-fat diet and water by gavage; 2) HFHS group received the high-fat, high-sucrose diet and water by gavage; 3) CBC18 group received the high-fat, highsucrose diet and the phenolic-rich extract from cambuci by gavage (18 $\mathrm{mg}$ GAE/kg body weight); and 4) CBC32 group received the high-fat, high-sucrose diet and the phenolic-rich extract from cambuci by gavage (32 $\mathrm{mg} \mathrm{GAE} / \mathrm{kg}$ body weight). The water and extracts were administered every day for 8 weeks.

According to the manufacturer, the chow diet provided $12.5 \mathrm{~kJ} / \mathrm{g}$ as energy, of which $63 \%$ was from carbohydrate, $25 \%$ from protein, and $12 \%$ from fat. The HFHS diet provided $19.4 \mathrm{~kJ} / \mathrm{g}, 41 \%$ of calories from sucrose, $20 \%$ from protein, and 39\% from fat, as previously described (LEMIEUX, PICARD, LABRIE, RICHARD, DESHAIES, 2003). Diets and water were available ad libitum during the experimental period of 8 weeks. Body weight and food intake were recorded every two days, and fasting blood glucose $(6 \mathrm{~h})$ measured from the 
caudal vein weekly throughout the study by using Accu-Chek Performa ${ }^{\circledR}$ (Roche, Mannheim, Germany).

After 8 weeks, mice were anesthetized with isoflurane, immediately euthanized by decapitation and their trunk blood was collected and the plasma separated by centrifugation at $3000 \mathrm{~g}$ for $20 \mathrm{~min}$ at $4{ }^{\circ} \mathrm{C}$. The tissues, including heart, liver, gastrocnemius muscle, and adipose tissues (inguinal, retroperitoneal, epididymal and brown) were removed, weighed, and immediately frozen under liquid nitrogen and stored at $-80{ }^{\circ} \mathrm{C}$.

\subsubsection{Glucose tolerance test (GTT)}

GTT was performed on the mice at week 7 of the experiment. The animals were fasted for $6 \mathrm{~h}$ and injected intraperitoneally with a glucose solution ( $1 \mathrm{~g} / \mathrm{kg}$ body weight $)$ and the glucose concentration was determined in tail blood collected at baseline (prior to injection) and at 15, 30, 45, 60 and 90 min post-injection, using Accu-Chek Performa ${ }^{\circledR}$ glucometer (Roche, Mannheim, Germany). Blood samples were collected at 0, 30, and $90 \mathrm{~min}$, and the plasma separated by centrifugation at $3000 \mathrm{~g}$ for $20 \mathrm{~min}$ at $4{ }^{\circ} \mathrm{C}$ for insulin determination (rat/mouse insulin ELISA kit, Millipore).

\subsubsection{Plasma biochemical parameters}

A LabMax $240^{\circledR}$ (LABTEST) clinical chemistry analyzer was used to determine plasma concentrations of total cholesterol, HDL-cholesterol, LDL-cholesterol and triacylglycerol. Kits were purchased from LABTEST (Lagoa Santa, MG, Brazil) and the manufacturer's instructions were strictly followed.

\subsubsection{Gene expression analysis by quantitative PCR}

RNA purification, reverse transcription, and quantification by real-time PCR were performed as previously described (FESTUCCIA et al., 2008). RNA was extracted from the retroperitoneal adipose tissue (five animals per group) using illustra RNAspin Mini RNA Isolation kit (GE Healthcare, Buckinghamshir, UK) according to the manufacturer's instructions. RNA concentration was determined on a NanoDrop spectrophotometer (Thermo Scientific, Wilmington, USA). RNA samples were stored at $-80{ }^{\circ} \mathrm{C}$ until use for synthesis of 
cDNA and real-time PCR. Primers used for the PCR reactions are listed in Table 1. Results were expressed as the ratio between the expression of the target gene and the housekeeping gene RPL3, the expression of which was not significantly affected by the administration of CBC.

\subsubsection{Statistical analysis}

The results are presented as mean \pm SEM for groups based on nine to ten mice in each group for body and tissue weight, fasting blood glucose, blood glucose in GTT, plasma lipids. For plasma insulin and quantitative PCR, data were processed based on four to five mice in each group. The data for characterization of the extracts were presented as mean \pm SD for three replicates. The effects of phenolic compounds from cambuci at two doses on studied parameters were analyzed using a one-way (treatment) analysis of variance (ANOVA). Significant effects were analyzed using Tukey's studentized range or post hoc Fisher's least significant difference (LSD) tests (statistical significance was determined at $p<0.05$ ). The statistical analysis was performed using the SAS 9.3 package (SAS Institute, Inc., Cary, NC).

\subsection{Therapeutic protocol for cagaita}

\subsubsection{Preparation of polyphenol-rich cagaita extracts (PCE)}

PCE was prepared as previously described (DONADO-PESTANA; BELCHIOR; GENOVESE, 2015). Briefly, polyphenols were extracted from a commercial frozen pulp of cagaita purchased from a local producer (Urucuia ${ }^{\circledR}$, Central do Cerrado, Brasília DF, Brazil) by homogenization (1:20 w/v in dry weight) (Turratec TE-102, Tecnal) in $80 \%$ aqueous methanol, followed by centrifugation and filtration. The extraction process was repeated twice more, and then pooled filtrates were concentrated to remove methanol (Rotavapor R-210; Büchi, Switzerland). The polyphenol-rich extract was obtained adding the resulting aqueous extract onto a preconditioned $(100 \mathrm{~mL}$ of methanol, $150 \mathrm{~mL}$ of water) LC-18 SPE tube $(10 \mathrm{~g}$ of LC-18 SPE, Supelclean ${ }^{\mathrm{TM}}$ LC-18, Supelco). After washing with water, polyphenols were eluted with $200 \mathrm{~mL}$ of methanol. The eluate was evaporated to dryness and the residue resuspended in $70 \mathrm{~mL}$ of water, for PCE I extract, or $35 \mathrm{~mL}$ of water, for PCE II extract. 


\subsubsection{Animals and experimental design}

All animal procedures performed were previously approved by the Ethical Committee for Animal Research of the Faculty of Pharmaceutical Science of University of São Paulo (CEUA/FCF/378). Forty 8-week old male C57BL/6J mice of approximately $24 \mathrm{~g}$ were used in this study. The mice were matched by weight, housed in groups of 3 to 4 per cages, and kept at $22 \pm 1{ }^{\circ} \mathrm{C}$ under a 12-hour light/12-hour dark cycle. The animals were then acclimated and fed a low-fat chow diet (NUVILAB CR-1 ${ }^{\circledR}$ Sogorb Inc., São Paulo, Brazil) and water $a d$ libitum for one week to stabilize metabolic conditions prior to the study. After this acclimation period, the mice were randomly divided into 2 dietary groups. One $(n=30)$ was fed with HFS diet, consisting of $19.4 \mathrm{~kJ} / \mathrm{g}$ of energy, of which, $41 \%$ was from sucrose, $20 \%$ from protein, and 39\% from fat (soybean oil and lard 50:50), as previously described (LEMIEUX, PICARD, LABRIE, RICHARD, DESHAIES, 2003) for 6 weeks. The other (chow healthy group, $\mathrm{n}=10)$ was fed a low-fat chow diet $(12.5 \mathrm{~kJ} / \mathrm{g}, 63 \%$ of calories from carbohydrate, $25 \%$ from protein, and $12 \%$ from fat) during the same time period.

Body weight of mice was recorded weekly to ensure the development of obesity phenotype. After 6 weeks of HFS- or Chow-diets administration, the animals in the HFS group were randomly divided into three groups of ten mice each, as follows: 1) an HFS control fed group, that received a daily water administration by gavage (HFS group); 2) an HFS fed group, that received a daily administration of PCE by gavage (7 mg gallic acid equivalent, GAE / $\mathrm{kg}$ body weight, PCE I group); and 3) an HFS fed group, that received a daily administration of PCE by gavage (14 mg GAE/kg body weight, PCE II group). The animals in the chow healthy group were kept on the low-fat diet through the experiment and received a daily water administration by gavage (Chow group). Diets and water were available ad libitum and administration of PCE or water was made during the experimental period of eight weeks after diet-induced obesity. Body weight and food intake were recorded every three days, and fasting blood glucose $(6 \mathrm{~h})$ was measured from the caudal vein weekly by using Accu-Chek Performa ${ }^{\circledR}$ (Roche, Mannheim, Germany). Finally, the mice were anesthetized with isoflurane and immediately euthanized by decapitation. Blood was collected from the trunk and serum separated by centrifugation at $3000 \mathrm{~g}$ for $20 \mathrm{~min}$ at $4{ }^{\circ} \mathrm{C}$. Tissues including liver and gastrocnemius muscle, and adipose tissues (inguinal, retroperitoneal, epididymal, and brown) were removed, separated, weighed, and immediately frozen under liquid nitrogen and stored at $-80^{\circ} \mathrm{C}$. 


\subsubsection{Oral glucose tolerance test (OGTT)}

At the $13^{\text {th }}$ week, the mice were fasted for $6 \mathrm{~h}$ and an oral glucose tolerance test (OGTT) was performed after gavage with a glucose solution ( $10 \%$ or $0.5 \mathrm{~g} / \mathrm{kg}$ body weight). The glucose concentration was determined in tail blood collected at the baseline (prior to gavage) and at 15, 30, 45, 60 and 90 min post-gavage, using the Accu-Chek Performa ${ }^{\circledR}$ glucometer (Roche, Mannheim, Germany). Blood samples (four mice per group) were collected at 0, 30, and $90 \mathrm{~min}$, and the serum separated by centrifugation at $3000 \mathrm{~g}$ for $20 \mathrm{~min}$ at $4{ }^{\circ} \mathrm{C}$ for insulin determination (Rat/Mouse Insulin ELISA Kit, Millipore, Missouri, USA). On the test day, animals were transferred to new cages to avoid their coprophagia habits that can interfere with the results. Additionally, PCE was administered by gavage $2 \mathrm{~h}$ prior the test in order to see possible biological effects of polyphenols.

\subsubsection{Oxygen consumption and respiratory exchange ratio (RER) determination}

Over the last week, animals (4 mice per group) were transferred to an Comprehensive Laboratory Monitoring System calorimeter (Oxymax Deluxe System, Columbus Instruments, Ohio), and adapted for one day before measuring oxygen consumption and respiratory exchange ratio (RER) by evaluating oxygen consumption/carbon dioxide production during 24 h.

\subsubsection{Lipolysis and isolation from epididymal adipocytes}

For lipolysis, approximately $100 \mathrm{mg}$ of epididymal adipose tissue (6 mice per group) was collected at the time of euthanasia and incubated in Krebs-Ringer-phosphate buffer ( $\mathrm{pH} 7.4$ ) for $10 \mathrm{~min}$ at $37{ }^{\circ} \mathrm{C}$ containing $5.5 \mathrm{mM}$ glucose and $2 \%$ fatty acid-free albumin (SigmaAldrich, St. Louis, USA) in the absence or presence of isoproterenol, for basal or stimulated conditions, respectively. The reaction was stopped on ice, and medium was carefully collected for measurement of glycerol release using Free Glycerol Determination Kit (Sigma-Aldrich, St. Louis, USA). The adipocytes diameter was measured as described previously (BELCHIOR et al., 2015). Briefly, tissue (approximately $150 \mathrm{mg}$ ) was incubated and digested with collagenase type II (1mg/mL, Sigma-Aldrich) in Krebs-Hepes buffer containing BSA 
(1\%) and glucose $(2 \mathrm{mmol} / \mathrm{L}), \mathrm{pH} 7.4$ at $37{ }^{\circ} \mathrm{C}$. The cell suspension was separated by centrifugation at $600 \mathrm{~g}$ for $10 \mathrm{~min}$. The floating mature adipocytes were collected and photographed (magnification of 40x) using a microscope camera (Moticam 1000, Motic, Richmond, Canada) and mean adipocyte diameter was determined by measuring 100 cells using the software Motic-Images Plus 2.0.

\subsubsection{Serum biochemical parameters}

The serum samples were analyzed for glucose, triacylglycerol (TAG), total cholesterol (TC), HDL-cholesterol (HDL-C), and non-esterified fatty acid (NEFA) levels using commercial kits (Labtest, MG, Brazil; Wako Diagnostic, VA, USA). The levels of LDLcholesterol were estimated calculating the Friedewald formula as: LDL-C $=$ TG - HDL-C (TAG/5) (FRIEDEWALD; LEVY; FREDRICKSON, 1972). Serum antioxidant capacity was measured by ORAC (DÁVALOS et al., 2004) and ferric reducing ability of serum (FRAP) assays (BENZIE, STRAIN, 1996). Both methods were performed on a Synergy H1 Hybrid Multi-Mode microplate reader (BioTek Instruments, Winooski, VT). The antioxidant capacity was calculated from a standard curve made with known concentrations of Trolox (6-hydroxy2,5,7,8-tetramethylchroman-2-carboxylic acid; Sigma Chemical Co., St. Louis, MO, USA) and expressed in terms of $\mu \mathrm{mol}$ Trolox equivalent per $\mathrm{mL}$ of serum for both assays.

\subsubsection{Fecal energy determination}

Feces collected from the cages at the final of the experimental period (last 3 days) were pooled per group and dried in an oven $\left(50{ }^{\circ} \mathrm{C}\right)$ for $36 \mathrm{~h}$. Feces were ground to a uniformly fine powder using a mortar and pestle and stored at $-20{ }^{\circ} \mathrm{C}$ until analysis. A representative sample of 0.8 to $1.0 \mathrm{~g}$ of the dried material was analyzed to determine the energy content using a bomb calorimeter (Model 1341, Parr Instrument Company, IL, USA).

\subsubsection{Gene expression analysis by quantitative PCR}

RNA purification, reverse transcription, and quantification by real-time PCR were performed as previously described (FESTUCCIA et al., 2008) with some modifications. RNA was extracted from the liver (five to six animals per group) using TRIzol ${ }^{\circledR}$ reagent 
(Invitrogen) and extraction was performed as described in the product information. RNA concentration was determined on a NanoDrop spectrophotometer (Thermo Scientific, Wilmington, USA). RNA samples were stored at $-80{ }^{\circ} \mathrm{C}$ until use for synthesis of cDNA and real-time PCR. Primers used for the PCR reactions are listed in Table 1. Results were expressed as the ratio between the expression of the target gene and the housekeeping gene RPL19, the expression of which was not significantly affected by the administration of PCE.

\subsubsection{Protein analysis by immunoblotting}

Hepatic tissue $(\sim 80 \mathrm{mg})$ was homogenized (T10, Ultra-Turrax $®)$ in buffer $(0.5 \mathrm{~mL})$ containing $50 \mathrm{mM}$ HEPES, $40 \mathrm{mM} \mathrm{NaCl}, 50 \mathrm{mM} \mathrm{NaF}, 2 \mathrm{mM}$ EDTA, $10 \mathrm{mM}$ sodium pyrophosphate, $10 \mathrm{mM}$ sodium glycerophosphate, $2 \mathrm{mM}$ sodium orthovanadate, $1 \%$ Triton-X 100, and EDTA-free protease inhibitors and centrifuged at $15,000 \mathrm{~g}$ for $10 \mathrm{~min}$ at $4{ }^{\circ} \mathrm{C}$. The supernatant protein was used for quantification by Pierce BCA Protein Assay Kit (Thermo Scientific, Rockford, USA). The proteins were denatured by boiling in Laemmli buffer, separated on SDS-PAGE gel (12\%) and transferred to PVDF membrane. The membranes

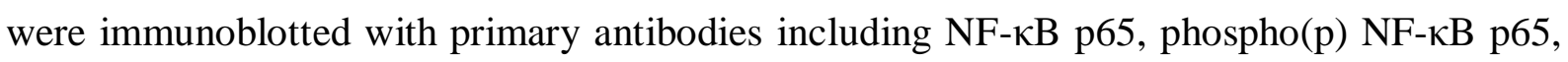
and $\beta$-actin (Cell Signalling Technology, Beverly, USA) diluted 1:1000 in 5\% milk. After primary incubation, the membranes were incubated with peroxidase-conjugated secondary antibody $(1: 10,000)$ and revealed with ECL enhanced chemiluminescence susbtrate (GE Healtcare). The results were presented as values quantified by densitometry using Image $\mathbf{J}$ software (National Institutes of Health, USA).

\subsubsection{Statistical analysis}

The results were presented as mean \pm SEM for groups based on nine to ten mice in each group for body and tissue weight, fasting blood glucose, blood glucose in OGTT, and serum biochemical. For fecal energy excretion, data were processed based on three repetitions in each group. The data for RER, $\mathrm{O}_{2}$ consumption, and serum insulin in OGTT was processed based on four mice in each group. PCR-RT, immunoblotting, and lipolysis were presented based on five to six mice in each group. The effects of PCE on the studied parameters were analyzed using a one-way (treatment) analysis of variance (ANOVA). Significant effects were analyzed using Dunnett's test with HFS group as control group (statistical significance was 
determined at $p<0.05)$. The Chow group was included only as a reference and was not included in the statistical analysis. The statistical analysis and figures were performed using the SAS 9.3 package (SAS Institute, Inc., Cary, USA) and GraphPad Prism (GP Prism, San Diego, USA). 
4. RESULTS 
4.1 Phenolic compounds from cagaita (Eugenia dysenterica DC.) fruit prevent body weight and fat mass gain induced by a high-fat, high-sucrose $\operatorname{diet}^{1}$

Carlos M. Donado-Pestana ${ }^{\mathrm{a}}$, Thiago Belchior ${ }^{\mathrm{b}}$, Maria Inés Genovese $^{\mathrm{a}, *}$

${ }^{a}$ Departamento de Alimentos e Nutrição Experimental, Faculdade de Ciências Farmacêuticas

- Universidade de São Paulo. Av. Prof. Lineu Prestes, 580, Bloco 14, São Paulo, SP, Brasil. CEP 05508-900.

${ }^{\mathrm{b}}$ Departamento de Fisiologia e Biofísica, Instituto de Ciências Biomédicas - Universidade de São Paulo. Av. Prof. Lineu Prestes, 1524, São Paulo, SP, Brasil. CEP 05508-000.

*Corresponding author: Maria Inés Genovese, Departamento de Alimentos e Nutrição Experimental, Faculdade de Ciências Farmacêuticas - Universidade de São Paulo. Av. Prof. Lineu Prestes, 580, Bloco 14, São Paulo, SP, Brasil. CEP 05508-900. Fone: +55 113091 3656; fax: +55 113815 4410; e-mail address: genovese@ @sp.br

${ }^{1}$ Manuscript published in Food Research International, v. 77 (2015), pp. 177-185 


\begin{abstract}
Cagaita (Eugenia dysenterica DC.) is a Brazilian Cerrado biome tree, whose fruit and leaves are used as alternative medicine by local communities to treat diarrhea, diabetes, and jaundice. Phenolic compounds from cagaita fruit have demonstrated in vitro antioxidant potential and inhibitory actions towards the activity of enzymes involved in carbohydrate metabolism. Herein, we evaluated whether administration of phenolic-rich extracts from cagaita (CGT) affects obesity and its metabolic complications induced by the intake of a highfat high-sucrose (HF/HS) diet during an eight-week period. Four groups of male C57BL/6J mice ( $n=9-10$ per group) fed either with a chow diet (Chow group) or an HF/HS diet were daily treated by gavage with water or CGT at doses of 7 and $14 \mathrm{mg}$ gallic acid equivalent (GAE)/kg body weight (HF/HS, CGT7, and CGT14 groups). Treatment with both doses of CGT attenuated the increase in body weight gain and fat accumulation induced by the intake of an HF/HS diet without affecting food intake. Such protection from a diet-induced obesity by CGT was associated with the attenuation of fasting hyperglycemia, hypertriglyceridemia, and hypercholesterolemia, with no effect on glycemic control post-glucose challenge. Furthermore, CGT treatment also improved plasma antioxidant status. The fecal triglycerides excretion was increased by CGT phenolics at both studied doses. No significant alteration in liver glycogen and total cholesterol content was noted among the groups, but a significant decrease in liver triacylglycerol was found in the CGT7 group when compared to the HF/HS group. These results indicate that phenolics from cagaita may play an important role in the prevention of obesity and its associated abnormalities, and also point out their potential for the development of new applications and complementary strategies in therapeutic alternatives.
\end{abstract}

Keywords: polyphenol; Myrtaceae; obesity; cagateira

\title{
1. Introduction
}

The worldwide prevalence of overweight and obesity combined rose by $27.5 \%$ in adults and $47.1 \%$ in children in the last three decades ( $\mathrm{Ng}$ et al., 2014). This has resulted in a dramatic increase in the prevalence of obesity-associated chronic diseases including type 2 diabetes, cardiovascular complications, and certain types of cancer. Evidence-based studies have demonstrated that the consumption of regular amounts of fruits and vegetables reduces 
the risk of developing obesity and associated diseases; such benefits have been partially attributed to molecules with high antioxidant capacity, which includes phenolic compounds found in these foods (Mujic et al., 2011; Scalbert, Manach, Morand, Remesy, \& Jimenez, 2005).

Brazil is the world's third largest fruit producer and the seventh largest producer of tropical fresh fruit (FAO, 2013). Due to its area, geographic location, climate, and soil conditions, Brazil has a natural abundance of native fruits; however, only a few of them are being exploited commercially, perhaps due to the limited amount of information available about their chemical composition, and biochemical and nutritional properties. The Brazilian Cerrado is the second largest biome in South America, occupying an area of more than 2 million hectares. In terms of biological diversity, the Brazilian Cerrado is recognized as the richest savanna in the world with 11,627 species of native plants (Ministério do Meio Ambiente - Brazil, 2015). Among this variety of species, some edible fruits are regularly consumed by the local population and commercially exploited such as pequi (Caryocar brasiliense), buriti (Muritia flexuosa), cagaita or cagateira (Eugenia dysenterica DC.), and mangaba (Hancornia speciosa). The cagaita fruit is a yellow-orange roughly spherical berry with a diameter of approximately 3-4 cm and mass varying between 15-37 $\mathrm{g}$ that has a sweetsour and slightly astringent taste (Cardoso, 2011; Clovegarden, 2015). The cagaita fruit is used in various regional preparations, such as jams, ice-cream, liqueurs, and juices; whereas both the fruit and the leaves are used as popular alternative medicine by local communities to treat diarrhea, diabetes, and jaundice (Lima et al., 2011). Cagaita is considered to be a source of vitamin $\mathrm{C}$ and phenolic compounds, including quercetin, ellagitannins, ellagic acid, and kaempferol (Abe, Lajolo, \& Genovese, 2012; Goncalves, Lajolo, \& Genovese, 2010; Cardoso, Martino, Moreira, Ribeiro, \& Pinheiro-Sant'Ana, 2011), which were previously shown to exert important biological functions preventing the development of obesity and type 2 diabetes (Scalbert et al., 2005; Del Rio, Borges, \& Crozier, 2010).

Studies from our group have found that phenolic compounds from cagaita are potent inhibitors of enzymes involved in the carbohydrate metabolism such as $\alpha$-amylase and $\alpha$ glucosidase in in vitro enzymatic assays (Goncalves et al., 2010). Here, we investigated whether the administration of CGT at two different doses protects mice from $\mathrm{HF} / \mathrm{HS}$ dietinduced obesity and metabolic complications. 


\section{Materials and methods}

\subsection{Preparation and characterization of phenolic-rich extract from cagaita}

The commercial frozen pulp of cagaita was obtained from Central do Cerrado, Urucuia ${ }^{\circledR}$ (Brasília DF, Brazil). Frozen samples were thawed at room temperature before extraction. A representative sample equivalent to $5.0 \mathrm{~g}$ of dry matter was homogenized and extracted in 100 $\mathrm{mL}$ of $80 \%$ aqueous methanol using a Turratec TE-102 (Tecnal) at $4000 \mathrm{rpm}$ for $1 \mathrm{~min}$, three times with intervals of $30 \mathrm{~s}$, in an ice-bath, followed by rotation using a magnetic stirrer (200 $\mathrm{rpm}$ ) at $5{ }^{\circ} \mathrm{C}$ for $30 \mathrm{~min}$. The extract was separated by centrifugation at $5000 \mathrm{~g}$ for $30 \mathrm{~min}$ and filtered through a Whatman No. 3 filter paper. The precipitate was resuspended twice in the aqueous alcoholic solution for additional extraction steps and then centrifuged and filtered as described above. The pooled filtrates were concentrated at $39{ }^{\circ} \mathrm{C}$ to remove methanol on a rotary evaporator (Rotavapor R-210; Büchi, Sweden), and $40 \mathrm{~mL}$ of extract was made with distilled water.

The aqueous extract was added onto a preconditioned $(100 \mathrm{~mL}$ of methanol, $150 \mathrm{~mL}$ of water) LC-18 SPE tube (10 g of LC-18 SPE, Supelclean ${ }^{\mathrm{TM}}$ LC-18, Supelco). After washing with water, the phenolic compounds were eluted with $200 \mathrm{~mL}$ of methanol. The eluate was evaporated to dryness and the residue resuspended in $70 \mathrm{~mL}$ of water, for CGT7 extract, or 35 $\mathrm{mL}$ of water, for CGT14 extract.

The extract was characterized regarding total phenolics (Singleton, Orthofer, \& LamuelaRaventos, 1999) and proanthocyanidin contents (Porter, Hrstich, \& Chan, 1985), antioxidant capacity by the oxygen radical absorbance capacity (ORAC) assay (Dávalos, GómezCordovés, \& Bartolomé, 2004), the 2,2-diphenyl-1-picrylhydrazyl (DPPH) radical-scavenging assay (Brand-Williams, Cuvelier, \& Berset, 1995), the ferric reducing antioxidant power (FRAP) assay (Benzie \& Strain, 1996), and the pancreatic lipase inhibitory activity (Nakai et al., 2005).

The identification and quantification of the main flavonoids and phenolic acids in cagaita were performed as described previously (Arabbi, Genovese, \& Lajolo, 2004), adding the aqueous extract onto a preconditioned $(20 \mathrm{~mL}$ of methanol, $60 \mathrm{~mL}$ of water) polyamide SC6 SPE tube (1 g, Macherey-Nagel GmbH and Co., Düren, Germany). After washing with water, phenolic compounds were eluted with $50 \mathrm{~mL}$ of methanol to elute neutral phenolics, and with $50 \mathrm{~mL}$ of methanol:ammonia (99.5:0.5) to elute acidic phenolics. These two fractions were 
pooled and evaporated to dryness under reduced pressure at $39{ }^{\circ} \mathrm{C}$, re-dissolved in HPLC grade methanol $(1 \mathrm{~mL})$, and filtered through a $0.22 \mu \mathrm{m}$ PTFE (polytetrafluoroethylene) filter (Millipore Ltd, Bedford, MA). Identification and quantification were performed using a Prodigy ODS3 reversed phase silica column (5 $\mu \mathrm{m}, 250$ x $4.6 \mathrm{~mm}$, Phenomenex Ltd, Torrance, CA), in an analytical reversed-phase HPLC (Hewlett-Packard 1100) system with an autosampler and a quaternary pump coupled to a diode array detector. Pure standards of quercetin, kaempferol, and ellagic acid dissolved in methanol (HPLC grade) were used to calibrate the standard curves and retention times. Calibration was performed by injecting the standards three times at five different concentrations. Peak identification was performed by comparing retention times and diode array spectral characteristics with the standards and the library spectra. Quantification of phenolic compounds was performed by comparing the peak area of the sample with that of the standards' peak area injected, and effected on the basis of external standard curves $(r \geq 0.998)$ for peaks detected and identified at $270 \mathrm{~nm}$ with spectral characteristics similar to the their respective standard. In the case of quercetin and kaempferol derivatives, results were expressed as $\mu \mathrm{g}$ of aglycone. The results were expressed by $\mathrm{mL}$ of extract.

Total ellagic acid was determined after acid hydrolysis according to Pinto, Lajolo and Genovese (2008). An aliquot of $0.5 \mathrm{~mL}$ of extract was dried under nitrogen and $2 \mathrm{~mL}$ of $2 \mathrm{~N}$ trifluoroacetic acid was added, and hydrolysis was performed at $120{ }^{\circ} \mathrm{C}$ for $90 \mathrm{~min}$. The hydrolyzed samples were evaporated to dryness under nitrogen, redissolved in methanol and filtered for HPLC analysis.

\subsection{Animals and experimental design}

All animal procedures performed had been previously approved by the Ethical Committee for Animal Research of the Faculty of Pharmaceutical Science of University of São Paulo (CEUA/FCF/378). Forty 8-week old male C57BL/6J mice of approximately $23 \mathrm{~g}$ were used in this study. The mice were matched by weight and kept at $22 \pm 1{ }^{\circ} \mathrm{C}$ under a 12 hour light/12-hour dark cycle. All mice were fed a low-fat chow diet (NUVILAB CR-1 ${ }^{\circledR}$ Sogorb Inc., São Paulo - SP, Brazil) ad libitum for one week before beginning the experiment.

The animals were randomly divided into four groups of ten mice each, as follows: 1) a chow fed group that received a daily water administration by gavage (Chow); 2) an HF/HS fed group that received a daily water administration by gavage (HF/HS); 3) an $\mathrm{HF} / \mathrm{HS}$ fed 
group that received a daily administration of phenolic-rich extract from cagaita by gavage (7 mg GAE/kg body weight, CGT7); and 4) an HF/HS fed group that received a daily administration of phenolic-rich extract from cagaita by gavage (14 mg GAE/kg body weight, CGT14).

According to the manufacturer, the chow diet provided $12.5 \mathrm{~kJ} / \mathrm{g}$ of energy, of which, $63 \%$ was from carbohydrate, $25 \%$ from protein, and $12 \%$ from fat. The HF/HS diet provided $19.4 \mathrm{~kJ} / \mathrm{g}, 41 \%$ of calories from sucrose, $20 \%$ from protein, and $39 \%$ from fat, as previously described (Lemieux, Picard, Labrie, Richard, \& Deshaies, 2003). The chemical composition excluding fiber and carbohydrates values - of the diets used in this study was as follows (in grams per 100 grams of diet): protein, 23.3; lipids, 4.6; ash, 7.0; and moisture, 9.2 for chow diet; and 19.3; 19.6; 4.0; 4.6 for the HF/HS diet respectively. Diets and water were available ad libitum during the experimental period of 8 weeks. Body weight and food intake were recorded every two days, and fasting blood glucose $(6 \mathrm{~h})$ was measured from the caudal vein weekly throughout the study by using Accu-Chek Performa ${ }^{\circledR}$ (Roche, Mannheim, Germany).

After 8 weeks, the mice were anesthetized with isoflurane and immediately euthanized by decapitation. Blood was collected from the trunk and plasma separated by centrifugation at $3000 \mathrm{~g}$ for $20 \mathrm{~min}$ at $4{ }^{\circ} \mathrm{C}$. Tissues, including heart, liver, gastrocnemius muscle, and adipose tissues (inguinal, retroperitoneal, epididymal and brown) were removed, separated, weighed, and immediately frozen under liquid nitrogen and stored at $-80^{\circ} \mathrm{C}$.

\subsection{Glucose tolerance test (GTT)}

At the $7^{\text {th }}$ week, the mice were fasted for $6 \mathrm{~h}$ and injected intraperitoneally with a glucose solution ( $1 \mathrm{~g} / \mathrm{kg}$ body weight), and the glucose concentration was determined in tail blood collected at the baseline (prior to injection) and at 15, 30, 45, 60 and 90 min post-injection, using the Accu-Chek Performa ${ }^{\circledR}$ glucometer (Roche, Mannheim, Germany).

\subsection{Plasma biochemical parameters}

A LabMax $240^{\circledR}$ clinical chemistry analyzer and appropriated kits were used to determine plasma levels of total cholesterol, HDL-cholesterol, LDL-cholesterol, triacylglycerol, urea and creatinine, following manufacturer's instructions (LABTEST, Lagoa Santa, MG, Brazil). Plasma antioxidant capacity was measured by ORAC (Dávalos et al., 2004) and ferric 
reducing ability of plasma (FRAP) assays (Benzie \& Strain, 1996). Both methods were performed on a Synergy H1 Hybrid Multi-Mode microplate reader (BioTek Instruments, Winooski, VT). The antioxidant capacity was calculated from a standard curve made with known concentrations of Trolox (6-hydroxy-2,5,7,8-tetramethylchroman-2-carboxylic acid; Sigma Chemical Co., St. Louis, MO, USA) and expressed in terms of $\mu$ mol Trolox equivalent per $\mathrm{mL}$ of plasma for both assays.

\subsection{Fecal lipids determination}

Feces collected from the cages at the final of the experimental period (last 3 days) were pooled per group and dried in an oven $\left(50{ }^{\circ} \mathrm{C}\right)$ for $36 \mathrm{~h}$. Feces were ground to a uniformly fine powder using a mortar and pestle and stored at $-20{ }^{\circ} \mathrm{C}$ until analysis. A representative sample of $0.5 \mathrm{~g}$ of the dried material was used for lipid extraction according to Folch, Lees, and Stanley (1957), using $7.5 \mathrm{~mL}$ of chloroform:methanol (2:1) and Ultra-Turrax ${ }^{\circledR}$ (T25, IKA) at $8000 \mathrm{rpm}$ for $3 \mathrm{~min}$. The lipids were filtered through a Whatman No. 3 filter paper and the residue was resuspended twice in the chloroform:methanol solution for additional extraction steps and then filtered as described above. The pooled filtrates were washed in two stages by using potassium chloride $(0.88 \%)$ and methanol:water (1:1) solution, respectively. Finally, the extract was dried in a nitrogen flow, weighted, and resuspended in isopropanol for the determination of total cholesterol and triglycerides concentrations using commercial kits (Labtest). The results were normalized to the weight of the sample and expressed in terms of mg per g of dry feces.

\subsection{Liver glycogen, triacylglycerol, and total cholesterol determination}

For liver glycogen determination, $50 \mathrm{mg}$ of tissue was digested for $10 \mathrm{~min}$ in $0.5 \mathrm{~mL} 30 \%$ $\mathrm{KOH}$ solution, at $100{ }^{\circ} \mathrm{C}$, and its extraction was performed in two stages of precipitation by using ethanol and $70 \%$ ethanol solution and centrifugation at $840 \mathrm{~g}$ for $30 \mathrm{~min}$ and $3000 \mathrm{~g}$ for $5 \mathrm{~min}$ at $4{ }^{\circ} \mathrm{C}$. The resultant glycogen precipitate was ressuspended in $0.5 \mathrm{~mL} 4 \mathrm{~N} \mathrm{H}_{2} \mathrm{SO}_{4}$ and heated at $100{ }^{\circ} \mathrm{C}$ for $10 \mathrm{~min}$, followed by dissolution in $0.5 \mathrm{~mL} 4 \mathrm{~N} \mathrm{NaOH}$. The resulting glucose solution was then measured spectrophotometrically with a Labtest kit (BioTek Instruments). Finally, the liver glycogen content was calculated using the formula proposed by Carroll, Longley, and Roe (1956) with a factor of 0.9 for converting glucose value to 
glycogen levels. On the other hand, liver triacylglycerol and total cholesterol content were analyzed by using an adapted Folch method (1957). Briefly, $50 \mathrm{mg}$ of tissue was used for lipid extraction and homogenized in $0.9 \mathrm{~mL}$ chloroform:methanol (2:1). After homogenization, $0.3 \mathrm{~mL}$ of methanol was added and centrifuged at $11000 \mathrm{rpm}$ for $15 \mathrm{~min}$. After the removal of the upper phase, washing in two stages by using $0.4 \mathrm{~mL}$ Folch solution, and conversion of the infranatant to a uniform phase with methanol, lipids were dried in a nitrogen flow, and resuspended in isopropanol for determination of total cholesterol and triglycerides concentrations by using commercial kits (Labtest). The results were normalized to the weight of the sample and expressed in terms of mg per $g$ of tissue.

\subsection{Statistical analysis}

The results are presented as mean \pm SEM for groups based on nine to ten mice in each group for body and tissue weight, fasting blood glucose, blood glucose in GTT, and plasma biochemical. For fecal lipids excretion, data were processed based on four to five repetitions in each group. The data for characterization of the extracts were presented as mean \pm SD for three replicates. The effects of the phenolic compounds from cagaita at two doses on the studied parameters were analyzed using a one-way (treatment) analysis of variance (ANOVA). Significant effects were analyzed using Tukey's studentized range or post hoc Fisher's least significant difference (LSD) test when the main treatment or interaction effects were significant (statistical significance was determined at $p<0.05$ ). The statistical analysis was performed using the SAS 9.3 package (SAS Institute, Inc., Cary, NC).

\section{Results}

The characterization of the phenolic-rich extracts from cagaita in relation to total phenolic, proanthocyanidin, flavonoid and phenolic acid contents, and antioxidant capacity is presented in Table 1. The ellagitannins in cagaita are represented by the difference between total ellagic acid and free ellagic acid contents detected after acid hydrolysis of the phenolicrich extracts. The tannins including ellagitannins and proanthocyanidins (hydrolysable and condensed tannins, respectively) represent the major classes of phenolic compounds found in cagaita (40-46\% for ellagitannins and 27-29\% for proanthocyanidins) followed by flavonoids and free phenolic acids, the latter being minor constituents. The content of total phenolic 
compounds found ( 0.88 and $1.77 \mathrm{mg} \mathrm{GAE} / \mathrm{mL}$, for CGT 7 and CGT14, respectively) were used to calculate the mean daily dose administered to each mouse per day ( $7 \mathrm{mg} \mathrm{GAE} / \mathrm{kg} / \mathrm{day}$ and $14 \mathrm{mg}$ GAE/kg/day for CGT7 and CGT14, respectively). The in vitro antioxidant capacity was proportional to the phenolic concentration and the extract showed a high inhibitory activity toward pancreatic lipase in vitro ( $\mathrm{IC}_{50} 25.3 \mu \mathrm{g} \mathrm{GAE} / \mathrm{mL}$ reaction) when compared to the effectiveness of the drug Orlistat $\left(\mathrm{IC}_{50} 28.3 \mu \mathrm{g} / \mathrm{mL}\right)$, which is designed to treat obesity.

Daily administration of phenolic-rich extract from cagaita at two doses partially protected the mice from obesity induced by the intake of the HF/HS diet. The body weight was significantly reduced $(p<0.05)$ in those animals on the CGT14 group when compared with those on the HF/HS group on the $4^{\text {th }}$ week and until the end of the experiment. After 8 weeks, the mice receiving CGT at the two doses showed lower $(p<0.05)$ body weight than those on the HF/HS group (Fig. 1a). The weight gain was significantly reduced $(p<0.05)$ in both the CGT7 and CGT14 groups relative to the HF/HS group, although the weight gain remained significantly higher than in the mice receiving the low-fat chow diet (Fig. 1b). In the same order, adiposity was greatly affected by the administration of CGT. In the CGT7 and CGT14 groups, an attenuation was observed in the increase of retroperitoneal (424 and $433 \mathrm{mg}$, respectively) (Fig. 1c), epididymal (999 and $994 \mathrm{mg}$ ) (Fig. 1d), inguinal (589 and $693 \mathrm{mg}$ ) (Fig. 1e), and brown (111 and $123 \mathrm{mg}$ ) (Fig. 1f) adipose depots when compared to the HF/HS group (598, 1379, 992 and $156 \mathrm{mg}$, respectively). However, the adipose tissue weights in the CGT groups remained significantly higher than in the Chow group. On the other hand, the administration of CGT did not have a significant effect on the tissue weights, including liver, heart, and gastrocnemius muscle (Figs. 1g, 1h, and 1i).

The daily food intake over the course of the experiment was not significantly different between groups fed with the HF/HS diet, whether receiving phenolic-rich extract or not. These groups have a lower food intake in grams than chow fed mice (Fig. 2a). Despite these differences, there were no significant differences in the calorie intake among the groups, because of the higher caloric density of the HF/HS diet when compared to the low-fat chow $\operatorname{diet}(19.4$ vs. $12.5 \mathrm{~kJ} / \mathrm{g}$ respectively) (Fig. $2 \mathbf{b})$. The food efficiency was lower $(p<0.05)$ in the CGT groups than in the HF/HS group (Fig. 2c). To examine the possible reasons for the reduction in adiposity and food efficiency, fecal lipids were measured in mice after administration of phenolic compounds from cagaita. As expected, the total fecal lipids was higher $(p<0.05)$ in the groups fed with the HF/HS diet, whether receiving the phenolic-rich 
extract or not, when compared to the Chow group. Although no significant differences were found in both CGT groups when compared to the HF/HS group, it was possible to observe a slightly higher total fecal lipid excretion in the groups receiving the phenolic extract (Fig. 2d). When the lipid composition of the feces was compared, a significant increase $(p<0.05)$ of triglycerides was observed in both CGT groups compared to the HF/HS group (Fig. 2e). In the same order, a trend for high fecal cholesterol (not significantly different) was observed in CGT14, but not in CGT7, when compared to the HF/HS group (Fig. 2f).

When the fasting blood glucose during the experiment was compared, a trend toward an increase was observed for the mice receiving the HF/HS diet. However, despite the blood glucose elevation, the mice receiving CGT presented lower average values than the HF/HS group (Fig. 3a). Fasting blood glucose in the CGT14 group, but not in the CGT7 group, significantly decreased $(p<0.05)$ at the $4^{\text {th }}$ and $8^{\text {th }}$ weeks of the experiment when compared to the HF/HS group, which showed an accelerated increase in blood glucose during the experiment. In addition, no significant differences $(p>0.05)$ in blood glucose levels were observed among the CGT14 and Chow groups at weeks 5 and 7. The results showed that both time and treatment were significant for the fasting glycemia values $(p<0.05)$, but the effect of the interaction between these two factors was not $(p=0.3028)$. By analyzing the effect on the time factor of fasting glycemia in each group, a significant increase $(p<0.05)$ was observed in the HF/HS only group, but no differences were observed in the other groups (Fig. 3a). Despite the reduction in fasting glycemia, the treatment with CGT did not affect the impairment in the glucose tolerance induced by the intake of an HF/HS diet, as evidenced by the absence of changes in glucose excursion and area under the curve (AUC) among the HF/HS-fed groups, whether receiving the phenolic-rich extract or not (Fig. 3b). No significant alterations in liver glycogen content were noted among the groups (Fig. 3c).

In the plasma biochemical profile, it was observed a significant decrease $(p<0.05)$ in triacylglycerol levels in both CGT groups $\left(1.13\right.$ and $0.98 \mathrm{mmol} \mathrm{L}^{-1}$ for CGT7 and CGT14, respectively) when compared to the HF/HS group $\left(1.52 \mathrm{mmol} \mathrm{L}^{-1}\right)$. The triacylglycerol levels in the CGT groups were similar $(p>0.05)$ to the level in the animals of the Chow group (1.10 mmol L ${ }^{-1}$ ) (Fig. 4a). The total cholesterol and HDL-cholesterol levels were unaltered in the CGT groups in comparison with the HF/HS group, which presented the highest concentrations $(p<0.05)$ compared to the Chow group (Figs. $4 \mathbf{b}$ and $4 \mathbf{c}$ ). The LDL-cholesterol levels were lower $(p<0.05)$ in CGT14, but not in CGT7, when compared to the HF/HS group (Fig. 4d). The LDL-cholesterol levels in CGT14 were similar $(p>0.05)$ to those animals in the Chow 
group. In addition, two important plasma markers of renal failure, whose increase is related to a common complication of diabetes, urea, and creatinine, were also evaluated. There was a significant decrease $(p<0.05)$ in plasma creatinine levels in the CGT14 group compared to the HF/HS group diet (Fig. 4e). However, no effect $(p>0.05)$ was observed in the urea concentrations among the groups (Fig. 4f). On the other hand, the plasma antioxidant capacity was significantly increased $(p<0.01)$ in the CGT14 group when compared to the HF/HS group, as evidenced in both ORAC and FRAP assays (Figs. 4g and 4h). Moreover, CGT phenolics reduced significantly $(p<0.05)$ hepatic triacylglycerol (Fig, $4 \mathbf{i})$ in the lower cagaita dose (CGT7), and a non-significant decrease of $20 \%$ was observed in the CGT14 group when compared to the HF/HS group. We also examined the effects of CGT on hepatic total cholesterol (Fig. 4j) but no significant differences were found among the groups.

\section{Discussion}

Growing evidence indicates that an elevated intake of dietary phenolics may have beneficial effects, including protection against obesity and chronic associated diseases (Anhê et al., 2013; Hanhineva et al., 2010; Wang et al., 2014). Our main findings indicate that phenolic compounds from cagaita attenuated the increase in body weight gain, adiposity, fasting hyperglycemia (but not the postprandial glucose), hypertriglyceridemia, hypercholesterolemia, and hepatic triacylglycerol accumulation induced by intake of HF/HS. In addition, CGT improved the plasma antioxidant capacity and fecal triglycerides excretion. Altogether those findings suggest that phenolic compounds of CGT may have an important role in the prevention of diet-induced obesity and its associated abnormalities.

Herein, we evaluated the effect of two doses (7 and $14 \mathrm{mg}$ GAE per kg body weight) of phenolic-rich extracts from cagaita in an experimental model of obesity induced by feeding mice with an HF/HS diet. The HF/HS diet-induced obesity in mice mimics most of the phenotypes seen in human obesity. Because obesity responds to a high dietary intake of carbohydrates and lipids, $\mathrm{HF} / \mathrm{HS}$ feeding is an appropriate model for studying the complications associated with this disease. It has been shown that a high-fat and/or highsucrose diet exacerbates glucose intolerance, insulin resistance, diabetes mellitus, and high levels of circulating free fatty acids in both obese and lean mice (Sumiyoshi, Sakanaka, \& Kimura, 2006; Yang, Miyahara, Takeo, \& Katayama, 2012). We have studied two doses of CGT in which the lower one (CGT7) was calculated to be equivalent to consuming the 
quantity of phenolic compounds present in a minimum of $0.5 \mathrm{~g}$ cagaita dry weight $/ \mathrm{kg}$ body weight. This quantity, in turn, is equivalent to consuming $400 \mathrm{~g}$ of fruit (with approximately $90 \%$ moisture content) per day by a $70-\mathrm{kg}$ individual. This is the portion of fruits and vegetables recommended by WHO/FAO for the prevention of chronic diseases such as heart disease, cancer, diabetes and obesity (WHO/FAO, 2004). However, using the recommendation to calculate the human equivalent dose provided by Food and Drug Administration (FDA, 2005), the lower dose would be equivalent to a human dose of $34 \mathrm{mg}$ of phenolics/day. Considering the average dietary intake of phenolic compounds in Western diets of $1 \mathrm{~g} /$ day (Scalbert \& Williamson, 2000), we could conclude that beneficial health effects are obtained with a very low dose, easily attained through diet.

The administration of CGT in both doses significantly reduced body weight and weight gain when compared with the HF/HS group. Consistent with these findings, Heber et al., (2014) reported that C57BL/6J mice gained less weight on an HF/HS diet and supplementation with phenolic-enriched extracts. In the same order, the body composition of mice confirms that the administration of CGT promotes a reduction in body fat accumulation despite the negative effects of the HF/HS diet. Polyphenols have been shown to modulate physiological and molecular pathways that are involved in energy metabolism, adiposity, and obesity (Meydani \& Hasan, 2010). The mechanisms by which adiposity can be regulated by phenolic compounds involve multiple pathways. In our results, a more enhanced trend of fecal lipid excretion (mainly triglycerides) in the mice receiving CGT was observed when compared to the HF/HS group, suggesting a regulation of energy balance. These findings may explain, at least in part, the lack of body weight gain and the reduction in adiposity. However, these results must be normalized to the daily amount of feces excreted by each group, considering that obesity and type diets (low or high-fat) may have an effect on the gut motility (Mushref, \& Srinivasan, 2013), regulating fecal excretion.

As it is known, the development of obesity results in part from an excess of dietary lipids and carbohydrates uptake, therefore an effective way to prevent obesity is decreasing fat absorption from the intestine by inhibiting pancreatic lipase activity, which is a key enzyme for lipid absorption. Orlistat, a specific pancreatic lipase inhibitor, is clinically used for preventing obesity and hyperlipidemia. However, orlistat therapy can favor deficiencies of lipid-soluble vitamins and essential fatty acids (Carriere et al., 2001; Nakai et al., 2005). Phenolic compounds may have anti-obesity properties by inhibiting pancreatic lipase activity, as previously demonstrated in studies in vitro and in vivo with mice and humans (Grove, Sae- 
tan, Kennett, \& Lambert, 2012; Hsu et al., 2006; Sugiyama et al., 2007). In accordance with the data presented in the characterization of the phenolic-rich extract related to their effectiveness when compared to Orlistat, it is reasonable to hypothesize that the CGTmediated modulation of lipid excretion appears to possibly be, at least in part, due to the inhibitory effects against pancreatic lipase by CGT; however, further studies are necessary to confirm this hypothesis in vivo.

Phenolic compounds from cagaita (mainly with the higher dose, CGT14), exhibited fasting glucose-lowering properties modulating a hyperglycemic state induced by the HF/HS diet intake during the experiment period. To our knowledge, these findings are the first to demonstrate the potential of phenolic compounds from cagaita in improving the fasting glucose response with in vivo model of obesity. However, we did not find statistically significant differences during the GTT among the CGT and HF/HS groups. This event suggests that the phenolics from cagaita may be more effective as a strategy to the fasting glucose control instead of the postprandial glucose control. As it is known, both impaired fasting glucose and impaired glucose tolerance appear to result from different pathophysiological mechanisms. The decrease of fasting blood glucose may be involved in the improvement of insulin secretion, whereas glucose tolerance appears to result from peripheral insulin resistance (Nigam, Bourassa, Fortier, Guertin, \& Tardif, 2007). In this sense, evidence based on biological experiments suggests that phenolic compounds may stimulate insulin secretion from the pancreatic $\beta$-cells (Hanhineva et al., 2010) or protect against $\beta$ cell failure induced by HF/HS feeding (glucolipotoxicity) (Biden, Boslem, Chu, \& Sue). However, in the present study, plasma insulin levels were not determined in the course of the experimental period or during the GTT, and this limitation makes it difficult to confirm these hypotheses mentioned above.

Of special interest to our observations is the finding that impaired fasting glucose, and the ability of phenolic compounds from cagaita to modulate it, is associated with increased allcause and cardiovascular mortality in subjects, whereas postprandial hyperglycemia does not appear to be a risk factor (Nigam et al., 2007).

Other mechanism explaining lower hyperglycemia may be the suppression of hepatic glucose production through the inhibition of enzymes involved in glycogenolysis and/or gluconeogenesis by phenolic compounds, mainly glucose-6-phosphatase (G6Pase) and phosphoenolpyruvate carboxykinase (PEPCK) in the liver (Cheng et al., 2012; Jung, Park, 
Kim, \& Choi, 2012), though this is not clearly supported by our actual data for liver glycogen content where no significant alterations were noted among the groups.

Because the results for GTT were not in accordance with those expected on the hypothesis that the phenolic compounds can improve the postprandial glucose control, we suggest that further studies be performed using an oral glucose tolerance test (OGTT) and not intraperitoneally. The administration of glucose via an intraperitoneal injection means that there is no incretin response that is known to potentiate the glucose-mediated insulin response (Andrikopoulos, Blair, Deluca, Fam, \& Proietto, 2008). Furthermore, delivering the glucose orally in mice can provide, probably, better results in relation to the effects of phenolic compounds from cagaita on the inhibition of the carbohydrate-hydrolyzing enzymes (mainly $\mu$-glucosidase) in the digestive tract, and consequently blunting the postprandial plasma glucose, as previously demonstrated in vitro by our group. Additionally, phenolic compounds in fruits have also been shown to inhibit intestinal glucose transport, inhibiting sodiumdependent glucose transporter 1 and glucose transporter 2 (Ader, Block, Pietzsch, \& Wolffram, 2001; Manzano \& Williamson, 2010). Andrikopoulos et al. (2008) suggested that the OGTT is a more sensitive technique to discern differences in plasma glucose levels in chow compared with high-fat-fed mice. Another possible explanation by which phenolic compounds had no effect on glycemic control post-glucose challenge can probably be found by subjecting animals to fasting periods on a weekly basis. It was suggested that intermittent feeding decreases glucose tolerance (Cerqueira et al., 2011), which could therefore underestimate the effect of CGT phenolics during GTT.

Our results showed that phenolic-rich extracts from cagaita exert a protective effect against dyslipidaemia associated with diet-induced obesity. The administration of CGT in both doses attenuated hypertriglyceridemia and hypercholesterolemia induced by $\mathrm{HF} / \mathrm{HS}$ feeding. As it is known, individuals with type 2 diabetes mellitus have a characteristic dyslipidemia that has, as its central feature, an overproduction of low-density lipoproteins and hypertriglyceridemia (Ginsberg, Zhang, \& Hernandez-Ono, 2005). A recent study showed that phenolic compounds extracted from Citrus bergamia are effective to reduce LDLcholesterol levels by exerting inhibitory effects on 3-hydroxy-3-methylglutaryl-CoA reductase (HMGR), leading to an increased synthesis of hepatic LDL-Receptor; the latter process allows a subsequent clearance of LDL-cholesterol from the systemic circulation (Di Donna et al., 2014). Since HMGR inhibitors have also been shown to contribute to decreasing plasmatic triglycerides levels, these authors also observed a decrease in both serum and 
hepatic triglycerides. A previous study demonstrated that phenolics from cambuci, a Brazilian native fruit (belonging to the same Myrtaceae family), also improved the lipid profile of mice fed on a high-fat, high-sucrose diet, reducing cholesterol levels and also reducing slightly the triacylglycerol levels in plasma (Donado-Pestana, Belchior, Festuccia, \& Genovese, 2015). In addition to the plasma lipid profile, the administration of CGT (CGT14) decreased the levels of plasma creatinine when compared with the HF/HS group. In a clinical trial, it was observed that the risk of developing metabolic disorders such as obesity and type 2 diabetes lead to kidney and liver dysfunction in individuals, leading to an increase in the content of creatinine when compared to healthy individuals (Andra, Charisiadis, \& Makris, 2014). On the other hand, CGT phenolics reduced hepatic triacylglycerol accumulation; as it is known, a high rate of triacylglycerol accumulation in the liver is a measure of steatosis, which in combination with oxidative stress and inflammation may lead to the pathogenesis of non-alcoholic fatty liver disease, which usually develops in the setting of insulin resistance and obesity (Anhe et al., 2015). Similar to our results, the administration of a phenolic-rich cranberry extract to mice also decreased the hepatic triacylglycerol accumulation (Anhe et al., 2015).

Given the increasing interest in the role of antioxidants in health maintenance, phenolic compounds have been suggested to play a beneficial role in the prevention of the oxidative stress associated with chronic diseases (Henning et al., 2012; O’Byrne, Devaraj, Grundy, \& Jialal, 2002). The antioxidant capacity of phenolics is, to some extent, associated with the number of hydroxyl groups and the arrangement of functional groups on the phenolic core molecular structure. Both the configuration and total number of hydroxyl groups substantially influence the mechanism of antioxidant activity (Duluc, Soleti, Clere, Andriantsitohaina, \& Simard, 2012). In a recent review Zhang, Zhu, and Jiang (2014), outline that the antioxidant properties of polyphenols and their action mechanisms go beyond the modulation of oxidative stress. These authors also reported that polyphenols play an important role in the treatment of obesity through a mechanism involving the antioxidative function and scavenging of free radicals. Quercetin, a flavonoid found in cagaita, contributes significantly to the antioxidant potential because its structure effectively stabilizes the free radicals after hydrogen donation. An additional $\mathrm{OH}$ group at the $\mathrm{B}$ ring 5' position of quercetin increases the ORAC (Slatnar, Jakopic, Stampar, Veberic, \& Jamnik, 2012). Interestingly, our observations also indicated that the plasma antioxidant capacity was increased in the groups fed an HF/HS diet when compared to the Chow group. This phenomenon may be attributed to the dietary-induced oxidative stress, which appears to be regulated by a biological defense response, possibly 
inducing an antioxidant response to the oxidative stress elevated by the long-term exposure to the HF/HS diet (Kim, Sohn, Ahn, Lee, \& Lee, 2004).

Finally, our major findings indicated that phenolic compounds from cambuci reduced body weight and adiposity. However, as previously mentioned, we cannot rule out that the mechanisms by which adiposity can be regulated involve multiple pathways. In mice fed a high-fat diet, it was demonstrated that the phenolic compounds reduce adiposity by suppressing angiogenesis in adipose tissue, upregulating adipocyte energy metabolism and apoptosis, and downregulating preadipocyte differentiation (Ejaz, Wu, Kwan, \& Meydani, 2009). These mechanisms and their modulation by CGT phenolics need to be further investigated.

\section{Conclusion}

In conclusion, our present findings demonstrate that phenolic compounds from cagaita fruit have beneficial health effects on obesity management in C57BL/6J mice fed on a highfat high-sucrose diet. We assume that phenolics from cagaita can have an important role in the prevention of diet-induced obesity and their associated abnormalities, via attenuation of body weight gain, reduction of adiposity, fasting glucose-lowering properties, suppression of hypertriglyceridemia, plasma LDL-cholesterol, and hepatic triacylglycerol accumulation, and improvement in the plasma antioxidant status and fecal triglycerides excretion. Thus, phenolics from cagaita may point out their potential for the development of new applications and therapeutic approaches. However, further studies are necessary to elucidate the mechanisms of action of metabolites in different models on these modulatory effects, as well as their bioavailability.

\section{Acknowledgments}

The authors thank São Paulo Research Foundation (FAPESP 2013/19797-6) and Coordenação de Aperfeiçoamento de Pessoal de Nível Superior (CAPES/PEC-PG 5554-11-0) for the financial support. We also thank Prof. William Tadeu Festuccia and Wendel Sabóia da Silva for the revision of the manuscript, and Priscila Robertina dos Santos and Luis Daniel Daza Ramírez for help with animal procedures. 


\section{References}

Ader, P., Block, M., Pietzsch, S., \& Wolffram, S. (2001). Interaction of quercetin glucosides with the intestinal sodium/glucose co-transporter (SGLT-1). Cancer Letters, 162(2), 175180.

Andra, S. S., Charisiadis, P., \& Makris, K. C. (2014). Obesity-mediated association between exposure to brominated trihalomethanes and type II diabetes mellitus: An exploratory analysis. Science of the Total Environment, 485, 340-347.

Andrikopoulos, S., Blair, A. R., Deluca, N., Fam, B. C., \& Proietto, J. (2008). Evaluating the glucose tolerance test in mice. American Journal of Physiology - Endocrinology and Metabolism, 295(6), E1323-1332.

Anhe, F. F., Roy, D., Pilon, G., Dudonne, S., Matamoros, S., Varin, T. V., et al. (2015). A polyphenol-rich cranberry extract protects from diet-induced obesity, insulin resistance and intestinal inflammation in association with increased Akkermansia spp. population in the gut microbiota of mice. Gut, 64(6), 872-883.

Arabbi, P. R., Genovese, M. I., \& Lajolo, F. M. (2004). Flavonoids in vegetable foods commonly consumed in brazil and estimated ingestion by the Brazilian population. Journal of Agricultural and Food Chemistry, 52(5), 1124-1131.

Benzie, I. F. F., \& Strain, J. J. (1996). The ferric reducing ability of plasma (FRAP) as a measure of "antioxidant power": The FRAP assay. Analytical Biochemistry, 239(1), 70-76.

Biden, T. J., Boslem, E., Chu, K. Y., \& Sue, N. (2014). Lipotoxic endoplasmic reticulum stress, $\beta$ cell failure, and type 2 diabetes mellitus. Trends in Endocrinology \& Metabolism, 25(8), 389-398.

Brand-Williams, W., Cuvelier, M. E., \& Berset, C. (1995). Use of a free radical method to evaluate antioxidant activity. LWT - Food Science and Technology, 28(1), 25-30

Cardoso, L. D., Martino, H. S. D., Moreira, A. V. B., Ribeiro, S. M. R., \& Pinheiro-Sant'Ana, H. M. (2011). Cagaita (Eugenia dysenterica DC.) of the Cerrado of Minas Gerais, Brazil: Physical and chemical characterization, carotenoids and vitamins. Food Research International, 44(7), 2151-2154.

Carriere, F., Renou, C., Ransac, S., Lopez, V., De Caro, J., Ferrato, F., et al. (2001). Inhibition of gastrointestinal lipolysis by Orlistat during digestion of test meals in healthy volunteers. American Journal of Physiology-Gastrointestinal and Liver Physiology, 281(1), G16-G28. 
Carroll, N. V., Longley, R. W., \& Roe, J. H. (1956). The determination of glycogen in liver and muscle by use of anthrone reagent. Journal of Biological Chemistry, 220(2), 583-593.

Cerqueira, F. M., da Cunha, F. M., Caldeira da Silva, C. C., Chausse, B., Romano, R. L., Garcia, C. C. M., et al. (2011). Long-term intermittent feeding, but not caloric restriction, leads to redox imbalance, insulin receptor nitration, and glucose intolerance. Free Radical Biology and Medicine, 51(7), 1454-1460.

Cheng, D. M., Kuhn, P., Poulev, A., Rojo, L. E., Lila, M. A., \& Raskin, I. (2012). In vivo and in vitro antidiabetic effects of aqueous cinnamon extract and cinnamon polyphenolenhanced food matrix. Food Chemistry, 135(4), 2994-3002.

Clovegarden. (2015). Myrtles - Order myrtales: Varieties - Europe \& the Americas. URL http://www.clovegarden.com/ingred/myrtle.html (Accessed 25.05.15).

Dávalos, A., Gómez-Cordovés, C., \& Bartolomé, B. (2004). Extending applicability of the oxygen radical absorbance capacity (ORAC-fluorescein) assay. Journal of Agricultural and Food Chemistry, 52(1), 48-54.

Del Rio, D., Borges, G., \& Crozier, A. (2010). Berry flavonoids and phenolics: Bioavailability and evidence of protective effects. British Journal of Nutrition, 104, S67S90.

Di Donna, L., Iacopetta, D., Cappello, A.R., Gallucci, G., Martello, E., Fiorillo,M., et al. (2014). Hypocholesterolaemic activity of 3-hydroxy-3-methyl-glutaryl flavanones enriched fraction from bergamot fruit (Citrus bergamia): "In vivo" studies. Journal of Functional Foods, 7, 558-568.

Donado-Pestana, C. M., Belchior, T., Festuccia, W. T., \& Genovese, M. I. (2015). Phenolic compounds from cambuci (Campomanesia phaea O. Berg) fruit attenuate glucose intolerance and adipose tissue inflammation induced by a high-fat, high-sucrose diet. Food Research International, 69(0), 170-178.

Duluc, L., Soleti, R., Clere, N., Andriantsitohaina, R., \& Simard, G. (2012). Mitochondria as potential targets of flavonoids: Focus on adipocytes and endothelial cells. Current Medicinal Chemistry, 19(26), 4462-4474.

Ejaz, A., Wu, D. Y., Kwan, P., \& Meydani, M. (2009). Curcumin Inhibits Adipogenesis in 3T3-L1 Adipocytes and Angiogenesis and Obesity in C57/BL Mice. Journal of Nutrition, 139(5), 919-925.

FAO, Food and Agriculture Organization of the United Nations. (2013). FAOSTAT database. URL http://faostat.fao.org/site/291/default.aspx (Accessed 05.04.13). 
Folch, J., Lees, M., \& Stanley, G. H. S. (1957). A simple method for the isolation and purification of total lipides from animal tissues. Journal of Biological Chemistry, 226(1), 497-509.

Ginsberg, H. N., Zhang, Y. L., \& Hernandez-Ono, A. (2005). Regulation of plasma triglycerides in insulin resistance and diabetes. Archives of Medical Research, 36(3), 232240.

Gonçalves, A., Lajolo, F. M., \& Genovese, M. I. (2010). Chemical composition and antioxidant/antidiabetic potential of Brazilian native fruits and commercial frozen pulps. Journal of Agricultural and Food Chemistry, 58(8), 4666-4674.

Hanhineva, K., Torronen, R., Bondia-Pons, I., Pekkinen, J., Kolehmainen, M., Mykkanan, H., et al. (2010). Impact of Dietary Polyphenols on Carbohydrate Metabolism. International Journal of Molecular Sciences, 11(4), 1365-1402.

Heber, D., Zhang, Y. J., Yang, J. P., Ma, J. E., Henning, S. M., \& Li, Z. P. (2014). Green tea, black tea, and oolong tea polyphenols reduce visceral fat and inflammation in mice fed high-fat, high-sucrose obesogenic diets. Journal of Nutrition, 144(9), 1385-1393.

Henning, S. M., Wang, P. W., Said, J., Magyar, C., Castor, B., Doan, N., et al. (2012). Polyphenols in brewed green tea inhibit prostate tumor xenograft growth by localizing to the tumor and decreasing oxidative stress and angiogenesis. Journal of Nutritional Biochemistry, 23(11), 1537-1542.

Jung, U. J., Park, Y. B., Kim, S. R., \& Choi, M. S. (2012). Supplementation of persimmon leaf ameliorates hyperglycemia, dyslipidemia and hepatic fat accumulation in type 2 diabetic mice. Plos One, 7(11), e49030.

Kim, S., Sohn, I., Ahn, J. I., Lee, K. H., \& Lee, Y. S. (2004). Hepatic gene expression profiles in a long-term high-fat diet-induced obesity mouse model. Gene, 340(1), 99-109.

Lemieux, C., Picard, F., Labrie, F., Richard, D., \& Deshaies, Y. (2003). The estrogen antagonist EM-652 and dehydroepiandrosterone prevent diet- and ovariectomy-induced obesity. Obesity Research, 11(3), 477-490.

Lima, T. B., Silva, O. N., Silva, L. P., Rocha, T. L., Grossi-de-Sa, M. F., Franco, O. L., et al. (2011). In vivo effects of cagaita (Eugenia dysenterica, DC.) leaf extracts on diarrhea treatment. Evidence-Based Complementary and Alternative Medicine, ID309390, 1-10.

Manzano, S., \& Williamson, G. (2010). Polyphenols and phenolic acids from strawberry and apple decrease glucose uptake and transport by human intestinal Caco-2 cells. Molecular Nutrition \& Food Research, 54(12), 1773-1780. 
Meydani, M., \& Hasan, S. T. (2010). Dietary polyphenols and obesity. Nutrients, 2(7), 737751.

Ministério do Meio Ambiente, Brazil. (2015). O Bioma Cerrado. URL http://www.mma.gov.br/biomas/cerrado (Accessed 10.01.15).

Mushref, M. A., \& Srinivasan, S. (2013). Effect of high fat-diet and obesity on gastrointestinal motility. Annals of Translational Medicine, 1(2), 14.

Nakai, M., Fukui, Y., Asami, S., Toyoda-Ono, Y., Iwashita, T., Shibata, H., et al. (2005). Inhibitory effects of oolong tea polyphenols on pancreatic lipase in vitro. Journal of Agricultural and Food Chemistry, 53(11), 4593-4598.

Ng, M., Fleming, T., Robinson, M., et al. (2014). Global, regional, and national prevalence of overweight and obesity in children and adults during 1980-2013: a systematic analysis for the Global Burden of Disease Study 2013. Lancet (14), 60460-604688, pii: S0140-6736.

Nigam, A., Bourassa, M. G., Fortier, A., Guertin, M. C., \& Tardif, J. C. (2007). Fasting but not postprandial (postmeal) glycemia predicts the risk of death in subjects with coronary artery disease. Canadian Journal of Cardiology, 23(11), 873-878.

Pinto, M. S., Lajolo, F. M., \& Genovese, M. I. (2008). Bioactive compounds and quantification of total ellagic acid in strawberries (Fragaria $x$ ananassa Duch.). Food Chemistry, 107, 1629-1635.

Porter, L. J., Hrstich, L. N., \& Chan, B. G. (1985). The conversion of procyanidins and prodelphinidins to cyanidin and delphinidin. Phytochemistry, 25(1), 223-230.

Scalbert, A., Manach, C., Morand, C., Remesy, C., \& Jimenez, L. (2005). Dietary polyphenols and the prevention of diseases. Critical Reviews in Food Science and Nutrition, 45(4), 287-306.

Scalbert, A., \& Williamson, G. (2000). Dietary intake and bioavailability of polyphenols. The Journal of Nutrition, 130(8S Suppl), 2073s-2085s.

Singleton, V. L., Orthofer, R., \& Lamuela-Raventos, R. M. (1999). Analysis of total phenols and other oxidation substrates and antioxidants by means of Folin-Ciocalteu reagent. Oxidants and Antioxidants, 299, 152-178, (Pt A).

Slatnar, A., Jakopic, J., Stampar, F., Veberic, R., \& Jamnik, P. (2012). The effect of bioactive compounds on in vitro and in vivo antioxidant activity of different berry juices. Plos One, 7(10), e47880.

Sugiyama, H., Akazome, Y., Shoji, T., Yamaguchi, A., Yasue, M., Kanda, T., et al. (2007). Oligomeric procyanidins in apple polyphenol are main active components for inhibition of 
pancreatic lipase and triglyceride absorption. Journal of Agricultural and Food Chemistry, 55(11), 4604-4609.

Sumiyoshi, M., Sakanaka, M., \& Kimura, Y. (2006). Chronic intake of high-fat and highsucrose diets differentially affects glucose intolerance in mice. Journal of Nutrition, 136(3), 582-587.

U.S. Food and Drug Administration (FDA). (2005). Guidance for industry: Estimating the maximum safe starting dose in initial clinical trials for therapeutics in adult healthy volunteers. Washington, DC: U.S. FDA.

Wang, S., Moustaid-Moussa, N., Chen, L. X., Mo, H. B., Shastri, A., Su, R., et al. (2014). Novel insights of dietary polyphenols and obesity. Journal of Nutritional Biochemistry, 25(1), 1-18.

WHO/FAO, World Health Organization and Food and Agriculture Organization of the United Nations. (2004). Fruit and vegetables for health: Report of a joint FAO/WHO Workshop. Kobe: FAO/WHO.

Zhang, W. L., Zhu, L., \& Jiang, J. G. (2014). Active ingredients from natural botanicals in the treatment of obesity. Obesity Reviews, 15(12), 957-967. 


\section{Figure captions}

Fig. 1. Body weight (a), weight gain (b), retroperitoneal (c), epididymal (d), inguinal (e), and brown (f) adipose depot mass, and liver (g), heart (h), and gastrocnemius muscle (i) weights of mice fed on high-fat high-sucrose or chow diets and receiving water (Chow and HF/HS groups) or phenolic-rich extracts from cagaita at two doses (CGT7 and CGT14) by gavage for 8 weeks. Data are means \pm SEM from each treatment $(n=9-10)$. \# $(p<0.05) \mathrm{HF} / \mathrm{HS}$ vs. CGT14, \#\# ( $p<0.05)$ HF/HS vs. CGT7 and CGT14, * $(p<0.05)$ vs. HF/HS.

Fig. 2. Food intake (a), total energy intake (b), food efficiency (c), total fecal lipids (d), fecal triglycerides (e), and fecal cholesterol (f) of mice fed on high-fat high-sucrose or chow diets and receiving water (Chow and HF/HS groups) or phenolic-rich extracts from cagaita at two doses (CGT7 and CGT14) by gavage for 8 weeks. Data for food and total energy intake are average food consumption per day for the entire 8-wk experiment $(n=28)$. Food efficiency was calculated as $\mathrm{g}$ of body weight gain per $\mathrm{g}$ food eaten throughout that time period $(n=9$ 10). Data for fecal lipids are means \pm SEM from pooled samples collected on the last three days of experimental period $(n=4-5) . *(p<0.05)$ vs. HF/HS; \# $(p<0.05)$ vs. other groups.

Fig. 3. Weekly variation of fasting blood glucose (6 h) (a), blood glucose and the glucose area-under-the-curve (AUC; inset) (b) during glucose tolerance test, and liver glycogen content (d) of mice fed on high-fat high-sucrose or chow diets and receiving water (Chow and HF/HS groups) or phenolic-rich extracts from cagaita at two doses (CGT7 and CGT14) by gavage for 8 weeks. Data are means \pm SEM from each treatment $(n=9-10) . \$(p<0.05)$ HF/HS vs. CGT14 and Chow; $\uparrow(p>0.05)$ Chow = CGT14; $*(p<0.05)$ vs. other groups.

Fig. 4. Plasma and liver biochemical profile of mice fed on high-fat high-sucrose or chow diets and receiving water (Chow and HF/HS groups) or phenolic-rich extracts from cagaita at two doses (CGT7 and CGT14) by gavage for 8 weeks. Data are means \pm SEM from each treatment $(n=9-10) . *(p<0.05)$ vs. HF/HS; \# $(p<0.05)$ vs. other groups. 
Table 1. Characterization of phenolic-rich extracts from cagaita, CGT7 and CGT14, administered to C57BL/6J mice by oral gavage for 8 weeks.

\begin{tabular}{|c|c|c|}
\hline & $\begin{array}{l}\text { Phenolic-rich } \\
\text { Extract CGT7 }\end{array}$ & $\begin{array}{l}\text { Phenolic-rich } \\
\text { Extract CGT14 }\end{array}$ \\
\hline Total phenolics (mg GAE/mL) & $0.88 \pm 0.06$ & $1.77 \pm 0.05$ \\
\hline Proanthocyanidins (mg QT/mL) & $0.26 \pm 0.01$ & $0.48 \pm 0.04$ \\
\hline \multicolumn{3}{|c|}{ Flavonoids and phenolic acids ( $\mu \mathrm{g} / \mathrm{mL})$} \\
\hline Quercetin derivatives & $7.37 \pm 0.28$ & $14.82 \pm 0.55$ \\
\hline Kaempferol derivatives & $2.92 \pm 0.26$ & $5.87 \pm 0.52$ \\
\hline Free ellagic acid & $4.92 \pm 0.46$ & $9.89 \pm 0.93$ \\
\hline Total ellagic acid & $354.39 \pm 28,89$ & $823.08 \pm 29.88$ \\
\hline ORAC ( $\mu$ mol Trolox/mL) & $8.41 \pm 0.51$ & $28.28 \pm 3.10$ \\
\hline DPPH ( $\mu$ mol Trolox/mL) & $8.13 \pm 0.81$ & $21.01 \pm 0.41$ \\
\hline FRAP $(\mu \mathrm{mol}$ Trolox/mL $)$ & $8.27 \pm 0.26$ & $14.88 \pm 0.40$ \\
\hline $\begin{array}{l}\text { Pancreatic lipase } \\
\text { inhibition }\left(\mathrm{IC}_{50}-\mu \mathrm{g} \mathrm{GAE} / \mathrm{mL}\right. \\
\text { reaction })^{1}\end{array}$ & $25.26 \pm 1.82$ & $25.26 \pm 1.82$ \\
\hline
\end{tabular}

Results are expressed as mean \pm SD values $(n=3)$; GAE, gallic acid equivalent; QTE, quebracho tannin equivalent.

${ }^{1}$ Orlistat control $\mathrm{IC}_{50} 28.3 \mu \mathrm{g} / \mathrm{mL}$ reaction. 

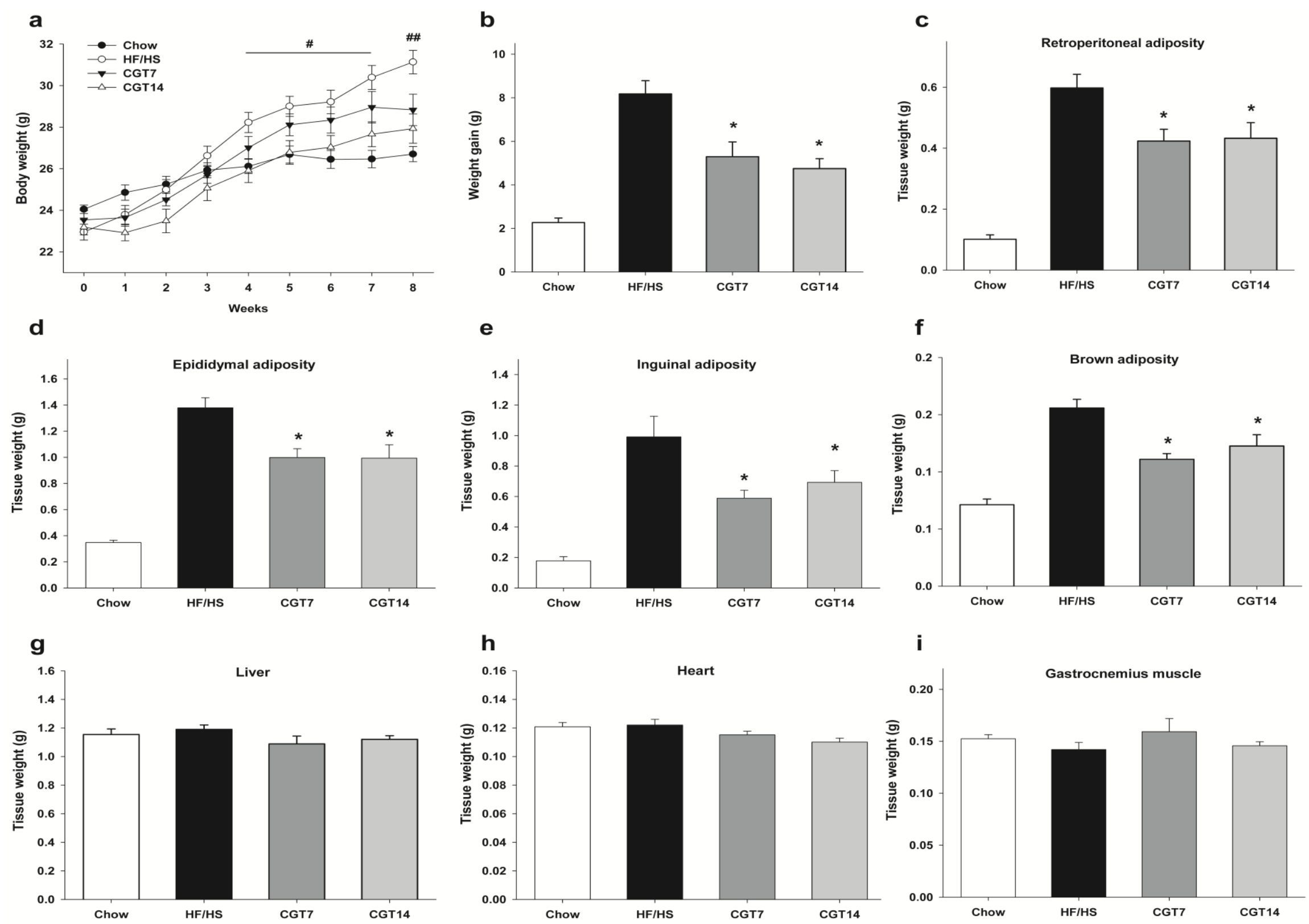

Figure 1 
a

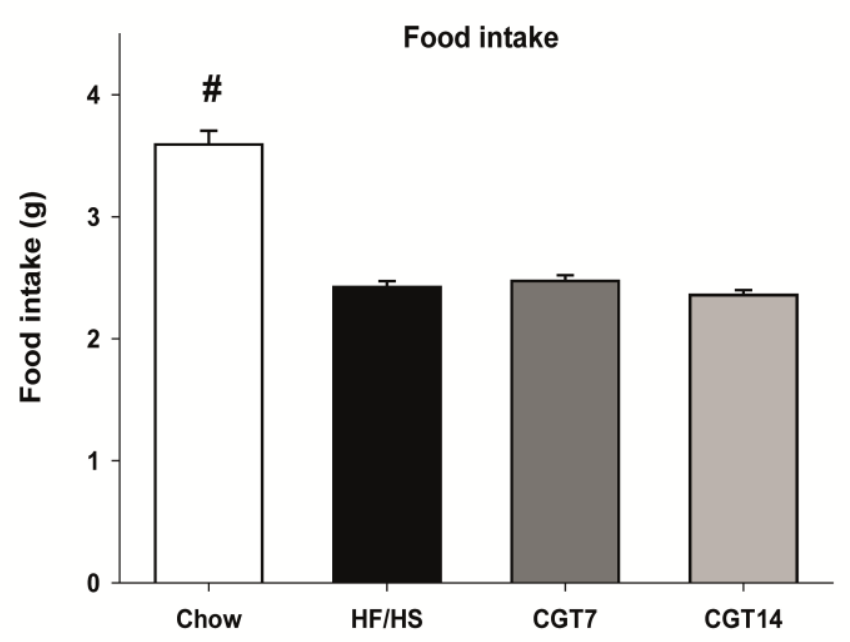

d

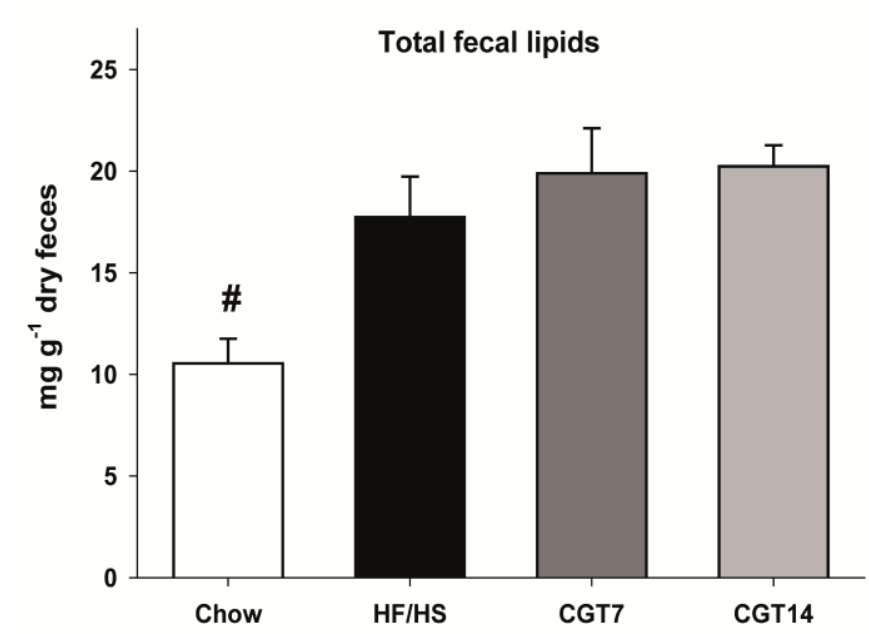

b

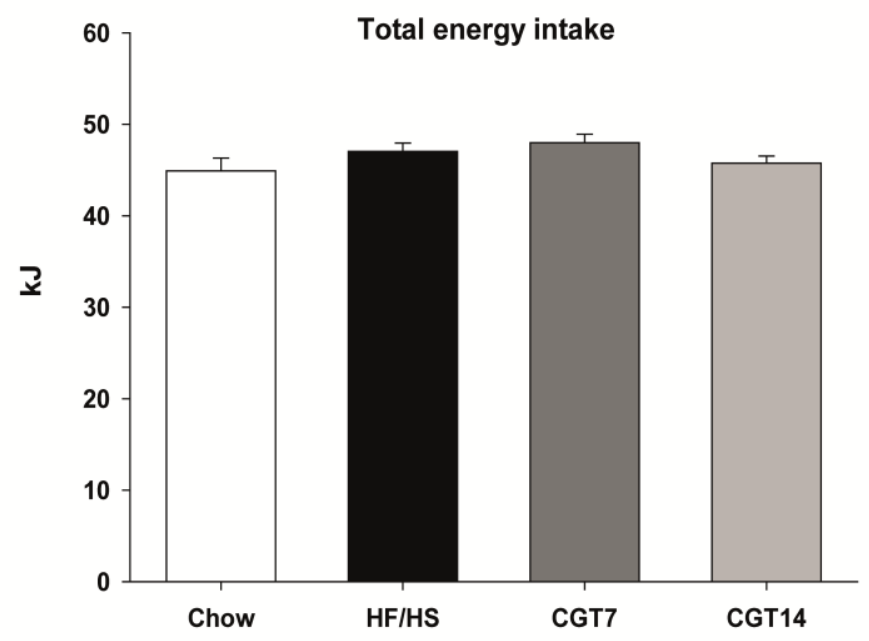

e

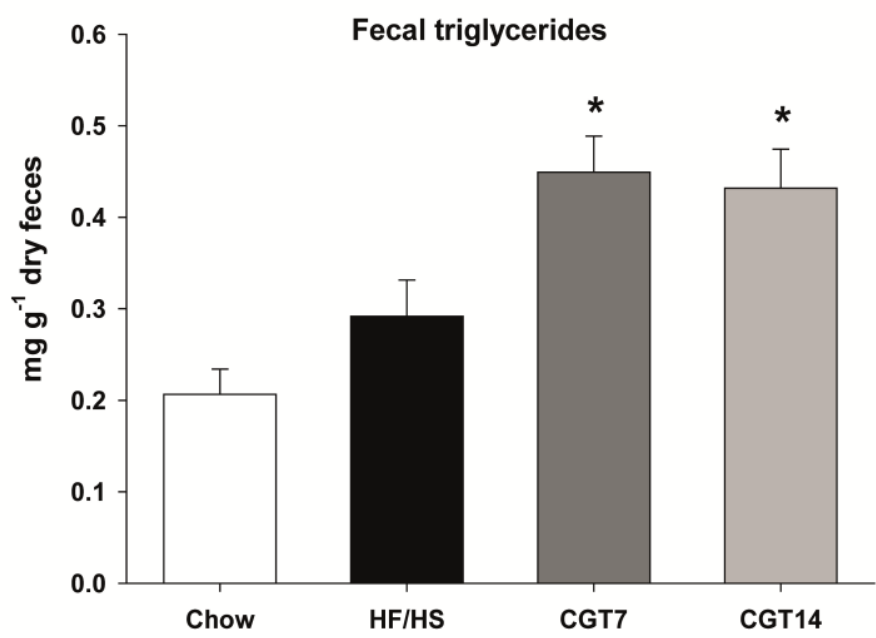

c
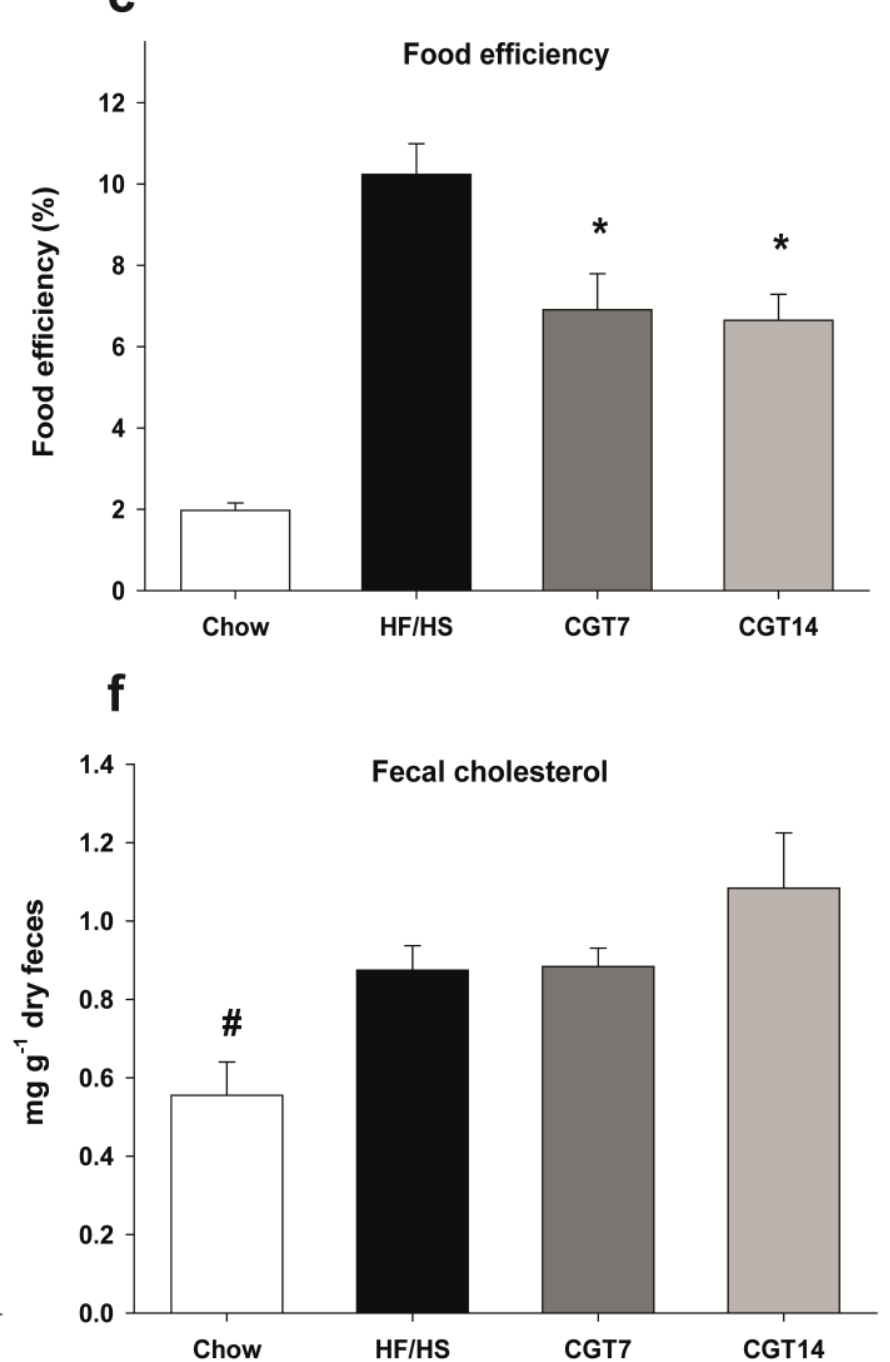

Figure 2 

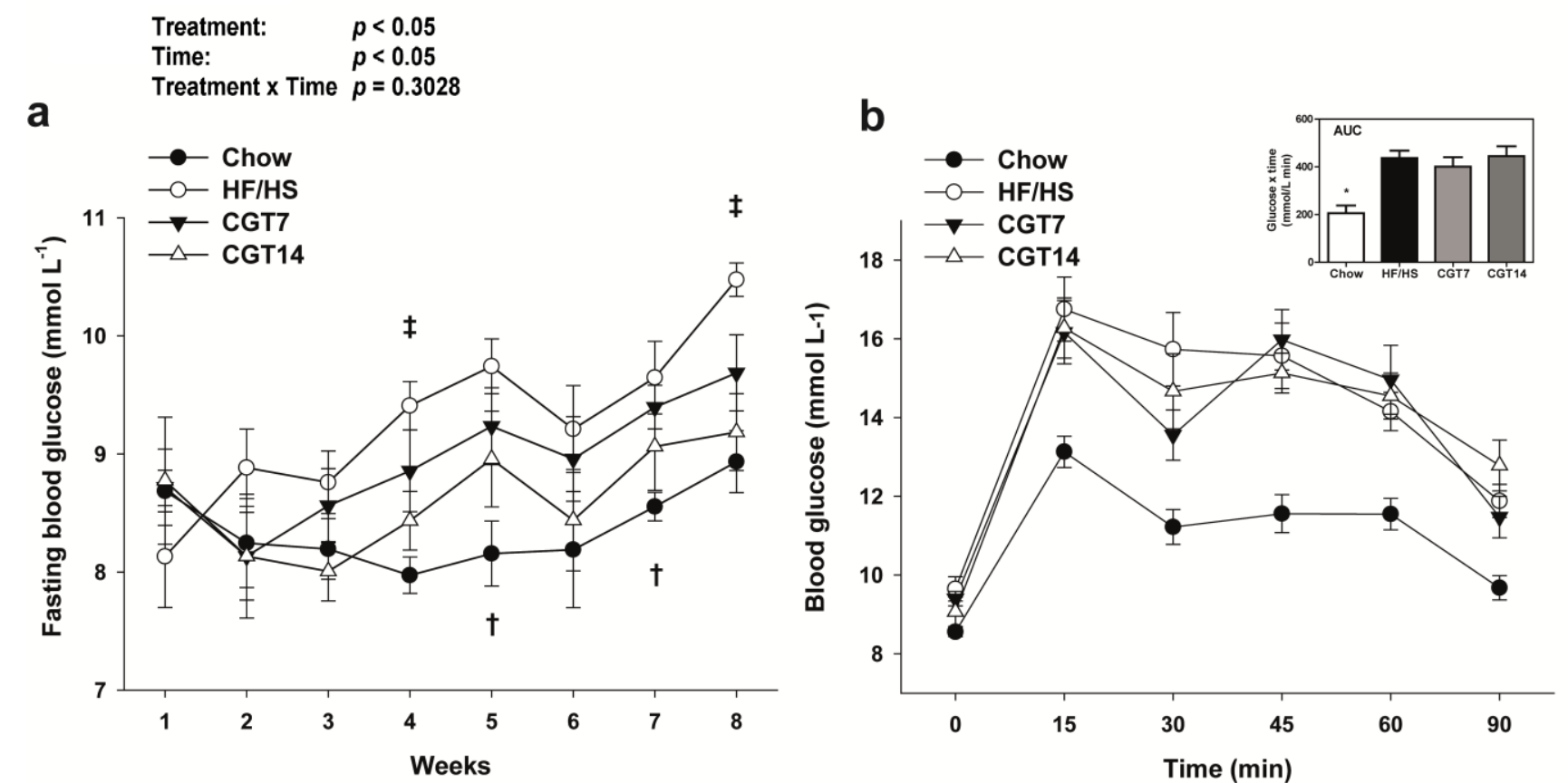

C

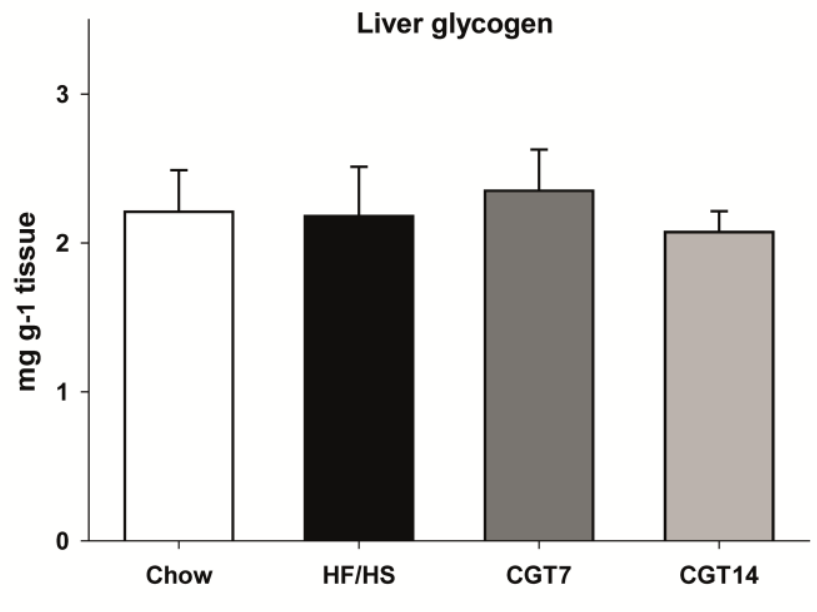

Figure 3 

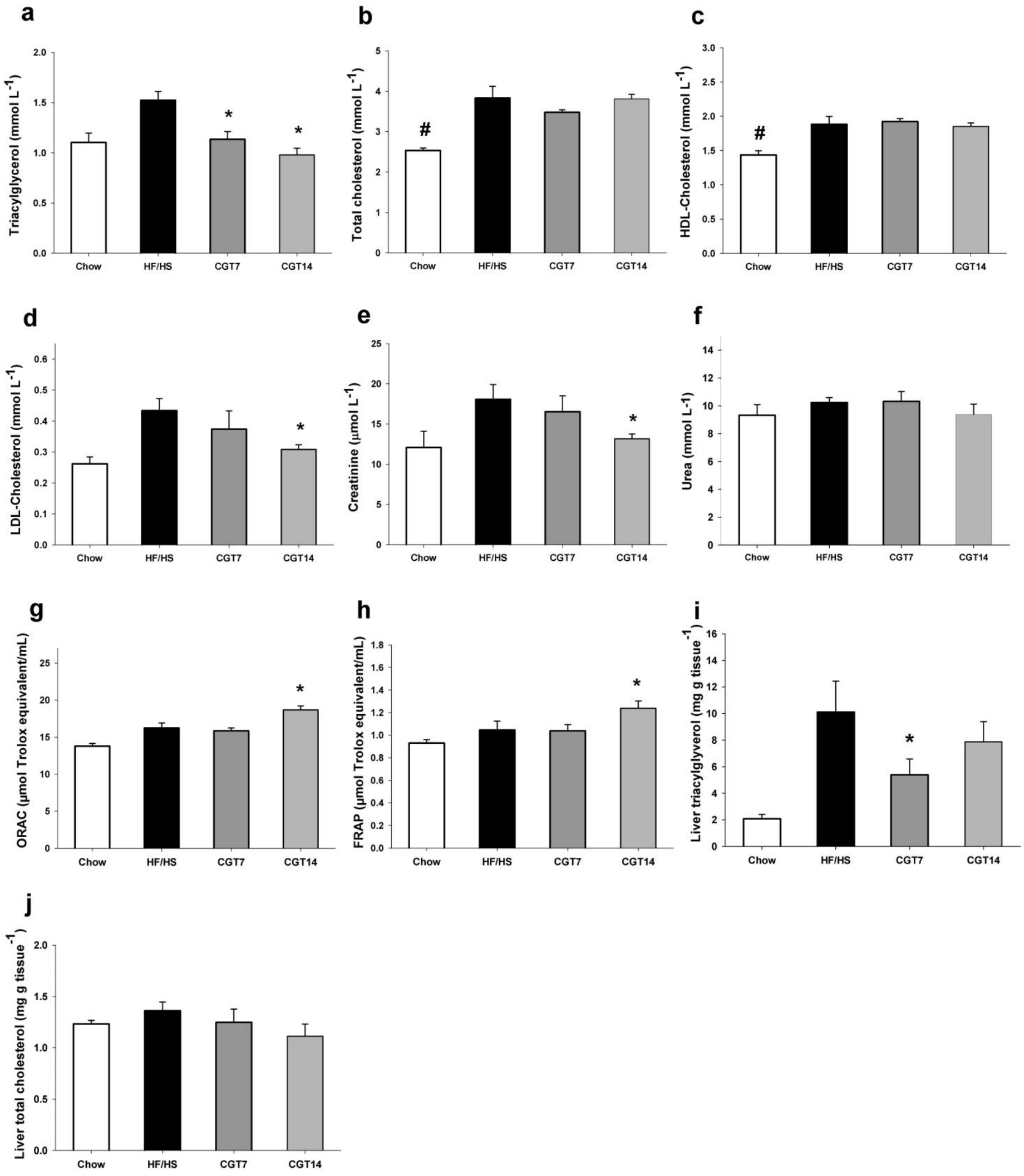

Figure 4 
4.2 Phenolic compounds from cambuci (Campomanesia phaea Berg.) fruit attenuate glucose intolerance and adipose tissue inflammation induced by high-fat, high-sucrose $\operatorname{diet}^{2}$

Carlos M. Donado-Pestana ${ }^{\mathrm{a}}$, Thiago Belchior ${ }^{\mathrm{b}}$, William T. Festuccia ${ }^{\mathrm{b}}$, Maria Inés Genovese ${ }^{\mathrm{a}, *}$

a Departamento de Alimentos e Nutrição Experimental, Faculdade de Ciências Farmacêuticas - Universidade de São Paulo. Av. Prof. Lineu Prestes, 580, Bloco 14, São Paulo, SP, Brasil. CEP 05508-900.

${ }^{\mathrm{b}}$ Departamento de Fisiologia e Biofísica, Instituto de Ciências Biomédicas - Universidade de São Paulo. Av. Prof. Lineu Prestes, 1524, São Paulo, SP, Brasil. CEP 05508-000.

*Corresponding author: Maria Inés Genovese, Departamento de Alimentos e Nutrição Experimental, Faculdade de Ciências Farmacêuticas - Universidade de São Paulo. Av. Prof. Lineu Prestes, 580, Bloco 14, São Paulo, SP, Brasil. CEP 05508-900. Fone: +55 113091 3656; fax: +55 113815 4410; e-mail address: genovese @usp.br

\footnotetext{
${ }^{2}$ Manuscript published in Food Research International, v. 69 (2015), pp. 170-178
} 


\begin{abstract}
Elevated intake of certain dietary components, such as phenolic compounds of fruits and vegetables, reduces the risk of developing obesity and other metabolic diseases characterized by a chronic, low-grade inflammation. Cambuci (Campomanesia phaea Berg.) is a Brazilian Atlantic Coastal Forest fruit rich in phenolic compounds including ellagitannins and proanthocyanidins that were previously shown to display anti-inflammatory actions. Herein we investigated whether the administration of phenolic-rich extract from cambuci (CBC) at two different doses protects mice from diet induced obesity, insulin resistance, and chronic peripheral inflammation. In order to verify this, C57BL/6J mice fed either with a chow or a high-fat, high-sucrose (HFHS) diet were daily treated by gavage with water or CBC (18 and $32 \mathrm{mg}$ gallic acid equivalent, GAE/kg body weight) for 8 weeks and evaluated for body mass, adiposity, glucose tolerance, and adipose tissue inflammation. Despite the absence of changes in body weight gain and adiposity, administration of CBC at two different doses protected mice from the disarrangements in glucose homeostasis induced by HFHS feeding as evidenced by the reduced fasting glycemia and insulinemia and improved glucose tolerance featured by $\mathrm{CBC}$ treated mice. Along with glucose homeostasis, $\mathrm{CBC}$ administration also protected mice from adipose tissue inflammation induced by HFHS feeding as evidenced by the lower expression of proinflammatory cytokines tumor necrosis factor-alpha $(T N F-\alpha)$ and interleukin-6 (IL-6) and macrophage markers CDIIb, F4/80, and CD86 in retroperitoneal adipose tissue. Furthermore, the higher dose of CBC increased plasma HDL-cholesterol while reducing LDL-cholesterol levels. Altogether, our findings indicate that phenolic compounds from cambuci have potentially beneficial actions protecting mice from HFHS diet-induced glucose intolerance and adipose tissue inflammation.
\end{abstract}

Keywords: polyphenols; Myrtaceae; hyperglycemia; macrophages; cytokines

\title{
1. Introduction
}

Obesity, defined as an abnormal or excessive accumulation of body fat, is a serious health issue threatening modern society. Obesity, the prevalence of which has markedly increased in the last decades, is associated with the development of serious chronic diseases such as cancer, diabetes and cardiomyopathies, among others, being a leading risk factor for deaths 
globally and an economic burden to society. Recent estimative indicates that overweight and obesity (body-mass index of $25 \mathrm{~kg} / \mathrm{m}^{2}$ or greater) affects approximately $37 \%$ of the world population, or 2.1 billion individuals worldwide ( $\mathrm{Ng}$ et al., 2014). This prevalence has also increased substantially in children and adolescents in developed and developing countries. In addition, overweight and obesity were estimated to cause 3.4 million deaths, in most cases, associated with cardiovascular diseases (Lim et al., 2012).

Several predisposing factors have been associated to obesity such as gender, ethnicity, socioeconomic condition, education level, and diet and regular physical activity with interactions among these factors (Paeratakul, Lovejoy, Ryan, \& Bray, 2002). Of special interest to this study are the findings that intake of diets rich in fruits and vegetables decrease the prevalence of obesity and associated diseases namely type 2 diabetes, cardiovascular diseases and cancer (Carter, Gray, Troughton, Khunti, \& Davies, 2010). Although the plausible mechanisms by which fruits and vegetables exert those protective actions are unknown, they may be related to natural antioxidant and anti-inflammatory properties featured by chemical components of these crops (Carter et al., 2010; Cherniack, 2011). These components include a wide range of molecules of different structural patterns, such as phenolic compounds, carotenoids, vitamins and minerals (Wang, Melnyk, Tsao, \& Marcone, 2011).

Brazil is the world's third largest fruit producer and seventh producer of tropical fresh fruit (FAO, 2013), among which are included a large number of native and exotic fruit species of potential interest to the food industry that remain underexplored. Among these are the Myrtaceae, a large family which is comprised of about 4000 species, including some Brazilian native fruits, such as jaboticaba (Myrciaria cauliflora Berg), camu-camu (Myrciaria dubia McVaugh), and cambuci (Campomanesia phaea Berg).

Cambuci grows in Brazil's Atlantic Coastal Forest, which is the world's richest forest in terms of biodiversity. Cambuci is unique in the genus, featuring an ovoid-rhomboidal structure with a horizontal ridge along with a strong sweet scent, but tasting extremely sour like lemons. These fruits are used in various typical preparations, mainly jams, jellies, icecream, and liqueurs (Kawasaki \& Landrum, 1997). Despite its consumption, limited information is available on the composition and functionality of bioactive compounds of cambuci and their potential health benefits. In a previous study evaluating ethanolic extracts of seven fruits from the Brazilian Atlantic Coastal Forest, cambuci featured the highest concentration of phenolic compounds (Haminiuk et al., 2011), such findings that were also 
observed when comparing commercial frozen pulps (Genovese, Pinto, Gonçalves, \& Lajolo, 2008).

Phenolic compounds from cambuci were also found to be potent inhibitors of carbohydrate-hydrolyzing enzymes ( $\alpha$-amylase and $\alpha$-glucosidase) in in vitro enzymatic assays (Gonçalves, Lajolo, \& Genovese, 2010). The suppression of glucose absorption through the inhibition of these enzymes may be one therapeutic approach to prevent the postprandial hyperglycemia. Thus, in the present study, we investigated whether the administration of phenolic-rich extract from cambuci (CBC) at two different doses protects mice from diet-induced obesity, hyperglycemia, insulin resistance and chronic peripheral inflammation. For this, C57BL/6J mice fed either with a chow or a high-fat, high-sucrose (HFHS) diet were daily treated by gavage with water or CBC (18 and $32 \mathrm{mg}$ gallic acid equivalent, GAE/kg body weight) for 8 weeks and evaluated for body mass, adiposity, glucose tolerance, and adipose tissue inflammation.

\section{Materials and methods}

\subsection{Preparation and characterization of phenolic-rich extract from cambuci}

The commercial frozen pulp of cambuci was obtained from Sítio do Bello (Paraibuna São Paulo, Brazil). Frozen samples were thawed at room temperature before extraction was performed. A representative sample equivalent to $5.0 \mathrm{~g}$ of dry matter was homogenized and extracted in $100 \mathrm{~mL}$ of $80 \%$ aqueous methanol using a Turratec TE-102 (Tecnal) at $4000 \mathrm{rpm}$ for $1 \mathrm{~min}$, three times with intervals of $30 \mathrm{~s}$, in an ice-bath, followed by rotation using a magnetic stirrer $(200 \mathrm{rpm})$ at $5{ }^{\circ} \mathrm{C}$ for $30 \mathrm{~min}$. The extract was separated by centrifuging for $30 \mathrm{~min}$ at $5000 \mathrm{~g}$ and filtered through a Whatman No. 3 filter paper. The precipitated was resuspended twice in the aqueous alcoholic solution for additional extraction steps and then centrifuged and filtered as described above. The pooled filtrates were concentrated at $39{ }^{\circ} \mathrm{C}$ to remove methanol on a rotary evaporator (Rotavapor R-210; Büchi, Sweden). The extract was made up to $40 \mathrm{~mL}$ with distilled water.

The aqueous extract was added onto a preconditioned $(100 \mathrm{~mL}$ of methanol, $150 \mathrm{~mL}$ of water) LC-18 SPE tube (10 g of LC-18 SPE, Supelclean ${ }^{\mathrm{TM}}$ LC-18, Supelco). After washing with water, the phenolic compounds were eluted with $200 \mathrm{~mL}$ of methanol. The eluate was 
evaporated to dryness and the residue ressuspended in $70 \mathrm{~mL}$ of water, for $\mathrm{CBC} 18$ extract, or $35 \mathrm{~mL}$ of water, for CBC32 extract.

The extract was characterized in relation to total phenolics (Singleton, Orthofer, \& Lamuela-Raventos, 1999), and proanthocyanidin contents (Porter, Hrstich, \& Chan, 1985), antioxidant capacity by the oxygen radical absorbance capacity (ORAC) assay (Dávalos, Gómez-Cordovés, \& Bartolomé, 2004), the 2,2- diphenyl-1-picrylhydrazyl (DPPH) radicalscavenging assay (Brand-Williams, Cuvelier, \& Berset, 1995), and the ferric reducing antioxidant power (FRAP) assay (Benzie \& Strain, 1996), and pancreatic lipase inhibitory activity (Nakai et al., 2005).

The identification and quantification of the main flavonoids and phenolic acids in cambuci was performed as described previously (Arabbi, Genovese, \& Lajolo, 2004), adding the aqueous extract onto a preconditioned $(20 \mathrm{~mL}$ of methanol, $60 \mathrm{~mL}$ of water) polyamide SC6 SPE tube (1 g, Macherey-Nagel GmbH and Co., Düren, Germany). After washing with water, phenolic compounds were eluted with $50 \mathrm{~mL}$ of methanol to elute neutral phenolics, and with $50 \mathrm{~mL}$ of methanol:ammonia (99.5:0.5) to elute acidic phenolics. These two fractions were evaporated to dryness under reduced pressure at $39{ }^{\circ} \mathrm{C}$, redissolved in HPLC grade methanol $(1 \mathrm{~mL})$ and filtered through $0.22 \mu \mathrm{m}$ PTFE (polytetrafluoroethylene) filters (Millipore Ltd, Bedford, MA). The identification and quantification was performed using a Prodigy ODS3 reversed phase silica column $(5 \mu \mathrm{m}, 250 \times 4.6 \mathrm{~mm}$, Phenomenex Ltd, Torrance, CA), in an analytical reversed-phase HPLC (Hewlett-Packard 1100) system with autosampler and quaternary pump coupled to a diode array detector. Total ellagic acid was determined after acid hydrolysis according to Pinto, Lajolo and Genovese (2008). An aliquot of $2 \mathrm{~mL}$ of extract was dried under nitrogen, $2 \mathrm{~mL}$ of $2 \mathrm{~N}$ trifluoroacetic acid were added, and the hydrolysis was performed at $120^{\circ} \mathrm{C}$ for $90 \mathrm{~min}$. The hydrolyzed samples were evaporated to dryness under nitrogen, redissolved in methanol and filtered for HPLC analysis.

\subsection{Animals and experimental design}

All animal procedures performed were previously approved by the Ethical Committee for Animals Research of the Faculty of Pharmaceutical Science of University of São Paulo (No. CEUA/FCF/378). 
Forty 8-week old male C57BL/6J mice, weighting approximately $24 \mathrm{~g}$, were used in this study. The mice were matched by weight and kept at $22 \pm 1{ }^{\circ} \mathrm{C}$ and under a 12-hour light/12hour dark cycle. All mice were fed a chow low-fat diet (NUVILAB CR-1 ${ }^{\circledR}$ Sogorb Inc., São Paulo - SP, Brazil) ad libitum for one week before beginning the experiment.

The animals were randomly divided into four groups of ten mice each, as follows: 1) Chow group received the chow low-fat diet and water by gavage; 2) HFHS group received the high-fat, high-sucrose diet and water by gavage; 3) CBC18 group received the high-fat, highsucrose diet and the phenolic-rich extract from cambuci by gavage (18 mg GAE/kg body weight); and 4) CBC32 group received the high-fat, high-sucrose diet and the phenolic-rich extract from cambuci by gavage (32 $\mathrm{mg} \mathrm{GAE} / \mathrm{kg}$ body weight). The water and extracts were administered every day for 8 weeks.

According to the manufacturer, the chow diet provided $12.5 \mathrm{~kJ} / \mathrm{g}$ as energy, of which $63 \%$ was from carbohydrate, $25 \%$ from protein, and $12 \%$ from fat. The HFHS diet provided $19.4 \mathrm{~kJ} / \mathrm{g}, 41 \%$ of calories from sucrose, $20 \%$ from protein, and $39 \%$ from fat, as previously described (Lemieux, Picard, Labrie, Richard, \& Deshaies, 2003). Diets and water were available ad libitum during the experimental period of 8 weeks. Body weight and food intake were recorded every two days, and fasting blood glucose $(6 \mathrm{~h})$ measured from the caudal vein weekly throughout the study by using Accu-Chek Performa ${ }^{\circledR}$ (Roche, Mannheim, Germany).

After 8 weeks, mice were anesthetized with isoflurane, immediately euthanized by decapitation and their trunk blood was collected and the plasma separated by centrifugation at $3000 \mathrm{~g}$ for $20 \mathrm{~min}$ at $4{ }^{\circ} \mathrm{C}$. The tissues, including heart, liver, gastrocnemius muscle, and adipose tissues (inguinal, retroperitoneal, epididymal and brown) were removed, weighed, and immediately frozen under liquid nitrogen and stored at $-80^{\circ} \mathrm{C}$.

\subsection{Glucose tolerance test (GTT)}

GTT was performed on the mice at week 7 of the experiment. The animals were fasted for $6 \mathrm{~h}$ and injected intraperitoneally with a glucose solution $(1 \mathrm{~g} / \mathrm{kg}$ body weight $)$ and the glucose concentration was determined in tail blood collected at baseline (prior to injection) and at 15, 30, 45, 60 and 90 min post-injection, using Accu-Chek Performa ${ }^{\circledR}$ glucometer (Roche, Mannheim, Germany). Blood samples were collected at 0, 30, and $90 \mathrm{~min}$, and the plasma separated by centrifugation at $3000 \mathrm{~g}$ for $20 \mathrm{~min}$ at $4{ }^{\circ} \mathrm{C}$ for insulin determination (rat/mouse insulin ELISA kit, Millipore). 


\subsection{Plasma biochemical parameters}

A LabMax $240^{\circledR}$ (LABTEST) clinical chemistry analyzer was used to determine plasma concentrations of total cholesterol, HDL-cholesterol, LDL-cholesterol and triacylglycerol. Kits were purchased from LABTEST (Lagoa Santa, MG, Brazil) and the manufacturer's instructions were strictly followed.

\subsection{Gene expression analysis by quantitative PCR}

RNA purification, reverse transcription, and quantification by real-time PCR were performed as previously described (Festuccia et al., 2008). RNA was extracted from the retroperitoneal adipose tissue (five animals per group) using illustra RNAspin Mini RNA Isolation kit (GE Healthcare, Buckinghamshir, UK) according to the manufacturer's instructions. RNA concentration was determined on a NanoDrop spectrophotometer (Thermo Scientific, Wilmington, USA). RNA samples were stored at $-80{ }^{\circ} \mathrm{C}$ until use for synthesis of cDNA and real-time PCR. Primers used for the PCR reactions are listed in Table 1. Results were expressed as the ratio between the expression of the target gene and the housekeeping gene RPL3, the expression of which was not significantly affected by the administration of CBC.

\subsection{Statistical analysis}

The results are presented as mean \pm SEM for groups based on nine to ten mice in each group for body and tissue weight, fasting blood glucose, blood glucose in GTT, plasma lipids. For plasma insulin and quantitative PCR, data were processed based on four to five mice in each group. The data for characterization of the extracts were presented as mean \pm SD for three replicates. The effects of phenolic compounds from cambuci at two doses on studied parameters were analyzed using a one-way (treatment) analysis of variance (ANOVA). Significant effects were analyzed using Tukey's studentized range or post hoc Fisher's least significant difference (LSD) tests (statistical significance was determined at $p<0.05$ ). The statistical analysis was performed using the SAS 9.3 package (SAS Institute, Inc., Cary, NC). 


\section{Results}

Figures 1a and 1b show a representative chromatographic profile $(270 \mathrm{~nm})$ of phenolic compounds extracted from cambuci. Flavonoid glycosides and phenolic acids were the most widespread phenolic compounds detected by HPLC analysis of the CBC extract. Quercetin derivatives and ellagic acid were detected in the methanolic fraction, while in the methanol/ammonia fraction only ellagic acid was detected predominantly. The characterization of the phenolic-rich extracts from cambuci in relation to total phenolics, proanthocyanidins, flavonoids, and phenolic acids contents, and antioxidant capacity is presented in Table 2. As it can be seen, tannins were the main phenolic compounds in cambuci extract. Roughly, proanthocyanidins and ellagitannins (calculated discounting free ellagic acid from the total ellagic acid content) corresponded together to more than $80-85 \%$ of the total polyphenols. The concentrations of total phenolic compounds found $(2.26 \mathrm{mg}$ $\mathrm{GAE} / \mathrm{mL}$ and $4.01 \mathrm{mg} \mathrm{GAE} / \mathrm{mL}$, for $\mathrm{CBC} 18$ and $\mathrm{CBC} 32$ respectively) were used to calculate the mean daily dose administered to each mice per day $(18 \mathrm{mg}$ GAE/kg/day and $32 \mathrm{mg}$ GAE/kg/day for CBC18 and CBC32, respectively, considering body weight of each mice as $25 \mathrm{~g}$ at the beginning of the experiment). The in vitro antioxidant capacity was proportional to the phenolic concentrations; and the extract showed low inhibitory activity towards pancreatic lipase in vitro ( $\mathrm{IC}_{50} 321 \mu \mathrm{g} \mathrm{GAE} / \mathrm{mL}$ reaction) when compared to control Orlistat $\left(\mathrm{IC}_{50} 28.3\right.$ $\mu \mathrm{g} \mathrm{GAE} / \mathrm{mL}$ reaction).

As expected, the groups fed on a HFHS diet developed marked obesity when compared with mice kept on a chow diet. The administration of $\mathrm{CBC}$ in both doses did not produce statistical difference in the body weight relative to HFHS group (Fig. 2a). However, the total weight gain in the HFHS group tended to be slightly larger than that of the CBC groups $(8.4 \pm$ 0.7 for HFHS vs. $7.6 \pm 1.1$ and $7.1 \pm 0.6$ for $\mathrm{CBC} 18$ and $\mathrm{CBC} 32$, respectively) but overall this difference was not significant (Fig. 2b). The intake of a high-fat, high-sucrose diet induced an increase $(p<0.05)$ in weight gain when compared to the animals receiving chow diet.

Because of the higher caloric density of the HFHS diet (19.4 vs. $12.5 \mathrm{~kJ} / \mathrm{g}$, HFHS vs. Chow), the groups fed on a HFHS diet, receiving or not the phenolic-rich extract, consumed more calories than the Chow group (Table 3). The higher dose of phenolic-rich extract from cambuci $(\mathrm{CBC} 32)$ diminished $(p<0.05)$ the food and energy intake when compared to the HFHS group. Food efficiency was similar between the groups fed on a HFHS diet, suggesting a similar behavior in the efficiency to convert dietary energy into body mass; and HFHS, 
CBC18, and $\mathrm{CBC} 32$ groups showed higher food efficiency when compared to the Chow group.

When the fasting blood glucose during the experiment was compared, a trend toward increase was observed for mice receiving the HFHS diet. However, despite of the elevation in blood glucose, mice receiving $\mathrm{CBC}$ presented lower average values than the HFHS group (Fig. 3). Fasting blood glucose in the CBC32 group, but not in the $\mathrm{CBC} 18$ group, significantly decreased $(p<0.05)$ at 4,5 , and 8 week of the experiment when compared to HFHS group, which showed an accelerated increase in the blood glucose during the experimental period. In addition, no significant difference $(p>0.05)$ in blood glucose levels were observed among CBC32 and Chow groups at weeks 4, 5, 6, and 8.

To further study the effect of phenolic compounds from cambuci on glucose metabolism, a glucose tolerance test (GTT) was performed. Blood glucose levels were consistently higher $(p<0.05)$ during the GTT in the HFHS group when compared to levels in both CBC18 and CBC32 groups (Fig. 4a). Phenolic compounds from cambuci, especially CBC32, improved glucose intolerance linked to HFHS intake by the reduction $(p<0.05)$ of both the blood glucose concentration and the area under the mean incremental glucose curve. Fasting blood glucose, measured just before the intraperitoneal glucose administration, was not different among the HFHS-fed groups, receiving or not the phenolic-rich extract, but higher $(p<0.05)$ than in the chow-fed mice. However, blood glucose was significantly lower during the GTT in the mice receiving $\mathrm{CBC} 18$ and $\mathrm{CBC} 32$ compared to the HFHS group at $15 \min (16.32 \pm$ 0.74 and $14.65 \pm 0.58$ vs. $18.04 \pm 0.69 \mathrm{mmol} \mathrm{L}^{-1}$ respectively), $30 \mathrm{~min}(16.19 \pm 0.65$ and $13.52 \pm 0.46$ vs. $18.74 \pm 0.76), 45 \min (15.15 \pm 0.71$ and $13.38 \pm 0.64$ vs. $16.71 \pm 0.51), 60$ $\min (14.73 \pm 0.88$ and $12.10 \pm 0.65$ vs. $17.64 \pm 0.75)$, and $90 \min (11.90 \pm 0.44$ and $11.16 \pm$ 0.52 vs. $13.64 \pm 0.65 \mathrm{mmol} \mathrm{L}^{-1}$ ). In the HFHS group, unexpectedly, the GTT was accompanied by a reduction in the plasma insulin concentration at $30 \mathrm{~min}$ (Fig. 4b). However, the area under the mean incremental insulin curve remained higher, but not significantly different, compared to both $\mathrm{CBC} 18$ and $\mathrm{CBC} 32$ groups, where a reduced concentration of insulin was observed.

The diet and/or administration of CBC did not have a significant effect on the tissue weight of mice, including liver, heart and gastrocnemius muscle (Table 3). In agreement with the fact that no differences were detected in body weight, adipose tissue masses were also not significantly different in both $\mathrm{CBC} 18$ and $\mathrm{CBC} 32$ groups when compared to the HFHS group. The two doses of phenolics did not protect against the HFHS diet-induced fat accumulation, 
as shown by the weight of retroperitoneal, epididymal, inguinal, and brown adipose tissues (BAT). As expected, fat accumulation was lower $(p<0.05)$ in the Chow group when compared to the groups fed a HFHS diet (Table 3). However, no differences were observed in BAT weight between the $\mathrm{CBC} 32$ group when compared to the Chow group.

Plasma lipid levels abnormalities may be related to the pathogenesis of obesity-related diseases. There were significant differences in plasma lipid levels among the groups fed on a HFHS diet, receiving or not phenolic-rich extract. As shown in Fig. 5, a significant increase ( $p$ $<0.05)$ in HDL cholesterol levels was observed in CBC32 group, and a non-significant increase of 9.6\% was observed in $\mathrm{CBC} 18$ group when compared to HFHS group. The values for LDL cholesterol were lower $(p<0.05)$ for CBC32 when compared to HFHS. LDL cholesterol levels in both $\mathrm{CBC} 18$ and $\mathrm{CBC} 32$ were similar $(p>0.05)$ to those animals in the Chow group. Furthermore, although no differences were observed in total cholesterol and triacylglycerol levels, the means were 7.7 and $13.1 \%$ lower, respectively, in the CBC32 group when compared to HFHS group.

To further explore the mechanism underlying obesity induced by a HFHS diet and its amelioration by phenolic compounds from cambuci, the effects of these compounds on inflammation markers in adipose tissue were evaluated. The diet-induced pro-inflammatory response induced by HFHS feeding in retroperitoneal adipose tissue was attenuated after administration of phenolic compounds from cambuci. This attenuation was significant for both $\mathrm{CBC} 18$ and $\mathrm{CBC} 32$ groups as evaluated by the reduced mRNA levels of proinflammatory cytokines tumor necrosis factor-alpha $(T N F-\alpha)(p<0.01)$ and interleukin-6 (IL6) $(p<0.05)$ when compared to HFHS group (Figs. 6a and 6b). Because obesity is known to promote the recruitment and infiltration of leukocytes into adipose tissue, the expression of macrophage markers in retroperitoneal adipose tissue was also evaluated. As expected, HFHS feeding increased adipose tissue mRNA levels of macrophage markers $C D 11 b, F 4 / 80$, and CD86. Interestingly, despite the absence of differences in the adiposity and weight gain, administration of phenolic compounds from cambuci significantly attenuated the HFHSinduced increase in mRNA levels of macrophage markers $C D 11 \mathrm{~b}$ and $F 4 / 80$ in adipose tissue (Figs. 6c and 6d). Phenolic compounds from cambuci at both doses significantly attenuated the increased $(p<0.01)$ mRNA levels of $C D 11 b$ induced by HFHS, whereas only mice treated with the higher cambuci dose (CBC32) displayed a significant reduction in F4/80 mRNA levels in comparison to the HFHS fed mice. Similarly, administration of phenolics was also linked to a significant reduction ( $p<0.05$ for CBC18, and $p<0.01$ for CBC32 when 
compared to HFHS group) in the expression of classically activated macrophages (proinflammatory M1) marker CD86 (Fig. 6e).

\section{Discussion}

This study demonstrated that phenolic compounds from cambuci have a protective role against the disarrangements in glucose homeostasis and adipose tissue inflammation induced by intake of a HFHS diet. More specifically, phenolic compounds from cambuci improved glucose tolerance, reduced fasting glycemia and insulinemia, protected against dyslipidemia, and attenuated adipose tissue macrophage recruitment and expression of inflammatory markers. Our findings add phenolic compounds from cambuci to an extensive list of fruits such as berries and apples and their constituents, that were previously shown to protect against the insulin resistance, hyperglycemia, and dyslipidemia associated to obesity and type 2 diabetes (Del Rio, Borges, \& Crozier, 2010; Manzano \& Williamson, 2010).

Phenolic compounds from cambuci were tested at two different doses, with the lowest corresponding to $18 \mathrm{mg}$ gallic acid equivalent $(\mathrm{GAE}) / \mathrm{kg}$ body weight, which is equivalent to consuming the quantity of phenolic compounds present in a minimum of $0.5 \mathrm{~g}$ cambuci dry weight $/ \mathrm{kg}$ body weight. This dose, in turn, is equivalent to consuming $400 \mathrm{~g}$ of fruit (with approximately $90 \%$ moisture content) per day by a $70-\mathrm{kg}$ individual. This is the portion of fruits recommended by WHO/FAO for the prevention of chronic diseases such as heart disease, cancer, diabetes, and obesity (WHO/FAO, 2004). The major classes of phenolic compounds found in cambuci are ellagic acid derivatives such as ellagitannins (hydrolysable tannins, about $40 \%$ of total phenolics), followed in lowest proportion by flavonoids, mainly quercetin derivatives (Abe, Lajolo, \& Genovese, 2012; Genovese et al., 2008). Furthermore, our actual results show that the proanthocyanidin content (condensed tannins) represent about $22-25 \%$ of total phenolics (Table 2). The predominance of tannins (hydrolysable or condensed) is probably associated with cambuci fruit features such as astringency and extremely sour taste. Previous studies have reported that ellagitannins and ellagic acid, which also are found in fruits such as berries and pomegranate, have several beneficial actions for human health, protecting it from the development of cardiovascular disease and reducing the risk of metabolic complications (Del Rio et al., 2010). 
In agreement with this notion, our major findings indicated that phenolic compounds from cambuci attenuated glucose intolerance, hyperinsulinemia (slightly low) and hyperglycemia induced by the intake of a HFHS diet. These results can be partly attributed to an improvement in peripheral insulin response, supporting the hypothesis that the phenolic compounds from fruits play an important part in the protection from the disarrangements in glucose homeostasis associated with obesity, diabetes, and metabolic syndrome (Cherniack, 2011). The glucose-lowering properties of phenolics from cambuci may be associated with various putative mechanisms by which glycemia can be regulated, involving multiple pathways. In addition to the inhibitory activity of carbohydrate-hydrolyzing enzymes ( $\alpha$ amylase and $\alpha$-glucosidase), previously demonstrated in in vitro enzymatic assays (Gonçalves et al., 2010) for cambuci, phenolic compounds in fruits have also been shown to inhibit intestinal glucose transport, inhibiting sodium-dependent glucose transporter 1 (SGLT1) and glucose transporter 2 (GLUT2) (Ader, Block, Pietzsch, \& Wolffram, 2001; Manzano \& Williamson, 2010). Furthermore, in contrast to the intestinal GLUT2, a previous study demonstrated that tannins, a major component of phenolics found in cambuci, induce the glucose transporter 4 (GLUT4) expression through activation of an insulin-mediated signaling pathway in adipocytes (Liu et al., 2005).

As glucose uptake by skeletal muscle accounts for the majority of glucose disposal in the post-prandial period, $\mathrm{CBC}$ phenolics could also have an effect on key regulatory proteins involved in glucose uptake into muscle (GLUT4, AKT, ERK, and others).

Other mechanism explaining lower hyperglycemia may be the suppression of hepatic glucose production through the inhibition of enzymes involved in glycogenolysis and/or gluconeogenesis. Phenolic compounds present in persimmon (Diospyros kaki) leaf and cinnamon, including proanthocyanidins and flavonoids (also present in cambuci), were effective in decreasing glucose-6-phosphatase (G6Pase) and phosphoenolpyruvate carboxykinase (PEPCK) activities in the liver of type 2 diabetic mice and H4IIE rat hepatoma cells (Jung, Park, Kim, \& Choi, 2012; Cheng et al., 2012).

There were no statistical differences between the groups in regards to the plasma insulin concentration during the GTT, possibly because of the modest number covered in the data analysis $(4-5)$. However, it is possible to observe that the insulin secretion at 30 min during GTT was lower, but not significantly, in the HFHS group even though their blood glucose level was higher when compared with $\mathrm{CBC}$ and Chow groups (Figure 4). The glucose intolerance in this group may be caused by the regulation of insulin secretion from the 
pancreas through higher levels of circulating free fatty acids and leptin, which promote the suppression of second-phase insulin secretion (Sumiyoshi, Sakanaka, \& Kimura, 2006). This reduction in early insulin secretion from pancreatic islets was observed in C57BL/6J mice fed a high-sucrose diet (Sumiyoshi et al., 2006). Our findings suggest that the administration of phenolic compounds from cambuci may results in a protection against $\beta$ cell failure induced by nutrient toxicity (glucolipotoxicity) (Biden, Boslem, Chu, \& Sue, 2014), and this phenomenon may be attributed to alternative pathways, including their role in reducing oxidative stress.

In the present study, we found that phenolic compounds from cambuci did not affect the body weight and adiposity in mice fed a HFHS diet. Previously, Lu, Zhu, Shen, and Gao (2012) reported that administration of phenolic compounds from green tea (rich in epigallocatechin gallate) to rats fed with a high-fat diet was associated with a reduction in body weight. In contrast, Neyrinck et al. (2013) showed that phenolic-rich extract from pomegranate peel, which include the predominant ellagitannins (similar to cambuci), did not modify the high-fat-induced body weight gain and adiposity in Balb/c mice. These discrepancies probably derive not only from a structural and biological diversity of phenolics used in the different studies, methods of administration, but also from various genetic backgrounds of animals, as well as diverse diets. Likewise, our observations also indicated that the $\mathrm{CBC}$ phenolics did not affect tissue weight including adipose tissues (retroperitoneal, epididymal, inguinal and brown), heart, liver, and gastrocnemius muscle when compared to the HFHS group. In accordance with our results, a previous study reported that phenolics from berries, which are characterized by the presence of ellagitannins and anthocyanins, did not significantly alter tissue weight, such as liver, heart, epididymal, and subcutaneous adipose tissues in mice fed an obesogenic high-fat diet (Prior et al., 2009). The lower food and energy intake in the animals receiving $\mathrm{CBC} 32$ may be attributed to various endocrine parameters that regulate the food intake. Phenolics may interact specifically with various appetite control pathways and reduce food intake, including leptin or leptin receptor, peripheral factors, and neuropeptides (Kao, Hiipakka, \& Liao, 2000).

Our results indicated that administration of phenolic compounds from cambuci at a dosage of $32 \mathrm{mg}$ GAE/kg body weight for 8 weeks increased the HDL-cholesterol and decreased the LDL-cholesterol concentrations in plasma in the animals fed on a high-fat, highsucrose diet. Dyslipidaemia in obesity is characterized by increased levels of LDL-cholesterol, triacylglycerols, and total cholesterol, and lower HDL-cholesterol levels. These lipoproteins, 
mainly HDL and LDL-cholesterols, are predictors of cardiovascular disease risk (Van Gaal, Mertens, \& De Block, 2006), and the HDL and LDL-cholesterol ratio is a major risk factor for coronary heart disease. The increase in plasma HDL-cholesterol level observed in CBC groups may facilitate the transport of cholesterol from peripheral tissues to the liver for its catabolism (Prince \& Sathya, 2010). High HDL-cholesterol concentration may promote the efflux of cholesterol from macrophages in the endothelium, inhibit the oxidative modification of LDL cholesterol, vascular inflammation and thrombosis, promote endothelial repair, enhance endothelial function, and improve diabetic control (Rye \& Barter, 2014). The mechanisms by which phenolic compounds elevate HDL-cholesterol concentrations remain unclear. One hypothesis is that up-regulation of lecithin cholesterol acyl transferase by treatment with phenolics may stimulate HDL-cholesterol turnover (Prince \& Sathya, 2010). On the other hand, evidence suggests that phenolics may increase the expression and production of apolipoprotein A1, the major protein component of HDL-cholesterol, in a human hepatoma cell line HepG2 (Lamon-Fava, 2000). Recently, Di Donna et al., (2014) reported that phenolic compounds isolated from bergamot (Citrus bergamia) fruit were effective in the treatment of hypercholesterolemia in a rat model. The daily supplementation with the phenolic-rich extract reduced the LDL-cholesterol levels, whereas an increase of the HDL-cholesterol was observed. These authors also suggested that phenolic compounds can exert inhibitory effects on 3-hydroxy-3-methylglutaryl-CoA reductase (HMGR), leading to an increased synthesis of hepatic LDL-Receptor; this latter process allows a subsequent clearance of LDL-cholesterol from systemic circulation. In the present study, we also found that administration of CBC phenolics had no effect on total cholesterol and triacylglycerol levels. Although values tended to be lower (CBC32 group) compared with HFHS group, no significant changes were observed. Unchanged total cholesterol levels may be the result of the reduced LDL-cholesterol and increased HDL-cholesterol concentrations. Evidence-based studies show an association between consumption of polyphenols and reduced plasma triacylglycerol levels, which may explain, at least in part, the reduced cardiovascular mortality associated with the consumption of diets rich in fruit and vegetables. Here, however, triacylglycerols were unaltered. Similar to our results, the chronic administration of pomegranate juice to type 2 diabetic subjects did not alter total triacylglycerol or cholesterol levels but increased HDL-cholesterol (Rosenblat, Hayek, \& Aviram, 2006).

Relative gene expression in the retroperitoneal adipose tissue for inflammatory cytokines and macrophage-specific markers showed that the administration of phenolic compounds 
from cambuci decreased inflammatory response in the adipose tissue through inhibition of gene expression of TNF- $\alpha, I L-6, C D 11 b, F 4 / 80$, and CD86. Considering the data presented herein, it is reasonable to hypothesize that the lower inflammatory mediator expressions by CBC phenolics might act in the adipose tissue or other tissues that participate in insulinstimulated glucose uptake (e.g. skeletal muscle). As it is known, obesity is associated with increased production of pro-inflammatory cytokines, such as $T N F-\alpha$ and $I L-6$, in adipose tissue. These cytokines activate several serine kinases, including $I \kappa B$ kinase $(I K K)$ and $J N K$, which are capable of inhibiting insulin action by promoting the phosphorylation of serine residues of the insulin signaling pathway, including serine phosphorylation of insulin receptor substrate-1 (IRS-1) (McArdle, Finucane, Connaughton, McMorrow, \& Roche, 2013). Favoring our hypothesis and confirming previous findings, both $T N F-\alpha$ and $I L-6$ expression levels have been reduced in white adipose tissue and described to mediate the antiinflammatory properties of other phenolic compounds such as epigallocatechin gallate in rats receiving a high-fat diet (Bao et al, 2014), or rice bran extracts, rich in polyphenols also in rats (Candiracci, Justo, Castano, Rodriguez-Rodriguez, \& Herrera, 2014). Other mechanism by which phenolic compounds may reduce $T N F-\alpha$ is by suppressing the activity of the proinflammatory transcriptional factor $N F \kappa B$. Park et al. (2012) showed that green tea extract (rich in epigallocatechin gallate) lowers $I \kappa B$ phosphorylation in epididymal adipose tissue of obese rats. The activation of $N F \kappa B$ in the cytosol is regulated by phosphorylation and proteolysis of $I \kappa B$. Degradation of $I \kappa B$ allows nuclear translocation of $N F \kappa B$, and thus, $N F \kappa B$ binds to promote sites for gene transcription. As $N F \kappa B$ regulates $T N F-\alpha$ expression, the suppression of $N F \kappa B$ may reduce $T N F-\alpha$ expression (Park et al., 2012). Furthermore, a previous study showed that quercetin decreased $T N F$ - $\alpha$-induced $I L-6, I L-1 b$, and $I L-8$ gene expression, in cultures of human adipocytes. Potential mechanisms for these antiinflammatory actions include direct effect such as suppression of the activation of $E R K, J N K$, and $N F \kappa B$, and indirect effects via PPAR $\gamma$ activation (Chuang et al., 2010). CBC phenolics decreased the accumulation of macrophages and M1 macrophages into adipose tissue. Macrophage accumulation in the adipose tissue occurs in the context of continuous tissue remodeling that is pathologically accelerated in the obese state. This accumulation is closely related to the dysfunction of glucose and lipid metabolism (Patel, Buras, \& Balasubramanyam, 2013; Xiao et al., 2014). With excessive weight gain, extreme increases in adipocyte size are accompanied by an elevated frequency of adipocyte death and macrophage accumulation and their M1 polarization (Patel et al., 2013). In agreement with previous 
findings, phenolic compounds also significantly decreased macrophage infiltration in adipose tissues of rats fed a high-fat diet (Bao et al., 2014).

Here, we demonstrated that the administration of $\mathrm{CBC}$ reduces adipose inflammation by decreasing macrophages infiltration, polarization to M1 proinflammatory phenotype and cytokines secretion. These effects might alleviate insulin resistance in obesity, as proinflammatory cytokines are strong inhibitors of insulin action in adipocytes, myocytes and hepatocytes.

\section{Conclusion}

In summary, phenolic compounds from cambuci fruit have an important role counteracting metabolic complications associated with obesity. Our results indicated that phenolic compounds from cambuci were effective in ameliorating glucose tolerance, as well as reducing insulinemia and fasting glycemia, and improving dyslipidemia by increasing HDL-cholesterol and decreasing the LDL-cholesterol. Although no changes in the body weight gain and adiposity were observed after administration of CBC, an attenuation of adipose tissue inflammation as evidenced by the reduction in pro-inflammatory cytokines $T N F-\alpha, I L-6$ and macrophage recruitment were observed in the retroperitoneal adipose tissue for both doses tested. Further studies are under way to determine additional molecular mechanisms involved in the effects observed. Thus, phenolic compounds may be an adjuvant therapeutic potential for improving the obesity management and its complications.

\section{Conflict of interest}

The authors declare no competing financial interest.

\section{Acknowledgements}

The authors thank São Paulo Research Foundation (FAPESP 2013/19797-6, 2010/521916, and 2013/50394-5) and Coordenação de Aperfeiçoamento de Pessoal de Nível Superior (CAPES/PEC-PG 5554-11-0 and CAPES/DFAIT 007/2013), for the financial support. 


\section{References}

Abe, L. T., Lajolo, F. M., \& Genovese, M. I. (2012). Potential dietary sources of ellagic acid and other antioxidants among fruits consumed in Brazil: Jabuticaba (Myrciaria jaboticaba (Vell.) Berg). Journal of the Science of Food and Agriculture, 92(8), 1679-1687.

Ader, P., Block, M., Pietzsch, S., \& Wolffram, S. (2001). Interaction of quercetin glucosides with the intestinal sodium/glucose co-transporter (SGLT-1). Cancer Letters, 162(2), 175180.

Arabbi, P. R., Genovese, M. I., \& Lajolo, F. M. (2004). Flavonoids in vegetable foods commonly consumed in brazil and estimated ingestion by the Brazilian population. Journal of Agricultural and Food Chemistry, 52(5), 1124-1131.

Bao, S. Q., Cao, Y. L., Fan, C. L., Fan, Y. X., Bai, S. T., Teng, W. P., et al. (2014). Epigallocatechin gallate improves insulin signaling by decreasing toll-like receptor 4 (TLR4) activity in adipose tissues of high- fat diet rats. Molecular Nutrition \& Food Research, 58(4), 677-686.

Benzie, I. F. F., \& Strain, J. J. (1996). The ferric reducing ability of plasma (FRAP) as a measure of "antioxidant power": The FRAP assay. Analytical Biochemistry, 239(1), 70-76.

Biden, T. J., Boslem, E., Chu, K. Y., \& Sue, N. (2014). Lipotoxic endoplasmic reticulum stress, $\beta$ cell failure, and type 2 diabetes mellitus. Trends in Endocrinology \& Metabolism, 25(8), 389-398.

Brand-Williams, W., Cuvelier, M. E., \& Berset, C. (1995). Use of a free radical method to evaluate antioxidant activity. LWT - Food Science and Technology, 28(1), 25-30

Candiracci, M., Justo, M. L., Castano, A., Rodriguez-Rodriguez, R., \& Herrera, M. D. (2014). Rice bran enzymatic extract-supplemented diets modulate adipose tissue inflammation markers in Zucker rats. Nutrition, 30(4), 466-472.

Carter, P., Gray, L. J., Troughton, J., Khunti, K., \& Davies, M. J. (2010). Fruit and vegetable intake and incidence of type 2 diabetes mellitus: systematic review and meta-analysis. British Medical Journal, 341, 1-8.

Cheng, D. M., Kuhn, P., Poulev, A., Rojo, L. E., Lila, M. A., \& Raskin, I. (2012). In vivo and in vitro antidiabetic affects of aqueous cinnamon extract and cinnamon polyphenolenhanced food matrix. Food Chemistry, 135, 2994-3002.

Cherniack, E. P. (2011). Polyphenols: planting the seeds of treatment for the metabolic syndrome. Nutrition, 27, 617-623. 
Chuang, C. C., Martinez, K., Xie, G. X., Kennedy, A., Bumrungpert, A., Overman, A., et al. (2010). Quercetin is equally or more effective than resveratrol in attenuating tumor necrosis factor- $\alpha$-mediated inflammation and insulin resistance in primary human adipocytes. American Journal of Clinical Nutrition, 92(6), 1511-1521.

Dávalos, A., Gómez-Cordovés, C., \& Bartolomé, B. (2004). Extending applicability of the oxygen radical absorbance capacity (ORAC-fluorescein) assay. Journal of Agricultural and Food Chemistry, 52(1), 48-54.

Del Rio, D., Borges, G., \& Crozier, A. (2010). Berry flavonoids and phenolics: bioavailability and evidence of protective effects. British Journal of Nutrition, 104, S67-S90.

Di Donna, L., Iacopetta, D., Cappello, A. R., Gallucci, G., Martello, E., Fiorillo, M., et al. (2014). Hypocholesterolaemic activity of 3-hydroxy-3-methyl-glutaryl flavanones enriched fraction from bergamot fruit (Citrus bergamia): "In vivo" studies. Journal of Functional Foods, 7, 558-568.

FAO, Food and Agriculture Organization of the United Nations. FAOSTAT database (updated January 2013). URL http://faostat.fao.org/site/291/default.aspx. Accesed 05.04.13.

Festuccia, W. T., Oztezcan, S., Laplante, M., Berthiaume, M., Michel, C., Dohgu, S., et al. (2008). Peroxisome proliferator-activated receptor-gamma-mediated positive energy balance in the rat is associated with reduced sympathetic drive to adipose tissues and thyroid status. Endocrinology, 149(5), 2121-2130.

Genovese, M. I., Pinto, M. D. S., Gonçalves, A., \& Lajolo, F. M. (2008). Bioactive compounds and antioxidant capacity of exotic fruits and commercial frozen pulps from Brazil. Food Science and Technology International, 14(3), 207-214.

Gonçalves, A., Lajolo, F. M., \& Genovese, M. I. (2010). Chemical Composition and Antioxidant/Antidiabetic Potential of Brazilian Native Fruits and Commercial Frozen Pulps. Journal of Agricultural and Food Chemistry, 58(8), 4666-4674.

Haminiuk, C. W. I., Plata-Oviedo, M. S. V., Guedes, A. R., Stafussa, A. P., Bona, E., \& Carpes, S. T. (2011). Chemical, antioxidant and antibacterial study of Brazilian fruits. International Journal of Food Science and Technology, 46(7), 1529-1537.

Jung, U. J., Park, Y. B., Kim, S. R., \& Choi, M. S., (2012). Supplementation of persimmon leaf ameliorates hyperglycemia, dyslipidemia and hepatic fat accumulation in type 2 diabetic mice. PlosOne, 7(11), e49030. 
Kao, Y. H., Hiipakka, R. A., \& Liao, S. S. (2000). Modulation of endocrine systems and food intake by green tea epigallocatechin gallate. Endocrinology, 141(3), 980-987.

Kawasaki, M. L., \& Landrum, L. R. (1997). A rare and potentially economic fruit of Brazil: cambuci, Campomanesia phaea (Myrtaceae). Economic Botany, 51(4), 403-405.

Lamon-Fava, S. (2000). Genistein activates apolipoprotein A-I gene expression in the human hepatoma cell line Hep G2. Journal of Nutrition, 130(10), 2489-2492.

Lemieux, C., Picard, F., Labrie, F., Richard, D., \& Deshaies, Y. (2003). The estrogen antagonist EM-652 and dehydroepiandrosterone prevent diet- and ovariectomy-induced obesity. Obesity Research, 11(3), 477-490.

Lim, S. S., Vos, T., Flaxman, A. D., Danaei, G., Shibuya, K., Adair-Rohani, H., et al. (2012). A comparative risk assessment of burden of disease and injury attributable to 67 risk factors and risk factor clusters in 21 regions, 1990-2010: a systematic analysis for the Global Burden of Disease Study 2010. Lancet, 380(9859), 2224-2260.

Liu, X., Kim, J. K., Li, Y., Li, J., Liu, F., \& Chen, X. (2005). Tannic acid stimulates glucose transport and inhibits adipocyte differentiation in 3T3-L1 cells. The Journal of Nutrition, $135,165-171$.

Lu, C. W., Zhu, W. B., Shen, C. L., \& Gao, W. M. (2012). Green Tea Polyphenols Reduce Body Weight in Rats by Modulating Obesity-Related Genes. Plos One, 7(6), 1-11.

Manzano, S., \& Williamson, G. (2010). Polyphenols and phenolic acids from strawberry and apple decrease glucose uptake and transport by human intestinal Caco-2 cells. Molecular Nutrition \& Food Research, 54(12), 1773-1780.

McArdle, M. A., Finucane, O. M., Connaughton, R. M., McMorrow, A. M., \& Roche, H. M. (2013). Mechanisms of obesity-induced inflammation and insulin resistance: insights into the emerging role of nutritional strategies. Frontiers in Endocrinology, 4, 1-23.

Nakai, M., Fukui, Y., Asami, S., Toyoda-Ono, Y., Iwashita, T., Shibata, H., et al. (2005). Inhibitory effects of oolong tea polyphenols on pancreatic lipase in vitro. Journal of Agricultural and Food Chemistry, 53(11), 4593-4598.

Neyrinck, A. M., Van Hee, V. F., Bindels, L. B., De Backer, F., Cani, P. D., \& Delzenne, N. M. (2013). Polyphenol-rich extract of pomegranate peel alleviates tissue inflammation and hypercholesterolaemia in high-fat diet-induced obese mice: potential implication of the gut microbiota. British Journal of Nutrition, 109(5), 802-809. 
Ng, M., Fleming, T., Robinson, M., et al. (2014). Global, regional, and national prevalence of overweight and obesity in children and adults during 1980-2013: a systematic analysis for the Global Burden of Disease Study 2013. Lancet, pii: S0140-6736 (14) 60460-8.

Paeratakul, S., Lovejoy, J. C., Ryan, D. H., \& Bray, G. A. (2002). The relation of gender, race and socioeconomic status to obesity and obesity comorbidities in a sample of US adults. International Journal of Obesity, 26(9), 1205-1210.

Park, H. J., Lee, J. Y., Chung, M. Y., Park, Y. K., Bower, A. M., Koo, S. I., et al. (2012). Green Tea Extract Suppresses NFкB Activation and Inflammatory Responses in DietInduced Obese Rats with Nonalcoholic Steatohepatitis. Journal of Nutrition, 142(1), 57-63.

Patel, P. S., Buras, E. D., \& Balasubramanyam A. (2013). The role of the immune system in obesity and insulin resistance. Journal of Obesity, ID 616193.

Pinto, M. S., Lajolo, F. M., \& Genovese, M. I. (2008). Bioactive compounds and quantification of total ellagic acid in strawberries (Fragaria $x$ ananassa Duch.). Food Chemistry, 107, 1629-1635.

Porter, L. J., Hrstich, L. N., \& Chan, B. G. (1985). The conversion of procyanidins and prodelphinidins to cyanidin and delphinidin. Phytochemistry, 25(1), 223-230.

Prince, P. S. M., \& Sathya, B. (2010). Pretreatment with quercetin ameliorates lipids, lipoproteins and marker enzymes of lipid metabolism in isoproterenol treated cardiotoxic male Wistar rats. European Journal of Pharmacology, 635(1-3), 142-148.

Prior, R. L., Wu, X., Gu, L., Hager, T., Hager, A., Wilkes, S., \& Howard, L. Purified berry anthocyanins but not whole berries normalize lipid parameters in mice fed an obesogenic high fat diet. Molecular Nutrition \& Food Research, 53, 1406-1418.

Rosenblat, M., Hayek, T., \& Aviram, M. (2006). Anti-oxidant effects of pomegranate juice (PJ) consumption by diabetic patients on serum and on macrophages. Atherosclerosis, 187, 363-371.

Rye, K. A., \& Barter, P. J. (2014). Thematic Review Series: High Density Lipoprotein Structure, Function, and Metabolism Cardioprotective functions of HDLs. Journal of Lipid Research, 55(2), 168-179.

Singleton, V. L., Orthofer, R., \& Lamuela-Raventos, R. M. (1999). Analysis of total phenols and other oxidation substrates and antioxidants by means of Folin-Ciocalteu reagent. Oxidants and Antioxidants, Pt A, 299, 152-178.

Sumiyoshi, M., Sakanaka, M., \& Kimura, Y. (2006). Chronic intake of high-fat and highsucrose diets differentially affects glucose intolerance in mice. Journal of Nutrition, $136(3), 582-587$. 
Van Gaal, L. F., Mertens, I. L., \& De Block, C. E. (2006). Mechanisms linking obesity with cardiovascular disease. Nature, 444(7121), 875-880.

Wang, S., Melnyk, J. P., Tsao, R., \& Marcone, M. F. (2011). How natural dietary antioxidants in fruits, vegetables and legumes promote vascular health. Food Research International, 44(1), 14-22.

WHO/FAO, World Health Organization and Food and Agriculture Organization of the United Nations. (2004). Fruit and vegetables for health: Report of a Joint FAO/WHO Workshop. Kobe: FAO/WHO.

Xiao, N., Mei, F., Sun, Y., Pan, G., Liu, B., \& Liu, K. (2014). Quercetin, luteolin, and epigallocatechin gallate promote glucose disposal in adipocytes with regulation of AMPactivated kinase and/or sirtuin 1 activity. Planta Medica, DOI: 10.1055/s-0034-1382864 


\section{Figure captions}

Fig. 1. HPLC chromatogram of flavonoid glycosides and phenolic acids extracted in the methanol (a) and methanol:ammonia (b) fractions from cambuci fruit.

Fig. 2. Body weight (a) and weight gain (b) of mice fed on high-fat high-sucrose or chow diets and receiving water (Chow and HFHS groups) or phenolic-rich extracts from cambuci at two doses (CBC18 and CBC32) by gavage for 8 weeks. Data are means \pm SEM from each treatment $(n=9-10) . *(p<0.05)$ Chow vs. other groups; $\dagger(p<0.05)$ CBC32 vs. HFHS.

Fig. 3. Weekly variation of fasting blood glucose $(6 \mathrm{~h})$ in mice fed on high-fat high-sucrose or chow diets and receiving water (Chow and HFHS groups) or phenolic-rich extracts from cambuci at two doses (CBC18 and CBC32) by gavage for 8 weeks. Data are means \pm SEM from each treatment $(n=9-10) . \ddagger(p<0.05)$ HFHS vs. CBC32 and Chow; $\dagger(p>0.05)$ Chow $=\mathrm{CBC} 32$.

Fig. 4. Blood glucose (a) and the glucose area-under-the-curve (AUC; inset) and plasma insulin (b) and the insulin AUC (inset) during glucose tolerance test in mice fed on high-fat high-sucrose or chow diets and receiving water (Chow and HFHS groups) or phenolic-rich extracts from cambuci at two doses $(\mathrm{CBC} 18$ and $\mathrm{CBC} 32)$ by gavage for 8 weeks. Data are means \pm SEM from each treatment ( $n=9-10$ for blood glucose; $n=4-5$ for plasma insulin). ${ }^{\mathrm{a}-\mathrm{c}}$ Bars with different letters were significantly different $(p<0.05)$.

Fig. 5. Plasma lipid levels of mice fed on high-fat high-sucrose or chow diets and receiving water (Chow and HFHS groups) or phenolic-rich extracts from cambuci at two doses (CBC18 and CBC32) by gavage for 8 weeks. Data are means \pm SEM from each treatment $(n=9-10)$. * $(p<0.05)$ vs. other groups; $\&(p>0.05)$ vs. Chow; \# $(p<0.05)$ vs. HFHS.

Fig. 6. Retroperitoneal adipose tissue mRNA expression of $T N F-\alpha$ (a), $I L-6$ (b), CDIIb (c), F4/80 (d), and CD86 (e) in mice fed on high-fat and high-sucrose and chow diets and receiving phenolic-rich extracts from cambuci at two doses ( $\mathrm{CBC} 18$ and $\mathrm{CBC} 32)$ by gavage for 8 weeks. Data are means \pm SEM from each treatment $(n=5){ }^{*} p<0.05$ vs. HFHS. 
Table 1. Primer sequences for real-time PCR.

\begin{tabular}{lcc}
\hline Primer name & \multicolumn{1}{c}{ Forward } & Reverse \\
\hline$T N F-\alpha$ & AGCCCACGTCGTAGCAAACCA & GCAGGGGCTCTTGACGGCAG \\
$I L-6$ & CCTCTCTGCAAGACTTCCATCCA & TCTCTGAAGGACTCTGGCTTTGTCT \\
$C D 11 b$ & GGCAGGAGTCGTATGTGAGG & AGCCAAGCTTGTATAGGCCA \\
$F 4 / 80$ & GCCACGGGGCTATGGGATGC & TCCCGTACCTGACGGTTGAGCA \\
$C D 86$ & CCCAGCAACACAGCCTCTAA & ACTCTGCATTTGGTTTTGCTGA \\
$R P L 3$ & AGGGGGCGGAGCCATCACTT & TTCACCTTAGATCCTGGCCTGTCA \\
\hline
\end{tabular}

$T N F-\alpha$, tumor necrosis factor-alpha; $I L-6$, interleukin-6; $C D 11 b$, integrin alpha M; F4/80 EGF-like module containing, mucin-like, hormone receptor-like sequence 1; CD86; CD86 antigen; RPL3, ribosomal protein L3;

Table 2. Characterization of phenolic-rich extracts of cambuci, $\mathrm{CBC} 18$ and $\mathrm{CBC} 32$, administered to C57BL/6J mice by oral gavage for 8 weeks.

\begin{tabular}{|c|c|c|}
\hline & $\begin{array}{c}\text { Phenolic-rich } \\
\text { Extract CBC18 }\end{array}$ & $\begin{array}{c}\text { Phenolic-rich } \\
\text { Extract CBC32 }\end{array}$ \\
\hline Total phenolics (mg GAE/mL) & $2.26 \pm 0.15$ & $4.01 \pm 0.25$ \\
\hline Proanthocyanidins (mg QTE/mL) & $0.51 \pm 0.04$ & $1.04 \pm 0.05$ \\
\hline \multicolumn{3}{|l|}{$\begin{array}{l}\text { Flavonoids and phenolic acids }(\mu \mathrm{g} \\
/ \mathrm{mL})\end{array}$} \\
\hline Quercetin derivatives & $3.53 \pm 0.40$ & $6.44 \pm 0.70$ \\
\hline Free ellagic acid & $9.57 \pm 0.29$ & $16.98 \pm 0.52$ \\
\hline Total ellagic acid & $1312 \pm 15$ & $2400 \pm 52$ \\
\hline ORAC ( $\mu$ mol Trolox/mL) & $12.91 \pm 0.77$ & $20.20 \pm 1.83$ \\
\hline DPPH $(\mu \mathrm{mol}$ Trolox/mL) & $14.71 \pm 1.78$ & $29.44 \pm 1.52$ \\
\hline FRAP ( $\mu$ mol Trolox/mL) & $13.87 \pm 2.07$ & $24.28 \pm 3.73$ \\
\hline $\begin{array}{l}\text { Pancreatic lipase } \\
\text { inhibition }\left(\mathrm{IC}_{50}-\mu \mathrm{g} \text { GAE } / \mathrm{mL}\right)^{1}\end{array}$ & n.d & $321.91 \pm 15.06$ \\
\hline
\end{tabular}

Results are expressed as mean \pm SD values $(n=3) .{ }^{1}$ Orlistat control $\mathrm{IC}_{50} 28.3 \mu \mathrm{g} / \mathrm{mL}$ reaction; GAE, gallic acid equivalent; QTE, quebracho tannin equivalent; n.d., not detected. 
Table 3. Diet consumption and organ weights of mice fed on high-fat high-sucrose or chow diets and receiving water (Chow and HFHS groups) or phenolic-rich extracts from cambuci at two doses (CBC18 and CBC32) by gavage for 8 weeks.

\begin{tabular}{|c|c|c|c|c|}
\hline & Chow & HFHS & $\mathrm{CBC} 18$ & $\mathrm{CBC} 32$ \\
\hline \multicolumn{5}{|l|}{ Intake } \\
\hline Food intake (g/day) & $3.89 \pm 0.06^{\mathrm{a}}$ & $3.07 \pm 0.04^{\mathrm{b}}$ & $2.90 \pm 0.06^{\mathrm{bc}}$ & $2.81 \pm 0.06^{\mathrm{c}}$ \\
\hline Energy intake (kJ/day) & $48.56 \pm 0.77^{\mathrm{c}}$ & $59.59 \pm 0.83^{\mathrm{a}}$ & $56.33 \pm 1.13^{\mathrm{ab}}$ & $54.48 \pm 1.20^{\mathrm{b}}$ \\
\hline Food efficiency $\dagger$ & $2.21 \pm 0.32^{\mathrm{b}}$ & $9.43 \pm 0.81^{\mathrm{a}}$ & $8.99 \pm 0.81^{\mathrm{a}}$ & $8.77 \pm 0.78^{\mathrm{a}}$ \\
\hline \multicolumn{5}{|l|}{ Tissue weight (mg) } \\
\hline Liver & $1013 \pm 31^{\mathrm{a}}$ & $1056 \pm 47^{\mathrm{a}}$ & $983 \pm 41^{\mathrm{a}}$ & $962 \pm 44^{\mathrm{a}}$ \\
\hline Heart & $119 \pm 3^{\mathrm{a}}$ & $119 \pm 7^{\mathrm{a}}$ & $109 \pm 3^{\mathrm{a}}$ & $110 \pm 3^{\mathrm{a}}$ \\
\hline Gastrocnemius muscle & $140 \pm 4^{\mathrm{a}}$ & $153 \pm 4^{\mathrm{a}}$ & $147 \pm 6^{\mathrm{a}}$ & $144 \pm 4^{\mathrm{a}}$ \\
\hline Retroperitoneal A. T. & $80 \pm 14^{\mathrm{b}}$ & $464 \pm 36^{\mathrm{a}}$ & $498 \pm 81^{\mathrm{a}}$ & $479 \pm 53^{\mathrm{a}}$ \\
\hline Epididymal A. T. & $287 \pm 22^{\mathrm{b}}$ & $1177 \pm 108^{\mathrm{a}}$ & $1197 \pm 180^{\mathrm{a}}$ & $1122 \pm 99^{\mathrm{a}}$ \\
\hline Inguinal A. T. & $192 \pm 24^{\mathrm{b}}$ & $870 \pm 79^{\mathrm{a}}$ & $858 \pm 161^{\mathrm{a}}$ & $880 \pm 103^{\mathrm{a}}$ \\
\hline Brown A. T. & $56 \pm 6^{\mathrm{b}}$ & $109 \pm 17^{\mathrm{a}}$ & $101 \pm 11^{\mathrm{a}}$ & $87 \pm 12^{\mathrm{ab}}$ \\
\hline
\end{tabular}

Results are expressed as mean \pm SEM values ( $n=9$ - 10 per group)

${ }^{\mathrm{a}-\mathrm{c}}$ Means within a row marked with different letters are significantly different $(p<0.05)$

$\dagger$ Expressed as (body weight gain [in g]/food intake [in g]) x 100

A. T., adipose tissu 

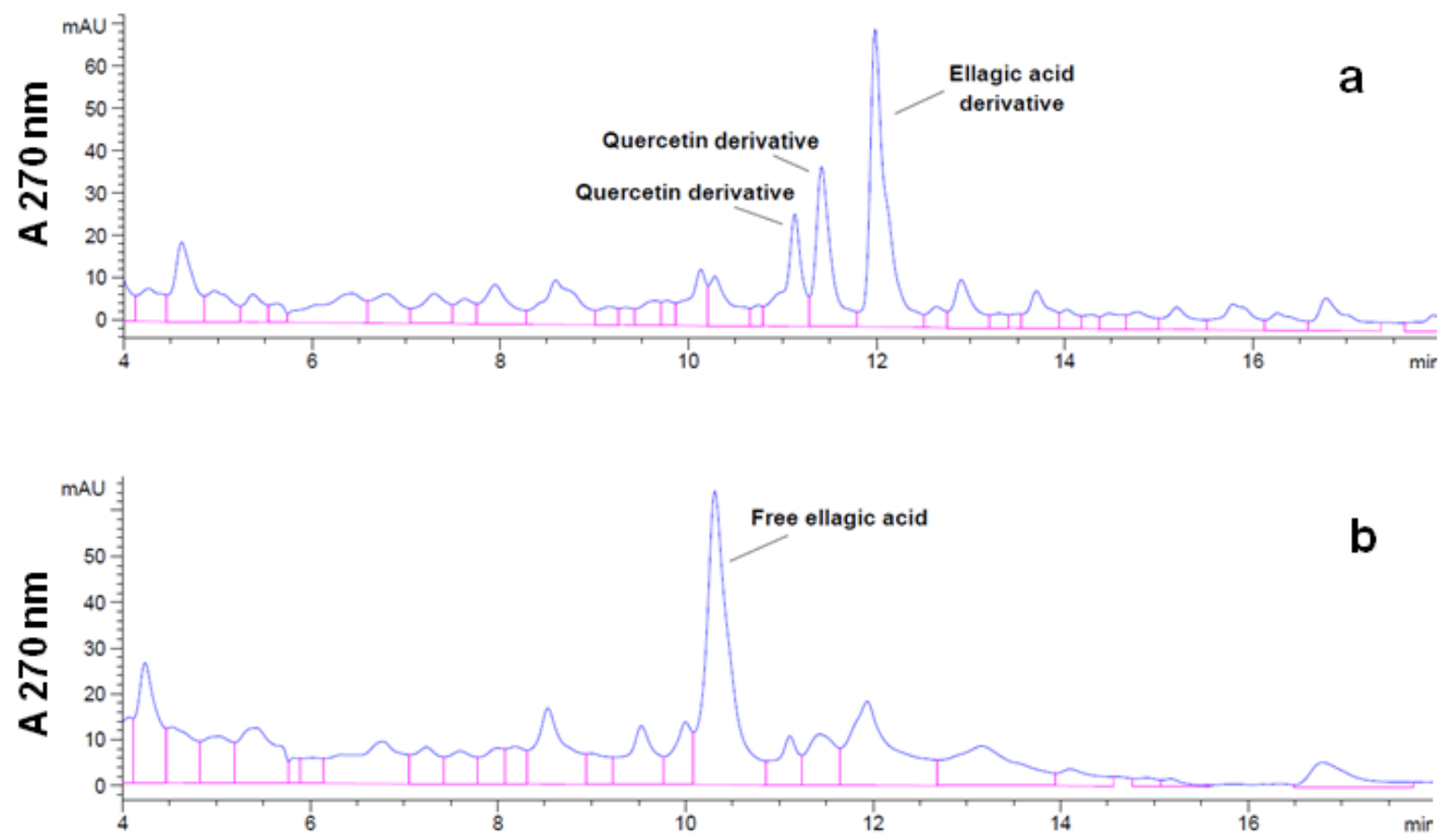

Figure 1
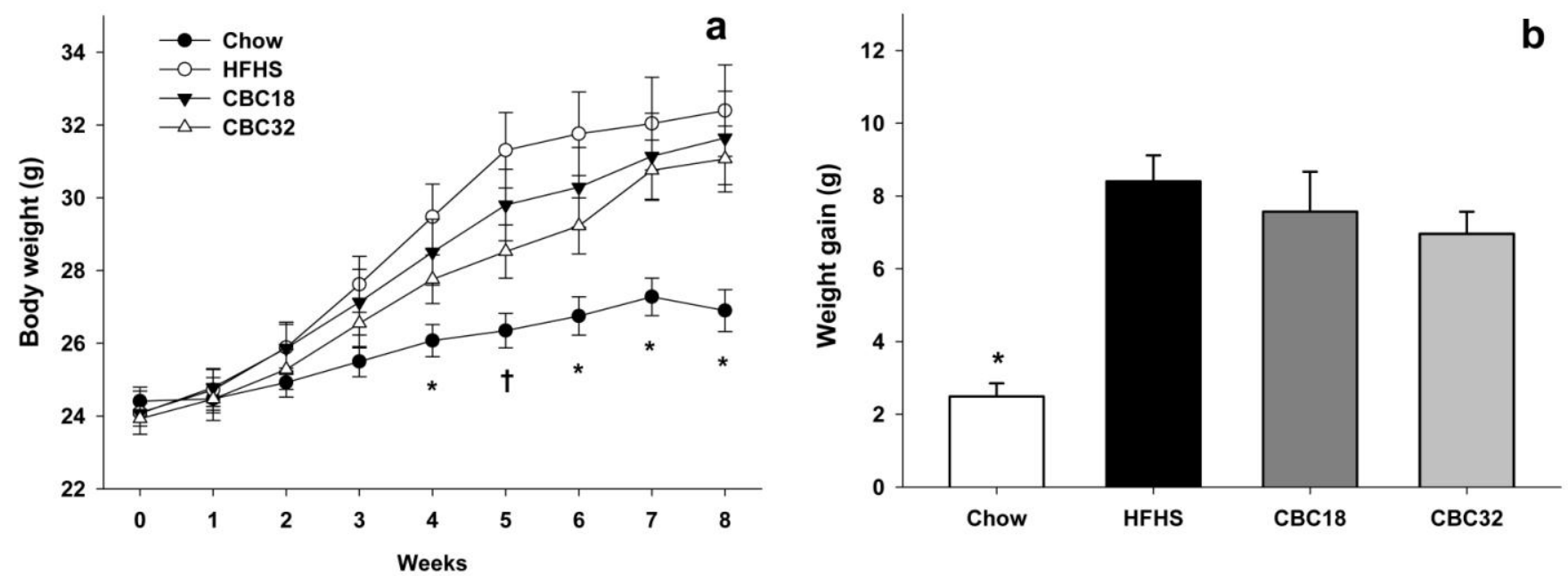

Figure 2 


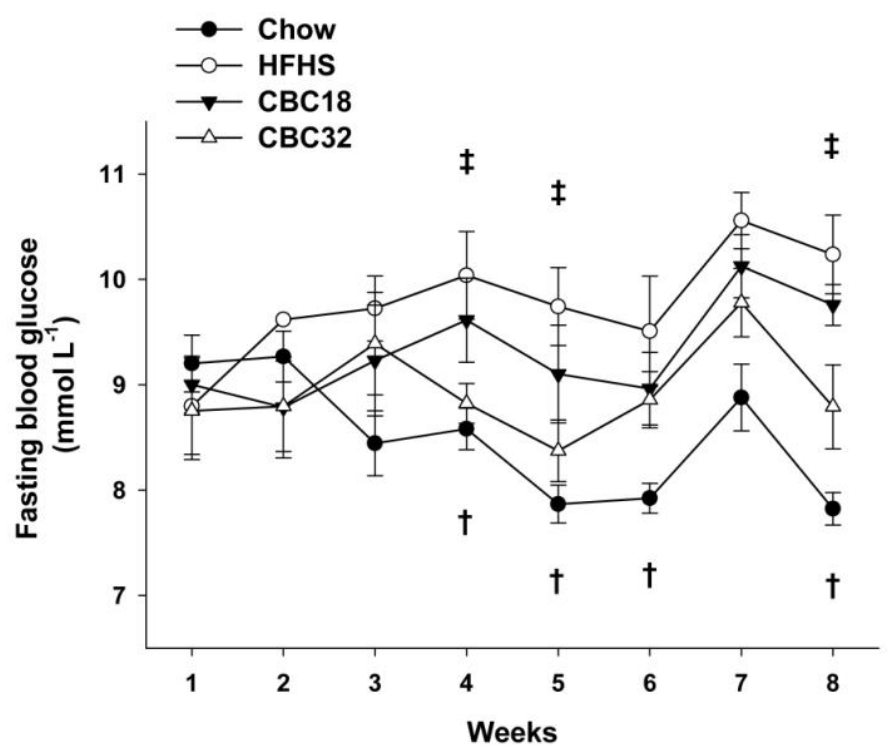

Figure 3
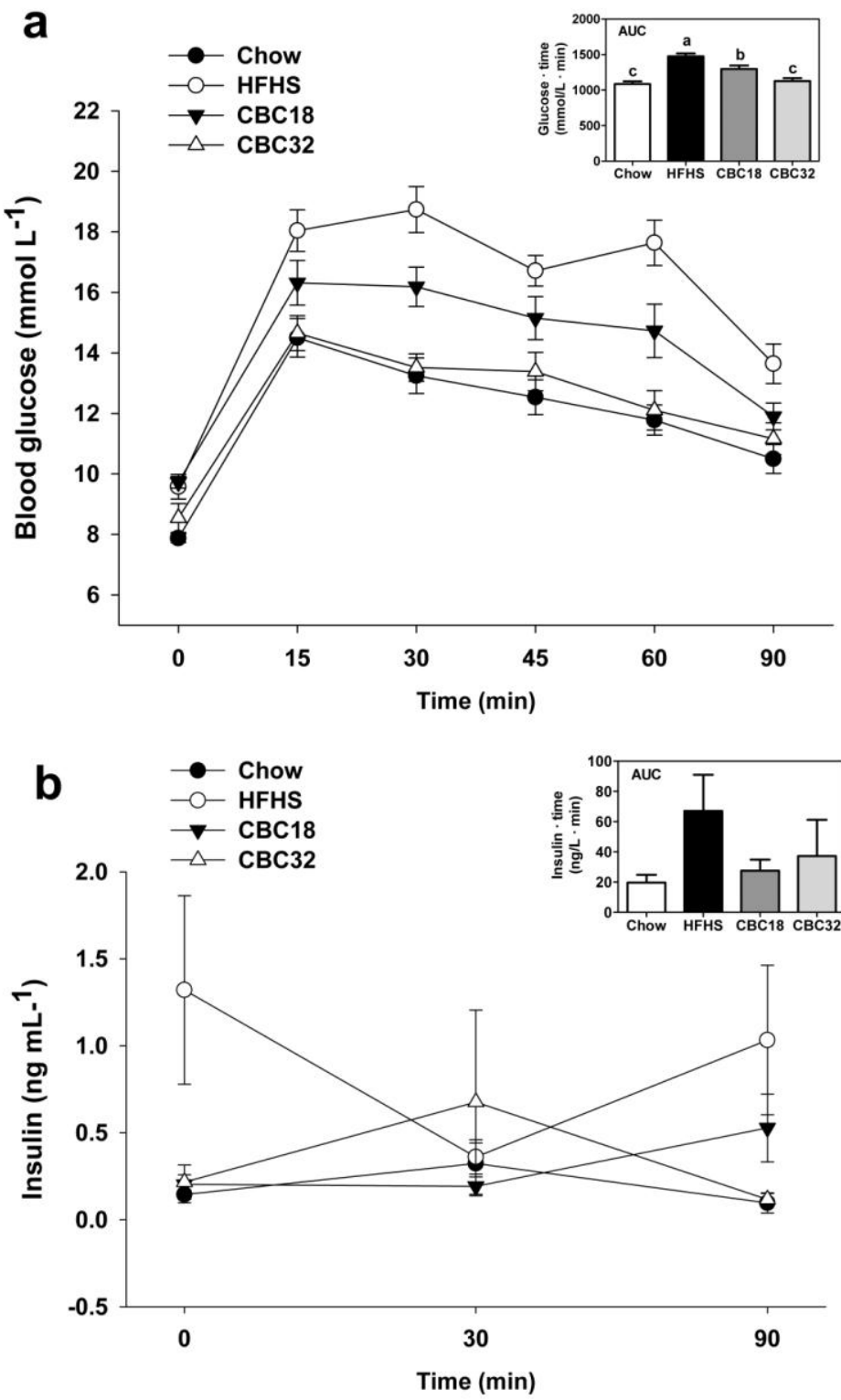

Figure 4 
a

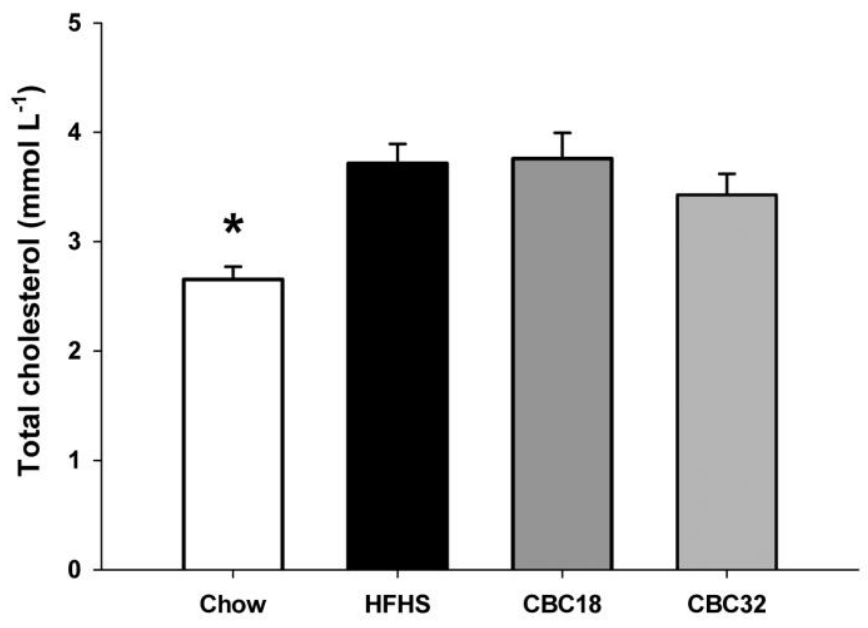

C

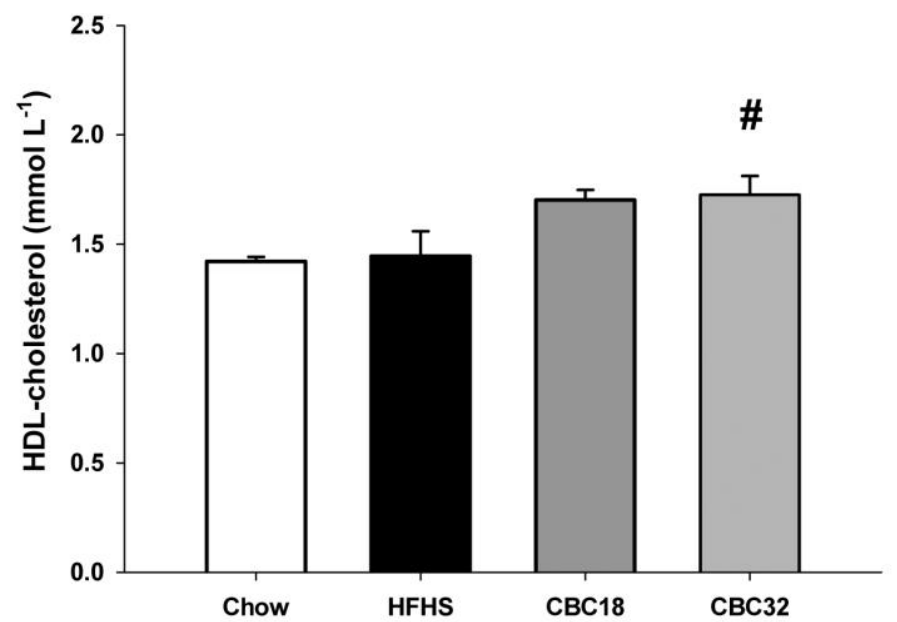

b
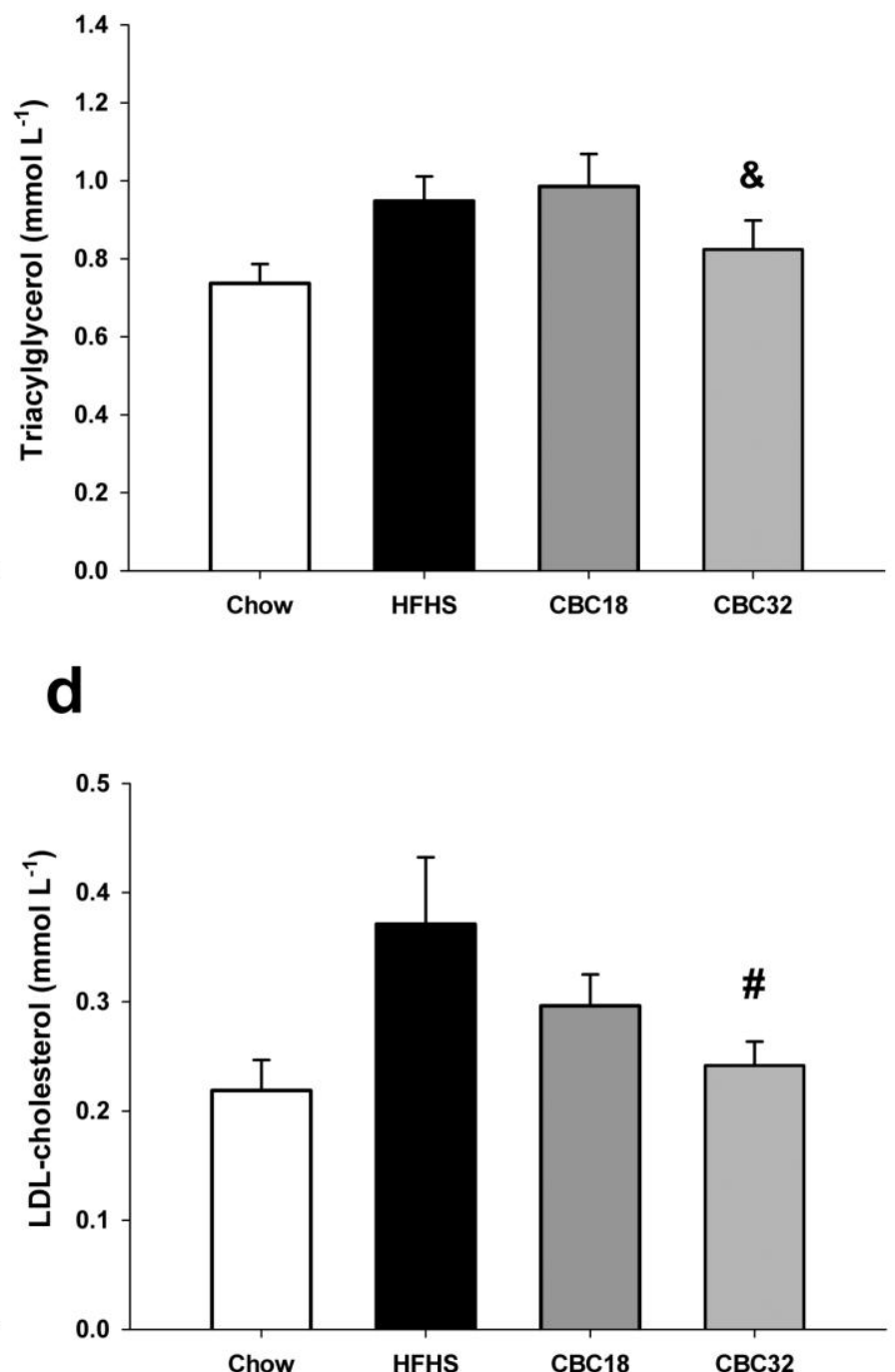

Figure 5 
a

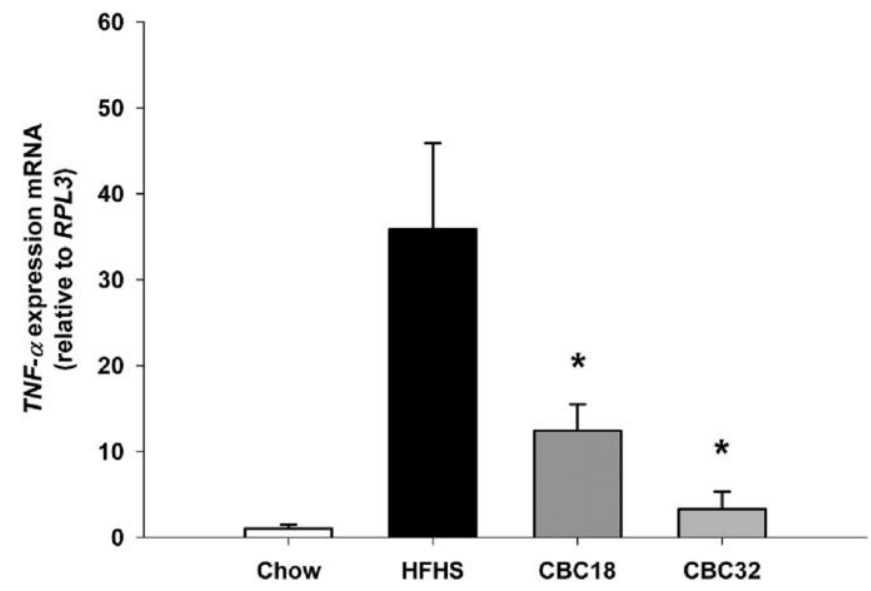

C

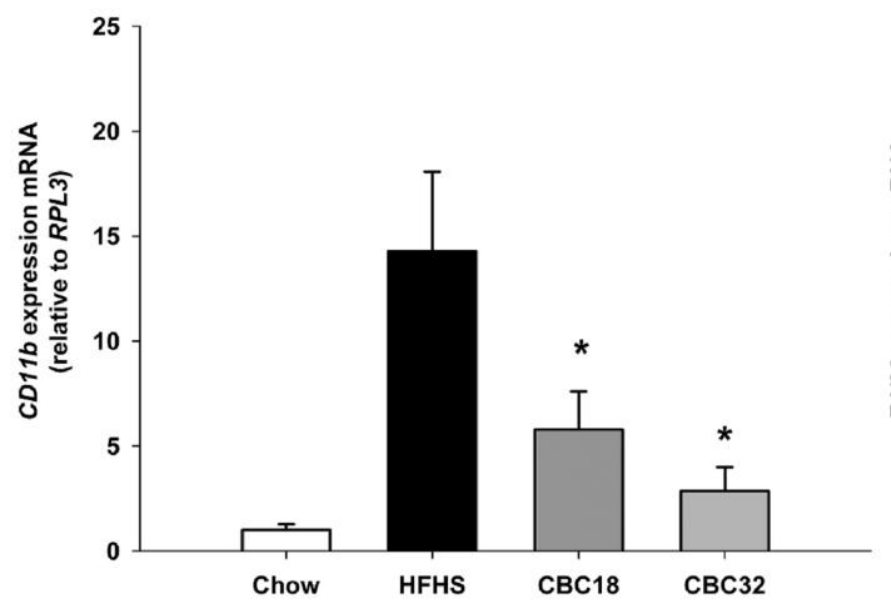

e

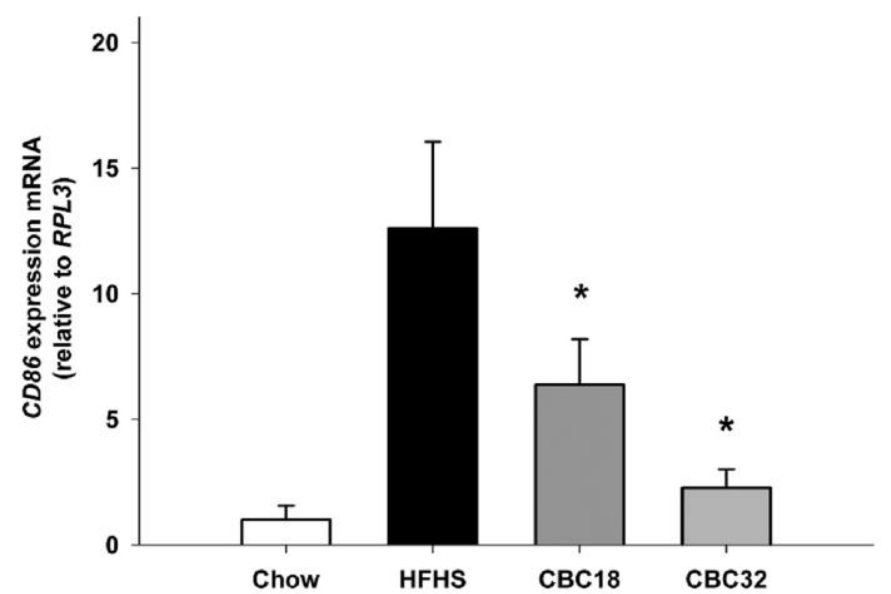

b
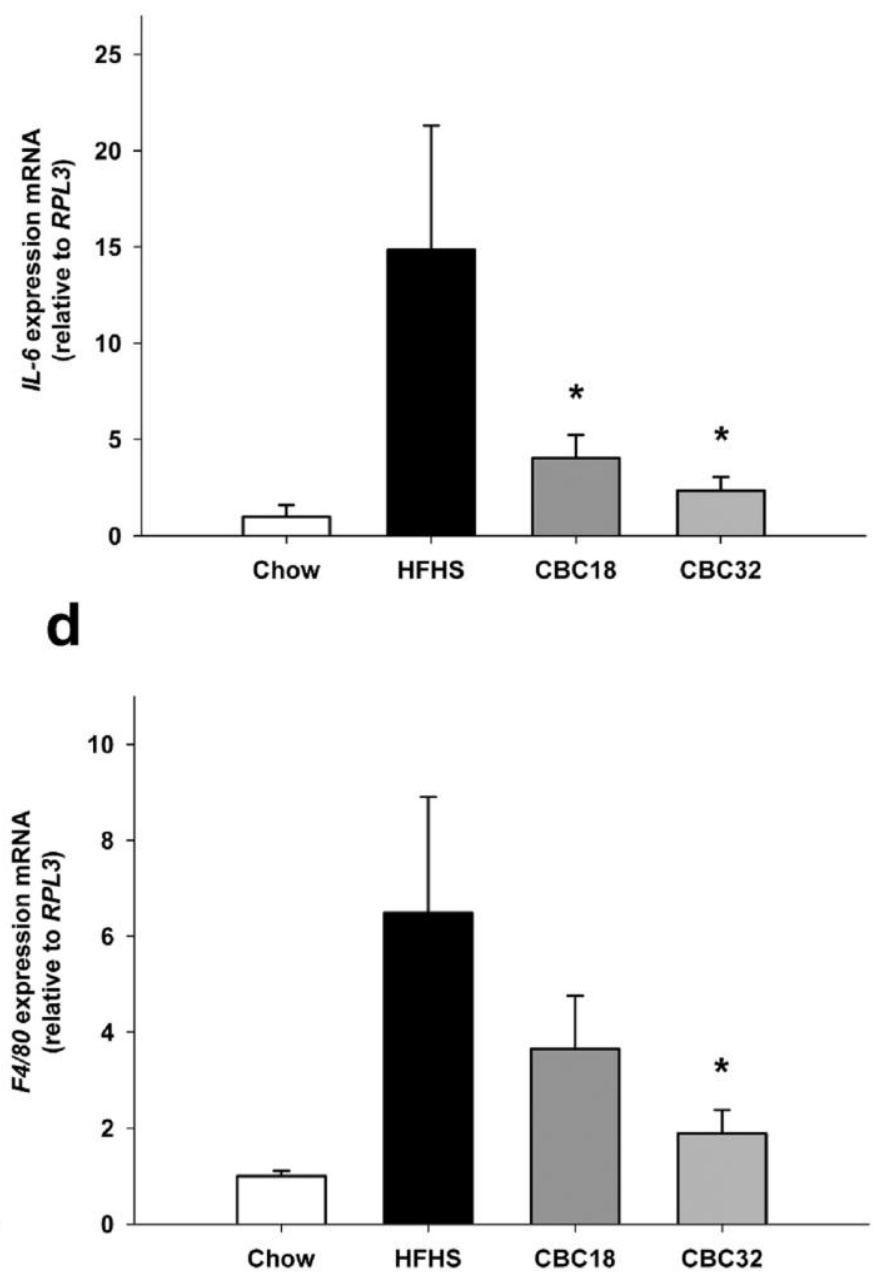

Figure 6 


\title{
4.3 Polyphenols from cagaita (Eugenia dysenterica DC.) improve glucose homeostasis and reduce hepatic inflammation in high-fat/high-sucrose-diet-induced obesity
}

\begin{abstract}
Polyphenol-rich cagaita (Eugenia dysenterica DC.) extracts (PCE) have been demonstrated to prevent body weight and fat mass gain induced by high-fat/high-sucrose (HFS) diet intake. Whether PCE also exerts protective effects in already developed obese mice is unknown. In order to test this hypothesis, male C57BL/6J obese mice induced by the intake of a HFS diet for six weeks were treated with PCE at two doses (PCE I and PCE II groups) or water (HFS and Chow groups) by oral gavage for further eight weeks. We found that PCE did not affect body weight, energy intake and absorption, and adiposity in obese mice when compared to the vehicle-treated HFS group. However, PCE protected against dyslipidemia and from the disarrangements in glucose metabolism as evidenced by the reduced fasting glycemia and improved glucose tolerance. These effects can be associated to attenuation in gluconeogenesis as evidenced by the lower expression of pyruvate carboxylase (PCX), and trend for a reduction in phosphoenolpyruvate carboxykinase (PEPCK) and glucose-6-phosphatase (G6Pase). PCE also decreased hepatic inflammation as evidenced by the reduced expression of pro-inflammatory cytokine tumor necrosis factor-alpha (TNF- $\alpha$ ) and reduced phosphorylated content of the pro-inflammatory transcriptional factor NF- $\kappa \mathrm{B}$. In conclusion, PCE improves glucose homeostasis in diet-induced obese mice by attenuating hepatic gluconeogenesis and inflammation.
\end{abstract}

Keywords: cagateira; Cerrado Brazilian; exotic fruit; Myrtaceae; phenolic compounds

\section{Introduction}

Polyphenols are plant-derived compounds widely known for their antioxidants properties and protective activity against oxidative stress and damage (Gorlach, Fichna, \& Lewandowska, 2015). Evidence suggests that dietary polyphenols exert anti-inflammatory and/or antioxidant effects in obesity-associated diseases. An important strategy to deal with obesity-associated complications is lowering oxidative stress and the levels of reactive oxygen 
species (ROS) (Wang et al., 2014). ROS is one of many factors that have been implicated in the development of insulin resistance as strongly supported by the extensive association among markers of oxidative stress along with obesity and diabetes (Houstis, Rosen, \& Lander, 2006). Therefore, polyphenols may have antiobesity and antidiabetic benefits due to their ability to act as an antioxidant and singlet oxygen quencher, therefore attenuating the deleterious effects of exacerbated ROS production, as well as, obesity-associated inflammation (Wang et al., 2014). Noteworthy, polyphenols exhibit far more biological activities than their antioxidative action (Gorlach et al., 2015), modulating different intracellular signaling cascades implicated in cell growth, proliferation and apoptosis (Crozier, Jaganath, \& Clifford, 2009).

The complexity of obesity and associated diseases present numerous challenges but also several opportunities for therapeutic intervention (Rosen \& Spiegelman, 2014). In this sense, plant-derived compounds including polyphenols have been shown, when consumed as a part of a regular and balanced diet, to exert beneficial effects against the development of obesity and associated abnormalities. These antioxidant, antiobesity, antidiabetic properties of polyphenols are being investigated by many pharmaceutical and food companies aiming the development of more effective concentrated extracts and the isolation of compounds with certain biological activity of interest (Granato, Alezandro, \& Nazzaro, 2015).

Tropical countries have a complex flora composed of a large amount of native and exotic fruit species, from which limited information about their biochemical and functional properties is available. The investigation of such properties may be of interest to the pharmaceutical and food industries (Costa, Garcia-Diaz, Jimenez, \& Silva, 2013). Cagaita (Eugenia dysenterica DC.) is a Brazilian Cerrado biome tree, whose fruit and leaves are used as alternative medicine by local communities to treat diarrhea, diabetes, and jaundice (Lima et al., 2011). Chemical characterization revealed that cagaita fruit is a source of vitamin $C$ and polyphenols such as ellagitannins, quercetin, and kaempferol (Cardoso, Martino, Moreira, Ribeiro, \& Pinheiro-Sant'Ana, 2011; Gonçalves, Lajolo, \& Genovese, 2010). Recently, we have shown that polyphenol-rich cagaita extract (PCE) contains high amounts of tannins such as ellagitannins and proanthocyanidins, as well as, low amounts of flavonoids such as quercetin and kaempferol derivatives, and phenolics acids such as ellagic acid. We also found that administration of PCE to male C57BL/6J mice protected from a high-fat/high-sucrose (HFS) induced obesity and associated abnormalities such as fasting hyperglycemia, hypertriglyceridemia, hypercholesterolemia, hepatic steatosis and oxidative stress (Donado- 
Pestana, Belchior, \& Genovese, 2015). In face of its robust effectiveness to prevent the development of diet-induced obesity and complications, we raised the question whether PCE could also be beneficial in an already developed obesity. To test this, diet-induced obese C57BL/6J mice were treated with PCE by oral gavage for 8 weeks and evaluated for body mass, adiposity, energy balance, lipolysis, glucose homeostasis, and hepatic inflammation.

\section{Materials and methods}

\subsection{Preparation of polyphenol-rich cagaita extracts (PCE)}

PCE was prepared as previously described (Donado-Pestana, Belchior, \& Genovese, 2015). Briefly, polyphenols were extracted from a commercial frozen pulp of cagaita purchased from a local producer (Urucuia ${ }^{\circledR}$, Central do Cerrado, Brasília DF, Brazil) by homogenization (1:20 w/v in dry weight) (Turratec TE-102, Tecnal) in $80 \%$ aqueous methanol, followed by centrifugation and filtration. The extraction process was repeated twice more, and then pooled filtrates were concentrated to remove methanol (Rotavapor R-210; Büchi, Switzerland). The polyphenol-rich extract was obtained adding the resulting aqueous extract onto a preconditioned $(100 \mathrm{~mL}$ of methanol, $150 \mathrm{~mL}$ of water) $\mathrm{LC}-18 \mathrm{SPE}$ tube $(10 \mathrm{~g}$ of LC-18 SPE, Supelclean ${ }^{\mathrm{TM}}$ LC-18, Supelco). After washing with water, polyphenols were eluted with $200 \mathrm{~mL}$ of methanol. The eluate was evaporated to dryness and the residue resuspended in $70 \mathrm{~mL}$ of water, for PCE I extract, or $35 \mathrm{~mL}$ of water, for PCE II extract.

\subsection{Animals and experimental design}

All animal procedures performed were previously approved by the Ethical Committee for Animal Research of the Faculty of Pharmaceutical Science of University of São Paulo (CEUA/FCF/378). Forty 8-week old male C57BL/6J mice of approximately $24 \mathrm{~g}$ were used in this study. The mice were matched by weight, housed in groups of 3 to 4 per cages, and kept at $22 \pm 1{ }^{\circ} \mathrm{C}$ under a 12 -hour light/12-hour dark cycle. The animals were then acclimated and fed a low-fat chow diet (NUVILAB CR-1 ${ }^{\circledR}$ Sogorb Inc., São Paulo, Brazil) and water ad libitum for one week to stabilize metabolic conditions prior to the study. After acclimation, mice were randomly divided into 2 dietary groups. One $(n=30)$ was fed with HFS diet, consisting of $19.4 \mathrm{~kJ} / \mathrm{g}$ of energy, of which, $41 \%$ was from sucrose, $20 \%$ from protein, and 
$39 \%$ from fat (soybean oil and lard 50:50), as previously described (Lemieux, Picard, Labrie, Richard, \& Deshaies, 2003) for 6 weeks. The other (chow healthy group, $n=10$ ) was fed a low-fat chow diet $(12.5 \mathrm{~kJ} / \mathrm{g}, 63 \%$ of calories from carbohydrate, $25 \%$ from protein, and $12 \%$ from fat) during the same time period.

Mice body weight was recorded weekly to ensure the development of obesity. After 6 weeks of HFS- or Chow-diets administration, the animals in the HFS group were randomly divided into three groups of ten mice each, as follows: 1) an HFS control fed group, that received a daily water administration by gavage (HFS group); 2) an HFS fed group, that received a daily administration of PCE by gavage ( $7 \mathrm{mg}$ gallic acid equivalent, GAE / $\mathrm{kg}$ body weight, PCE I group); and 3) an HFS fed group, that received a daily administration of PCE by gavage (14 mg GAE/kg body weight, PCE II group). The animals in the chow healthy group were kept on the low-fat diet through the experiment and received a daily water administration by gavage (Chow group). Diets and water were available ad libitum and administration of PCE or water was carried for eight weeks. Body weight and food intake were recorded every three days, and fasting blood glucose $(6 \mathrm{~h})$ was measured from the caudal vein weekly by using Accu-Chek Performa ${ }^{\circledR}$ (Roche, Mannheim, Germany). After 14 weeks, mice were anesthetized with isoflurane and immediately euthanized by decapitation. Blood was collected from the trunk and serum separated by centrifugation at $3000 \mathrm{~g}$ for 20 min at $4{ }^{\circ} \mathrm{C}$. Tissues including liver and gastrocnemius muscle, and adipose tissues (inguinal, retroperitoneal, epididymal, and brown) were removed, separated, weighed, and immediately frozen under liquid nitrogen and stored at $-80{ }^{\circ} \mathrm{C}$.

\subsection{Oral glucose tolerance test (OGTT)}

At the $13^{\text {th }}$ week, the mice were fasted for $6 \mathrm{~h}$ and an oral glucose tolerance test (OGTT) was performed after gavage with a glucose solution $(10 \%$ or $0.5 \mathrm{~g} / \mathrm{kg}$ body weight). The glucose concentration was determined in tail blood collected at the baseline (prior to gavage) and at 15, 30, 45, 60 and 90 min post-gavage, using the Accu-Chek Performa ${ }^{\circledR}$ glucometer (Roche, Mannheim, Germany). Blood samples (four mice per group) were collected at 0, 30, and $90 \mathrm{~min}$, and the serum separated by centrifugation at $3000 \mathrm{~g}$ for $20 \mathrm{~min}$ at $4{ }^{\circ} \mathrm{C}$ for insulin determination (Rat/Mouse Insulin ELISA Kit, Millipore, Missouri, USA). On the test day, animals were transferred to new cages to avoid their coprophagia habits that can interfere with 
the results. Additionally, PCE was administered by gavage $2 \mathrm{~h}$ prior the test in order to see possible biological effects of polyphenols.

\subsection{Oxygen consumption and respiratory exchange ratio $(R E R)$ determination}

Over the last week, animals (4 mice per group) were transferred to a Comprehensive Laboratory Monitoring System calorimeter (Oxymax Deluxe System, Columbus Instruments, Ohio), and adapted for one day before measuring oxygen consumption and respiratory exchange ratio (RER) by evaluating oxygen consumption/carbon dioxide production during $24 \mathrm{~h}$.

\subsection{Lipolysis and isolation from epididymal adipocytes}

For lipolysis, approximately $100 \mathrm{mg}$ of epididymal adipose tissue (6 mice per group) was collected at the time of euthanasia and incubated in Krebs-Ringer-phosphate buffer ( $\mathrm{pH} 7.4$ ) for $10 \mathrm{~min}$ at $37{ }^{\circ} \mathrm{C}$ containing $5.5 \mathrm{mM}$ glucose and $2 \%$ fatty acid-free albumin (SigmaAldrich, St. Louis, USA) in the absence or presence of isoproterenol, for basal or stimulated conditions, respectively. The reaction was stopped on ice, and medium was carefully collected for measurement of glycerol release using Free Glycerol Determination Kit (Sigma-Aldrich, St. Louis, USA). Adipocyte diameter was measured as described previously (Belchior et al., 2015). Briefly, tissue (approximately $150 \mathrm{mg}$ ) was incubated and digested with collagenase type II (1 mg/mL, Sigma-Aldrich) in Krebs-Hepes buffer containing BSA (1\%) and glucose (2 $\mathrm{mmol} / \mathrm{L}$ ), $\mathrm{pH} 7.4$ at $37^{\circ} \mathrm{C}$. Cell suspension was separated by centrifugation at $600 \mathrm{~g}$ for 10 min. The floating mature adipocytes were collected and photographed (magnification of 40x) using a microscope camera (Moticam 1000, Motic, Richmond, Canada) and mean adipocyte diameter was determined by measuring 100 cells using the software Motic-Images Plus 2.0.

\subsection{Serum biochemical parameters}

The serum samples were analyzed for glucose, triacylglycerol (TAG), total cholesterol (TC), HDL-cholesterol (HDL-C), and non-esterified fatty acid (NEFA) levels using commercial kits (Labtest, MG, Brazil; Wako Diagnostic, VA, USA). The levels of LDLcholesterol were estimated calculating the Friedewald formula as: LDL-C $=$ TG - HDL-C - 
(TAG/5) (Friedewald, Levy, \& Fredrickson, 1972). Serum antioxidant capacity was measured by oxygen radical absorbance capacity (ORAC) (Dávalos et al., 2004) and ferric reducing ability of serum (FRAP) assays (Benzie \& Strain, 1996). Both methods were performed on a Synergy H1 Hybrid Multi-Mode microplate reader (BioTek Instruments, Winooski, VT). The antioxidant capacity was calculated from a standard curve made with known concentrations of Trolox (6-hydroxy-2,5,7,8-tetramethylchroman-2-carboxylic acid; Sigma Chemical Co., St. Louis, MO, USA) and expressed in terms of $\mu \mathrm{mol}$ Trolox equivalent per $\mathrm{mL}$ of serum for both assays.

\subsection{Fecal energy determination}

Feces collected from the cages at the last 3 days of protocol were pooled per group and dried in an oven $\left(50{ }^{\circ} \mathrm{C}\right)$ for $36 \mathrm{~h}$. Feces were ground to a uniform fine powder using a mortar and pestle and stored at $-20{ }^{\circ} \mathrm{C}$ until analysis. A representative sample of 0.8 to $1.0 \mathrm{~g}$ of the dried material was analyzed to determine the energy content using a bomb calorimeter (Model 1341, Parr Instrument Company, IL, USA).

\subsection{Gene expression analysis by quantitative PCR}

RNA purification, reverse transcription, and quantification by real-time PCR were performed as previously described (Festuccia et al., 2008) with some modifications. RNA was extracted from liver (five to six animals per group) using TRIzol ${ }^{\circledR}$ reagent (Invitrogen) following supplier's recommendations. RNA content was determined on a NanoDrop spectrophotometer (Thermo Scientific, Wilmington, USA). RNA samples were stored at -80 ${ }^{\circ} \mathrm{C}$ until use for synthesis of cDNA and real-time PCR. Primers used for the PCR reactions are listed in Table 1. Results were expressed as the ratio between the expression of the target gene and the housekeeping gene RPL19, the expression of which was not significantly affected by the administration of PCE.

\subsection{Protein analysis by immunoblotting}

Liver ( $80 \mathrm{mg})$ was homogenized (T10, Ultra-Turrax®) in buffer $(0.5 \mathrm{~mL})$ containing 50 mM HEPES, $40 \mathrm{mM} \mathrm{NaCl},, 50 \mathrm{mM} \mathrm{NaF}, 2 \mathrm{mM}$ EDTA, $10 \mathrm{mM}$ sodium pyrophosphate, 10 
$\mathrm{mM}$ sodium glycerophosphate, $2 \mathrm{mM}$ sodium orthovanadate, $1 \%$ Triton-X 100, and EDTAfree protease inhibitors and centrifuged at $15,000 \mathrm{~g}$ for $10 \mathrm{~min}$ at $4{ }^{\circ} \mathrm{C}$. Protein content of the supernatant was determined by Pierce BCA Protein Assay Kit (Thermo Scientific, Rockford, USA). Next, proteins were denatured by boiling in Laemmli buffer, separated on SDS-PAGE gel $(12 \%)$ and transferred to PVDF membrane. Membranes were incubated with primary

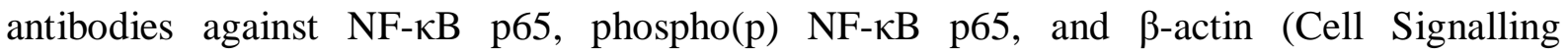
Technology, Beverly, USA) diluted 1:1000 in 5\% milk. Next, membranes were washed, incubated with peroxidase-conjugated secondary antibody $(1: 10,000)$ and revealed with enhanced chemiluminescence (ECL) substrate (GE Healtcare). Densitometry of bands was determined using Image $\mathbf{J}$ software (National Institutes of Health, USA).

\subsection{Statistical analysis}

Results are presented as mean \pm SEM. The effects of PCE on the studied parameters were analyzed using a one-way (treatment) analysis of variance (ANOVA). Significant effects were analyzed using Dunnett's test with HFS group as control group (statistical significance was determined at $p<0.05)$. The Chow group was included only as a reference and was not included in the statistical analysis. The statistical analysis and figures were performed using the SAS 9.3 package (SAS Institute, Inc., Cary, USA) and GraphPad Prism (GP Prism, San Diego, USA).

\section{Results}

3.1 Body weight, RER, oxygen consumption, energy intake and excretion, adiposity, adipocyte diameter, and lipolysis

As expected, during the initial 6-week period HFS-fed mice developed obesity as evidenced by the marked increase in body weight when compared to chow-fed mice. PCE administration to obese mice for 8 weeks did not affect body weight gain (Fig. 1a) and energy intake (Fig. 1b), but promoted the oxidation of carbohydrates as evidenced by the significantly increased respiratory exchange ratio (RER, Fig. 1c) in comparison to the HFS group. In addition to RER, PCE I, but not PCE II, administration increased mice oxygen consumption, which is suggestive of increased energy expenditure (Fig 1d). Finally, no 
differences were observed in fecal energy excretion between lean and obese mice, receiving PCE or not (Fig 1e).

Similar to body weight, adiposity, evaluated by the masses of several adipose depots, along liver and gastrocnemius muscle weights were not significantly influenced by PCE treatment (Table 2). Nevertheless, we found in both PCE groups slightly lower average values of adipose tissue masses ( $p=0.10$, for epididymal and total adiposity) when compared to the HFS group. As depicted in Fig. 1f, there was no clear evidence of the involvement of PCE in the increase of both basal and stimulated lipolysis evaluated by the glycerol release in epididymal adipocytes. However, mice receiving PCE exhibited a reduction in the size of the adipocyte when compared to the HFS group (Fig. 1g).

\subsection{Serum biochemical profile}

PCE markedly attenuated obesity-associated fasting hyperglycemia (Fig. 2a) and dyslipidemia as evidenced by the reduction in the hypercholesterolemia and hypertriacylglyceridemia (Figs. 2b-c). In addition, PCE at the lower dose reduced serum NEFA and LDL-cholesterol levels (Fig. 2d-f). Administration of PCE, however, did not significantly affect HDL-cholesterol levels and serum antioxidant status as evaluated by ORAC and FRAP assays (Figs. 2g-h).

\subsection{Glucose homeostasis}

As expected, obese mice displayed fasting hyperglycemia, such a phenotype that was significantly attenuated by treatment with PCE (Fig. 3a). These data demonstrate that PCE attenuated fasting hyperglycemia linked to HFS-diet intake even in obese mice, as observed by the reduction $(p<0.0001)$ in the area under the mean blood glucose curve in both doses studied (Fig. 3b). In accordance fasting glycemia, PCE attenuated obese-associated glucose intolerance as evidenced by the reduction of lower glucose excursion and area under the curve in a glucose tolerance test (Figs. 3c-d). The enhanced glucose tolerance featured by mice treated with PCE was accompanied by a reduction in plasma insulin to levels found in lean chow-fed mice (Figs. 3e-f).

We next investigated whether PCE improves glucose homeostasis by modulating hepatic glucose production through gluconeogenesis. For this, mRNA levels of enzymes key 
gluconeogenic enzymes phosphoenolpyruvate carboxykinase (PEPCK), glucose-6phosphatase (G6Pase), and pyruvate carboxylase (PCX) were evaluated. There was a significant reduction $(p<0.05)$ in the mRNA expression of PCX and a trend for PEPCK in the animals receiving PCE ( $p=0.08$; PCE I vs. HFS). However, no significant difference induced by PCE was observed in the mRNA levels of G6Pase (Figs. 3g-i).

\subsection{Hepatic inflammatory response}

We next evaluated whether PCE administration affects hepatic inflammatory status in obese mice. PCE attenuated liver inflammation by reducing the mRNA expression of TNF- $\alpha$ $(p<0.05)$, one of the major stress-induced pro-inflammatory cytokines (Fig. 4a). IL1- $\beta$, other type of pro-inflammatory cytokine associated to insulin resistance, was not significantly changed by administration of PCE. However, a non-significant decrease was observed in the PCE groups when compared to HFS group (Fig. 4b). Furthermore, the expression of makers for total (F4/80) and classically active macrophages M1 (CD86) were decreased by PCE, but these effects were weak and not significant between HFS and PCE groups (Figs. 4c-d). Additionally, to test the modulation of pro-inflammatory transcriptional factor by PCE,

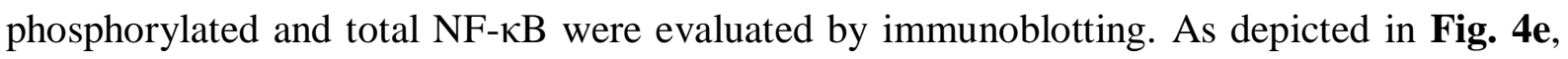
PCE induced a significant reduction in phosphorylation of NF- $\mathrm{B}$ in PCE II when compared to the HFS group.

\section{Discussion}

Bioactive compounds from plants such as polyphenols have been shown potential to reverse or prevent obesity and related metabolic disorders such as diabetes mellitus and cardiovascular disease (Burton-Freeman, Sandhu, \& Edirisinghe, 2016). Recently, we have shown that PCE prevents the development of diet-induced obesity and associated abnormalities in mice (Donado-Pestana, Belchior, \& Genovese, 2015). Herein, we show that administration of PCE to obese mice improves glucose homeostasis, attenuates dyslipidemia and reduces hepatic inflammation without affecting mice body weight and adiposity.

Unexpectedly in face of our previous report that PCE prevents the development of dietinduced obesity, administration of PCE to obese mice did not affect body weight or adiposity. Our findings, however, demonstrate that PCE increased mice oxygen consumption without 
affecting food intake and intestinal energy absorption, this indicates that perhaps a longer treatment period is required for the translation of increased energy expenditure into a reduced body weight and adiposity. Noteworthy, such mild, non-significant effects of PCE on body weight and adiposity may also be due to the content of polyphenols administrated in the current study (7 and $14 \mathrm{mg}$ of polyphenols expressed as gallic acid equivalent, data not shown) per $\mathrm{kg}$ body weight which are equivalent to a human dose (70 kg) of 34 and $68 \mathrm{mg}$ of polyphenols per day, respectively (FDA, 2005), such values that are below the average dietary intake of polyphenols in Western diets (1 g/day) (Scalbert \& Williamson, 2000). In accordance with the present study, polyphenol-rich extract of tea was also effective to prevent but not reverse body weight gain in C57BL/6J obese mice fed a high-fat diet (Fan et al., 2012).

Similarly to body weight, PCE administration to obese mice did not affect intestinal energy absorption as evaluated by fecal energy excretion indicating that PCE in vivo, is not as efficient in obesity model as in vitro to inhibit the activity of carbohydrate-hydrolyzing and pancreatic lipase enzymes (Gonçalves et al., 2010; Donado-Pestana, Belchior, \& Genovese, 2015).

In spite of the absence of effects on body weight and adiposity, PCE markedly improved glucose homeostasis in obese mice as evidenced by the increased carbohydrate utilization as fuel substrate evaluated by RER, reduced fasting glycemia and improved glucose tolerance as evaluated by OGTT. These findings not only extend our previous results showing that PCE prevents the development of diet-induced hyperglycemia (Donado-Pestana, Belchior, \& Genovese, 2015), but also indicate that PCE beneficial actions on glucose homeostasis are not secondary to changes in body weight and adiposity. Although the mechanisms by which PCE improves glucose homeostasis are still unknown, we found some evidences that this extract may act, at least in part, via a reduction in hepatic glucose production through gluconeogenesis. Indeed, PCE decreased hepatic mRNA levels of key gluconeogenic enzyme PCX, and tended to reduce those of PEPCK and G6Pase. Further studies are required to evaluate the contribution of hepatic glucose production and peripheral hexose utilization in the improvement of glucose homeostasis induced by PCE.

Gluconeogenesis is inappropriately active and elevated in type 2 diabetes mainly due to the hepatic resistance to the inhibitory actions of insulin upon this process (Puigserver et al., 2003), majorly contributing therefore to the disarrangements in glucose homeostasis seen in this condition. Using HepG2 cells, Cordero-Hererra et al., (2013) demonstrated that cocoa 
flavonoids, which constitute an important group of polyphenols, reduce the expression of PEPCK, inhibiting gluconeogenesis and consequently hepatic glucose production. In addition, polyphenols from cinnamon and persimmon (Diospyros kaki) leaves were also effective in decreasing G6Pase and PEPCK activities and gluconeogenesis in the liver of type 2 diabetic mice and H4IIE rat hepatoma cells (Cheng et al., 2012; Jung, Park, Kim, \& Choi, 2012). Finally, an aqueous extract of Moringa oleifera leaves possesses hypoglycemic effects that were attributed to a reduction in hepatic pyruvate carboxylase activity (El Latif, El Bialy, Mahboub, \& Eldaim, 2014). Altogether these findings indicate that some classes of polyphenols may hold potential as inhibitors of gluconeogenesis and hepatic glucose production in conditions of insulin resistance.

Obesity is commonly associated with a chronic, low-grade inflammatory process that affects major metabolic tissues and has been implicated in the development of insulin resistance (Itoh, Suganami, Hachiya, \& Ogawa, 2011). Indeed, activation of canonic proinflammatory toll like receptor-IKK-NFkB signaling pathway by either saturated fatty acids or lipopolysaccharide from the gut microbiota has been linked to obesity-associated insulin resistance. In accordance with the improvement on glucose homeostasis, PCE attenuated diet-induced hepatic proinflammatory response as evidenced by the reduction in the mRNA levels $(p<0.05)$ of tumor necrosis factor-alpha (TNF- $\alpha)$ and to a lesser extent (non-significant) of interleukin1- $\beta$ (IL1- $\beta$ ) and macrophage-specific markers (F4/80 and CD86). We demonstrated in a previous study that polyphenols from cambuci, a Brazilian native fruit (belonging to the same Myrtaceae family) also attenuated the HFS-induced proinflammatory response by reducing adipose tissue macrophage infiltration and polarization and mRNA levels of proinflammatory cytokines (Donado-Pestana, Belchior, Festuccia, \& Genovese, 2015).

Liver has one of the largest populations of resident macrophages known as Kupffer cells that produce various inflammatory mediators including cytokines (TNF- $\alpha$, IL1- $\beta$ ), prostaglandins and reactive oxygen species that could be involved in the development of hepatic insulin resistance upon obesity (Neyrinck et al., 2009; Tan et al., 2016). Therefore it is reasonable to hypothesize that the improvement in glucose homeostasis and other metabolic parameters induced by PCE may be due, at least in part, to an attenuation of hepatic inflammation. Indeed PCE administration markedly reduced the phosphorylated content of the proinflammatory transcriptional factor $\mathrm{NF \kappa B}$ that regulates the expression of some cytokines such as TNF- $\alpha$. Phosphorylation of NFkB p65 at Ser536, which was measured herein, is a 
step required for the initiation and optimal transcription of $\mathrm{NF \kappa B}$ target genes, being therefore considered as an indicative of NFKB activation

Although the mechanism by which PCE reduces NFאB activity is unknown, it may involve the direct interaction of PCE to NFאB preventing its binding to the DNA (Mackenzie, Delfino, Keen, Fraga, \& Oteiza, 2009; Fraga, Galleano, Verstraeten, \& Oteiza, 2010). B-type dimeric procyanidins (for example, B1 and B2) that are detected in serum after intake of proanthocyanidin-rich fruit extracts such as cagaita (Sano et al., 2003), inhibit NFkB-DNA binding both in isolated nuclear fractions and in purified p50 and Rel A proteins (Mackenzie et al., 2009; Fraga et al., 2010). Other potential mechanisms for anti-inflammatory actions of PCE include the polyphenols' ability to suppress the activation of extracellular signal-related kinase (ERK), c-Jun- $\mathrm{NH}_{2}$ terminal kinase (JNK), or peroxisome proliferator-activated receptor $\gamma(\operatorname{PPAR} \gamma)$ as observed previously for quercetin (polyphenol also present in cagaita) and resveratrol (Chuang et al., 2010), but these mechanisms need to be further explored in cagaita polyphenols.

\section{Conclusion}

In conclusion, our findings indicate that PCE improves glucose homeostasis and attenuates dyslipidemia in obese mice, without affecting body weight and adiposity. Mechanistically, these PCE beneficial actions seem to be mediated, at least in part, through a reduction in hepatic inflammation. These findings raised the notion that cagaita polyphenols have interesting functional properties to both prevent and treat obesity and associated diseases. Further studies unraveling PCE bioavailability, actions upon gut microbiota and efficacy in humans should be performed to deepen our knowledge about possible usage of PCE in the management of metabolic diseases.

\section{Acknowledgments}

The authors thank São Paulo Research Foundation (FAPESP 2013/19797-6) and Coordenação de Aperfeiçoamento de Pessoal de Nível Superior (CAPES/PEC-PG 5554-11-0) for the financial support. 


\section{References}

Belchior, T., Paschoal, V. A., Magdalon, J., Chimin, P., Farias, T. M., Chaves-Filho, A. B., \& Festuccia, W. (2015). Omega-3 fatty acids protect from diet-induced obesity, glucose intolerance, and adipose tissue inflammation through PPAR $\gamma$-dependent and PPAR $\gamma$ independent actions. Molecular Nutrition and Food Research, 59(5), 957-967.

Benzie, I.F.F., \& Strain, J.J. (1996). The ferric reducing ability of plasma (FRAP) as a measure of "'antioxidant power": The FRAP assay. Analytical Biochemistry, 239(1), 7076.

Burton-Freeman, B. M., Sandhu, A. K., \& Edirisinghe, I. (2016). Red raspberries and their bioactive polyphenols: cardiometabolic and neuronal health links. Advances in Nutrition: An International Review Journal, 7(1), 44-65.

Cardoso, L. de M., Martino, H. S. D., Moreira, A. V. B., Ribeiro, S. M. R., \& PinheiroSant'Ana, H. M. (2011). Cagaita (Eugenia dysenterica DC.) of the Cerrado of Minas Gerais, Brazil: Physical and chemical characterization, carotenoids and vitamins. Food Research International, 44(7), 2151-2154.

Cheng, D. M., Kuhn, P., Poulev, A., Rojo, L. E., Lila, M. A., \& Raskin, I. (2012). In vivo and in vitro antidiabetic effects of aqueous cinnamon extract and cinnamon polyphenolenhanced food matrix. Food Chemistry, 135(4), 2994-3002.

Chuang, C., Martinez, K., Xie, G., Kennedy, A., Bumrungpert, A., Overman, A., \& Mcintosh, M. K. (2010). Quercetin is equally or more effective than resveratrol in attenuating tumor necrosis factor- $\alpha-$ mediated inflammation and insulin resistance in primary human adipocytes. American Journal of Clinical Nutrition, 92(6), 1511-1521.

Cordero-Herrera, I., Martín, M. A., Bravo, L., Goya, L., \& Ramos, S. (2013). Cocoa flavonoids improve insulin signalling and modulate glucose production via AKT and AMPK in HepG2 cells. Molecular Nutrition and Food Research, 57(6), 974-985.

Costa, A. G. V., Garcia-Diaz, D. F., Jimenez, P., \& Silva, P. I. (2013). Bioactive compounds and health benefits of exotic tropical red-black berries. Journal of Functional Foods, 5(2), 539-549.

Crozier, A., Jaganath, I. B., \& Clifford, M. N. (2009). Dietary phenolics: chemistry, bioavailability and effects on health. Natural Product Reports, 26(8), 1001-1043.

Dávalos, A., Gómez-Cordovés, C., \& Bartolomé, B. (2004). Extending applicability of the oxygen radical absorbance capacity (ORAC-fluorescein) assay. Journal of Agricultural 
and Food Chemistry, 52(1), 48-54.

Donado-Pestana, C. M., Belchior, T., Festuccia, W. T., \& Genovese, M. I. (2015). Phenolic compounds from cambuci (Campomanesia phaea O. Berg) fruit attenuate glucose intolerance and adipose tissue inflammation induced by a high-fat, high-sucrose diet. Food Research International, 69, 170-178.

Donado-Pestana, C. M., Belchior, T., \& Genovese, M. I. (2015). Phenolic compounds from cagaita (Eugenia dysenterica DC.) fruit prevent body weight and fat mass gain induced by a high-fat, high-sucrose diet. Food Research International, 77, 177-185.

El Latif, A., El Bialy, B. E. S., Mahboub, H. D., \& Abd Eldaim, M. A. (2014). Moringa oleifera leaf extract ameliorates alloxan-induced diabetes in rats by regeneration of $\beta$ cells and reduction of pyruvate carboxylase expression. Biochemistry and Cell Biology, 92(5), 413-9.

Fan, S., Zhang, Y., Hu, N., Sun, Q., Ding, X., Li, G., \& Ji, G. (2012). Extract of kuding tea prevents high-fat diet-induced metabolic disorders in C57BL/6 mice via liver $\mathrm{X}$ receptor (LXR) $\beta$ Antagonism. PLoS ONE, 7(12), e51007.

Festuccia, W.T., Oztezcan, S., Laplante, M., Berthiaume, M., Michel, C., Dohgu, S., et al. (2008). Peroxisome proliferator-activated receptor- $\gamma$-mediated positive energy balance in the rat is associated with reduced sympathetic drive to adipose tissues and thyroid status. Endocrinology, 149(5), 2121-2130.

Fraga, C. G., Galleano, M., Verstraeten, S. V., \& Oteiza, P. I. (2010). Basic biochemical mechanisms behind the health benefits of polyphenols. Molecular Aspects of Medicine, $31(6), 435-445$.

Lima, T. B., Silva, O. N., Silva, L. P., Rocha, T. L., Grossi-De-Sá, M. F., Franco, O. L., \& Leonardecz, E. (2011). In vivo effects of cagaita (Eugenia dysenterica, DC.) leaf extracts on diarrhea treatment. Evidence-Based Complementary and Alternative Medicine, 2011, ID309390

Friedewald, W. T., Levy, R. I., \& Fredrickson, D. S. (1972). Estimation of the concentration of low-density lipoprotein cholesterol in plasma, without use of the preparative ultracentrifuge. Clinical Chemistry, 18(6), 499-502.

Gonçalves, de S. S. A. E., Lajolo, F. M., \& Genovese, M. I. (2010). Chemical composition and antioxidant/antidiabetic potential of brazilian native fruits and commercial frozen pulps. Journal of Agricultural and Food Chemistry, 58(8), 4666-4674.

Gorlach, S., Fichna, J., \& Lewandowska, U. (2015). Polyphenols as mitochondria-targeted 
anticancer drugs. Cancer Letters, 366(2), 141-149.

Granato, D., Alezandro, M. R., \& Nazzaro, F. (2015). Food bioactive compounds: Quality control and functional properties. Food Research International, 77, 73-74.

Houstis, N., Rosen, E. D., \& Lander, E. S. (2006). Reactive oxygen species have a causal role in multiple forms of insulin resistance. Nature, 440(7086), 944-948.

Itoh, M., Suganami, T., Hachiya, R., \& Ogawa, Y. (2011). Adipose tissue remodeling as homeostatic inflammation. International Journal of Inflammation, 2011, 720926.

Jung, U. J., Park, Y. B., Kim, S. R., \& Choi, M. S. (2012). Supplementation of persimmon leaf ameliorates hyperglycemia, dyslipidemia and hepatic fat accumulation in type 2 diabetic mice. PLoS ONE, 7(11), 1-10.

Lemieux, C., Picard, F., Labrie, F., Richard, D., \& Deshaies, Y. (2003). The estrogen antagonist EM-652 and dehydroepiandrosterone prevent diet- and ovariectomy-induced obesity. Obesity Research, 11(3), 477-490.

Mackenzie, G. G., Delfino, J. M., Keen, C. L., Fraga, C. G., \& Oteiza, P. I. (2009). Dimeric procyanidins are inhibitors of NF-кB-DNA binding. Biochemical Pharmacology, 78(9), $1252-1262$.

Neyrinck, A. M., Cani, P. D., Dewulf, E. M., De Backer, F., Bindels, L. B., \& Delzenne, N. M. (2009). Critical role of Kupffer cells in the management of diet-induced diabetes and obesity. Biochemical and Biophysical Research Communications, 385(3), 351-356.

Puigserver, P., Rhee, J., Donovan, J., Kitamura, Y., Altomonte, J., \& Dong, H. (2003). Insulin-regulated hepatic gluconeogenesis through FOXO1 - PGC-1 a interaction. Nature, 423, 550-555.

Rosen, E. D., \& Spiegelman, B. M. (2014). What we talk about when we talk about fat. Cell, 156(1-2), 20-44.

Sano, A., Yamakoshi, J., Tokutake, S., Tobe, K., Kubota, Y., \& Kikuchi, M. (2003). Procyanidin B1 is detected in human serum after intake of proanthocyanidin-rich grape seed extract. Bioscience, Biotechnology, and Biochemistry, 67(5), 1140-1143.

Scalbert, A., \& Williamson, G. (2000). Dietary intake and bioavailability of polyphenols. The Journal of Nutrition, 130, 2073S-2085S.

Tan, Q., Hu, J., Yu, X., Guan, W., Lu, H., Yu, Y., \& Tang, Z. (2016). The role of IL-1 family members and Kupffer cells in liver regeneration, Biomed Research International, ID64957932.

FDA, Food and Drug Administration, US (2005). Guidance for Industry - Estimating the 
maximum safe starting dose in initial clinical trials for therapeutics in adult healthy volunteers. US Department of Health and Human Services, Food and Drug Administration, Center for Drug Evaluation and Research, (July), 1-30.

Wang, S., Moustaid-Moussa, N., Chen, L., Mo, H., Shastri, A., Su, R., \& Shen, C. L. (2014). Novel insights of dietary polyphenols and obesity. Journal of Nutritional Biochemistry, 25(1), 1-18. 


\section{Figure captions}

Fig. 1. Body weight (a), energy intake (b), respiratory exchange rate (RER) (c), $\mathrm{O}_{2}$ consumption (d), fecal energy excretion (e), basal and isoproterenol-stimulated rates of glycerol release (f), and epididymal adipocyte diameter (magnification of 40x) (g) of obese mice fed on high-fat/high-sucrose or chow diets and receiving water (Chow and HFS groups) or polyphenol-rich cagaita extracts at two doses (PCE I and PCE II) by gavage. Data are mean \pm SEM $(n=9-10)$. Data for energy intake is reported as the food consumed for the 8 -wk experiment from group cages $(n=3)$. Data for RER and $\mathrm{O}_{2}$ are values obtained during $24 \mathrm{~h}$ from 4 mice in each treatment $(n=96)$. Data for fecal energy are values mean \pm SEM from pooled samples collected on the last week of experimental period $(n=3)$. Data for adipocyte diameter and lipolysis are mean $\pm \operatorname{SEM}(n=6) . *(p<0.05)$ vs. HFS.

Fig. 2. Serum biochemical profile of obese mice fed on high-fat/high-sucrose or chow diets and receiving water (Chow and HFS groups) or polyphenol-rich cagaita extracts at two doses (PCE I and PCE II) by gavage. Data are mean \pm SEM $(n=9-10) . *(p<0.05)$ vs. HFS.

Fig. 3. Weekly variation of fasting blood glucose (6 h) (a), glucose area-under-the-curve (AUC) (b), blood glucose (c), glucose-AUC (d), serum insulin (e) and insulin-AUC (f) during oral glucose tolerance test; and hepatic mRNA expression of pyruvate carboxylase (g), phosphoenolpyruvate carboxykinase (PEPCK) (h), and glucose-6-phosphatase (G6Pase) (i) of obese mice fed on high-fat/high-sucrose or chow diets and receiving water (Chow and HFS groups) or polyphenol-rich cagaita extracts at two doses (PCE I and PCE II) by gavage. Data for blood glucose are mean $\pm \operatorname{SEM}(n=10)$. Data for serum insulin are mean $\pm \operatorname{SEM}(n=4)$. Data for mRNA expression are mean $\pm \operatorname{SEM}(n=5-6) \phi(p<0.05)$ PCE I vs. HFS, $\phi \phi(p<$ $0.05)$ PCE I and PCE II vs. HFS, $* * *(p<0.0001)$ vs. HFS, $*(p<0.05)$ vs. HFS.

Fig. 4. Hepatic mRNA expression of TNF- $\alpha$ (a), IL1- $\beta$ (b), F4/80 (c), CD86 (d), representative immunoblots of phosphorylated NF- $\kappa B(p$ NF- $\kappa B)$, total NF- $\kappa B$, and $\beta$-actin,

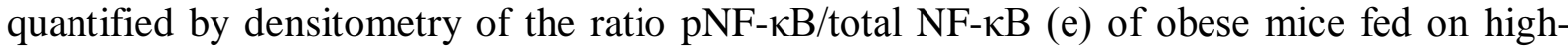
fat/high-sucrose or chow diets and receiving water (Chow and HFS groups) or polyphenolrich cagaita extracts at two doses (PCE I and PCE II) by gavage. Data are mean \pm SEM $(n=$ $5-6) *(p<0.05)$ vs. HFS. 
Table 1. Primer sequences for real-time PCR.

\begin{tabular}{|c|c|c|}
\hline Primer name $^{1}$ & Forward & Reverse \\
\hline PCX & CCCTTTCGCTCTAAGGTGCTAA & CCGAAGGTAGCCGTGAAGTC \\
\hline PEPCK & ACAACTGTTGGCTGGCTCTC & GGGCACTGTGTCTCTCTGCT \\
\hline G6Pase & CGTATGGATTCCGGTGTTTTG & GGGAAAGTGAGCAGCAAGGT \\
\hline TNF- $\alpha$ & AGCCCACGTCGTAGCAAACCA & GCAGGGGCTCTTGACGGCAG \\
\hline IL1- $\beta$ & GCCACCTTTTGACAGTGATGAG & TGATGTGCTGCTGCGAGATT \\
\hline $\mathrm{F} 4 / 80$ & GCCACGGGGCTATGGGATGC & TCCCGTACCTGACGGTTGAGCA \\
\hline CD86 & CCCAGCAACACAGCCTCTAA & ACTCTGCATTTGGTTTTGCTGA \\
\hline RPL19 & АСССТТССТСТTСССТАТGC & AGCCTGTGACTGTCCATT \\
\hline
\end{tabular}

${ }^{1} \mathrm{PCX}$, pyruvate carboxylase; PEPCK, phosphoenolpyruvate carboxykinase; G6Pase, glucose-6-phosphatase; TNF- $\alpha$, tumor necrosis factor-alpha; IL1- $\beta$, interleukin1-beta; F4/80 EGF-like module containing, mucin-like, hormone receptor-like sequence 1; CD86; CD86 antigen; RPL19, ribosomal protein L19.

Table 2. Organ weights of obese mice fed on high-fat/high-sucrose or chow diets and receiving water (Chow and HFS groups) or polyphenol-rich cagaita extracts at two doses (PCE I and PCE II) by gavage.

\begin{tabular}{lccccc}
\hline Tissue weight $(\mathrm{mg})$ & Chow & HFS & PCE I & PCE II & $P$-value \\
\hline Retroperitoneal A. T. & $137 \pm 46$ & $679 \pm 26$ & $590 \pm 53$ & $673 \pm 22$ & 0.17 \\
Epididymal A. T. & $354 \pm 40$ & $1938 \pm 56$ & $1604 \pm 169$ & $1906 \pm 94$ & 0.10 \\
Inguinal A. T. & $221 \pm 27$ & $1542 \pm 85$ & $1205 \pm 186$ & $1350 \pm 109$ & 0.22 \\
Brown A. T. & $75 \pm 7$ & $210 \pm 20$ & $166 \pm 17$ & $172 \pm 12$ & 0.14 \\
Total adiposity & $886 \pm 182$ & $4369 \pm 118$ & $3566 \pm 393$ & $4101 \pm 196$ & 0.10 \\
Liver & $1292 \pm 54$ & $1409 \pm 90$ & $1290 \pm 90$ & $1286 \pm 49$ & 0.46 \\
Gastrocnemius muscle & $154 \pm 5$ & $155 \pm 3$ & $149 \pm 5$ & $153 \pm 3$ & 0.53 \\
\hline
\end{tabular}

Results are expressed as mean \pm SEM values ( $n=10$ per group)

A. T., adipose tissue 
a
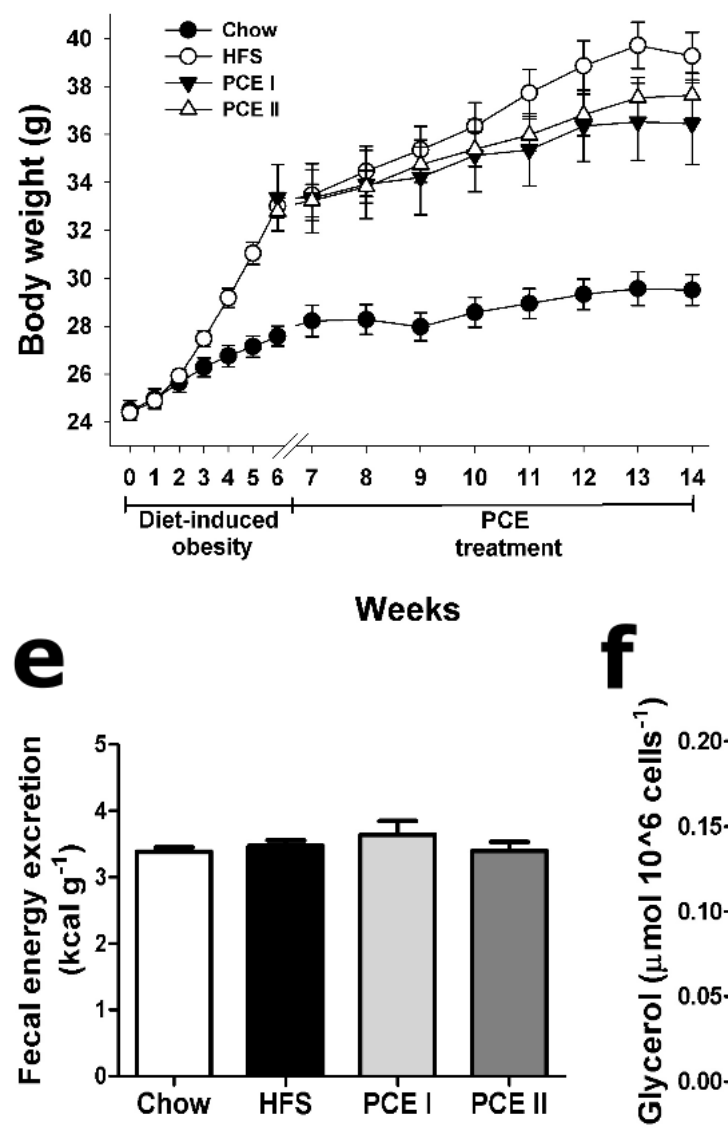

f b
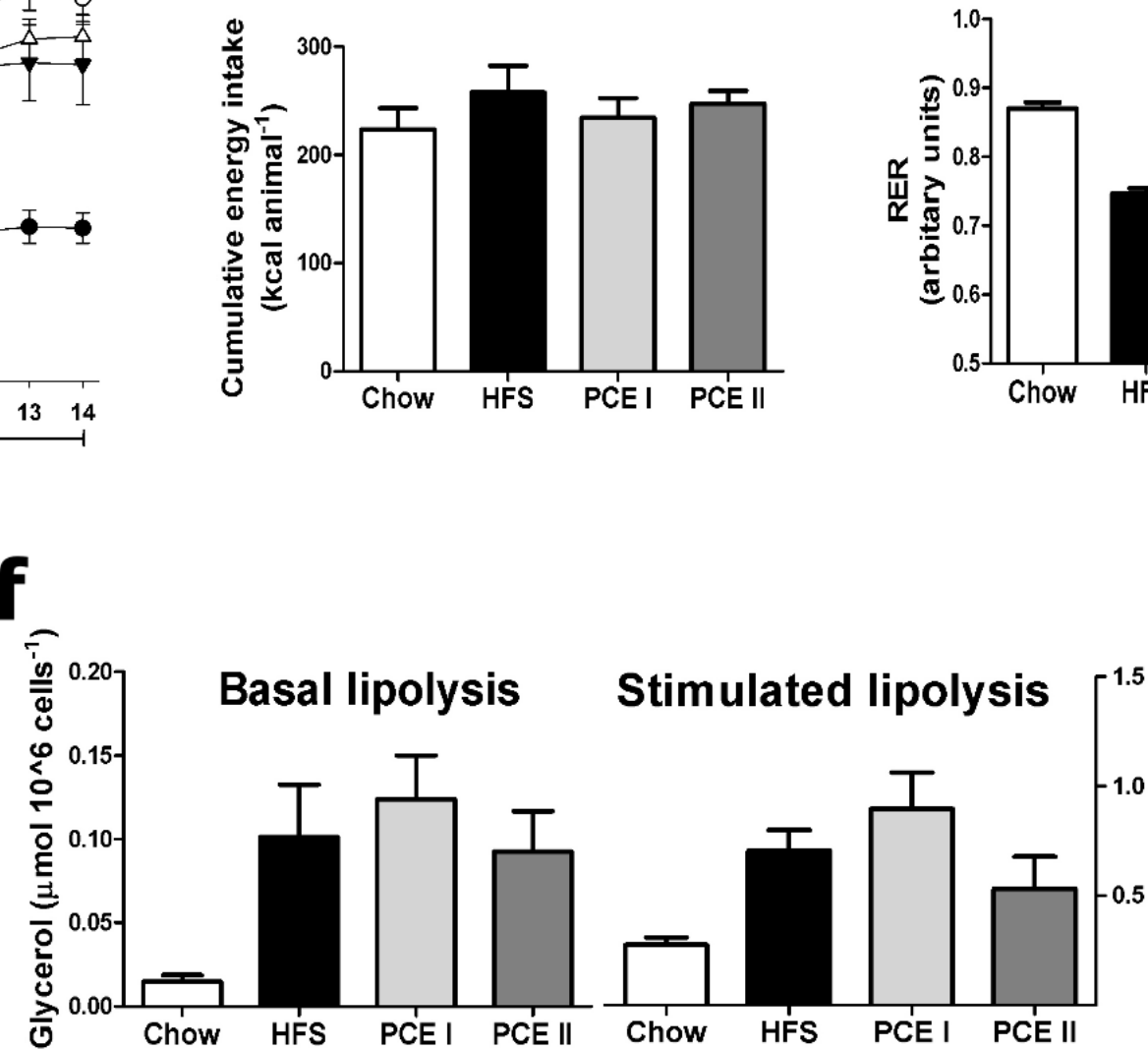

d
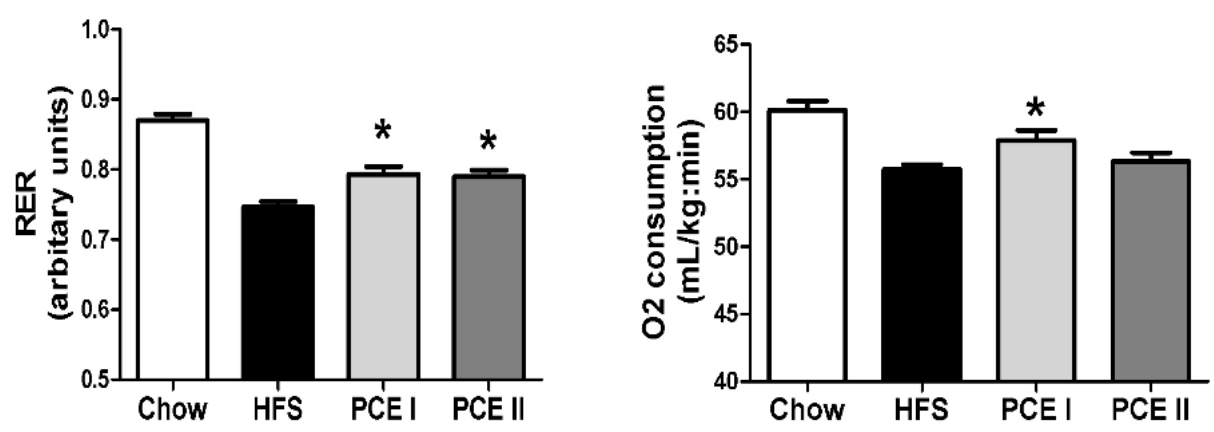

Figure 1

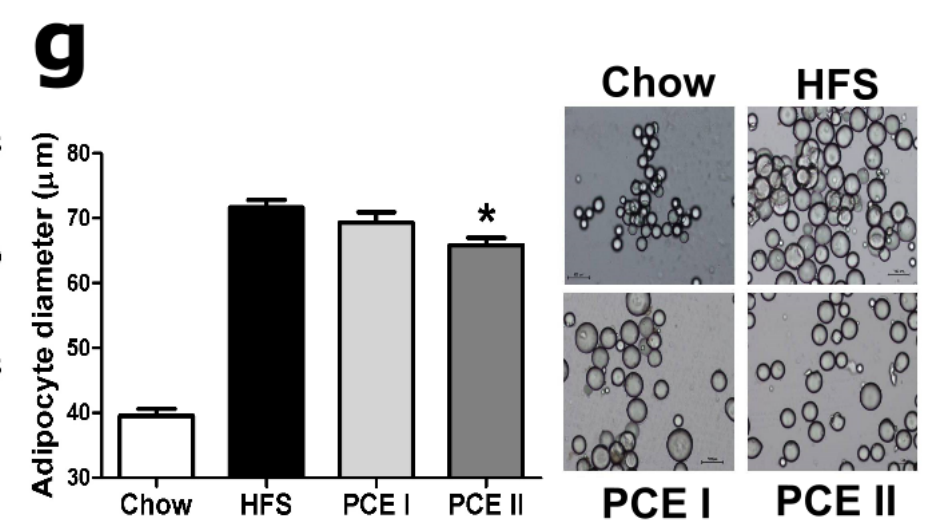


132
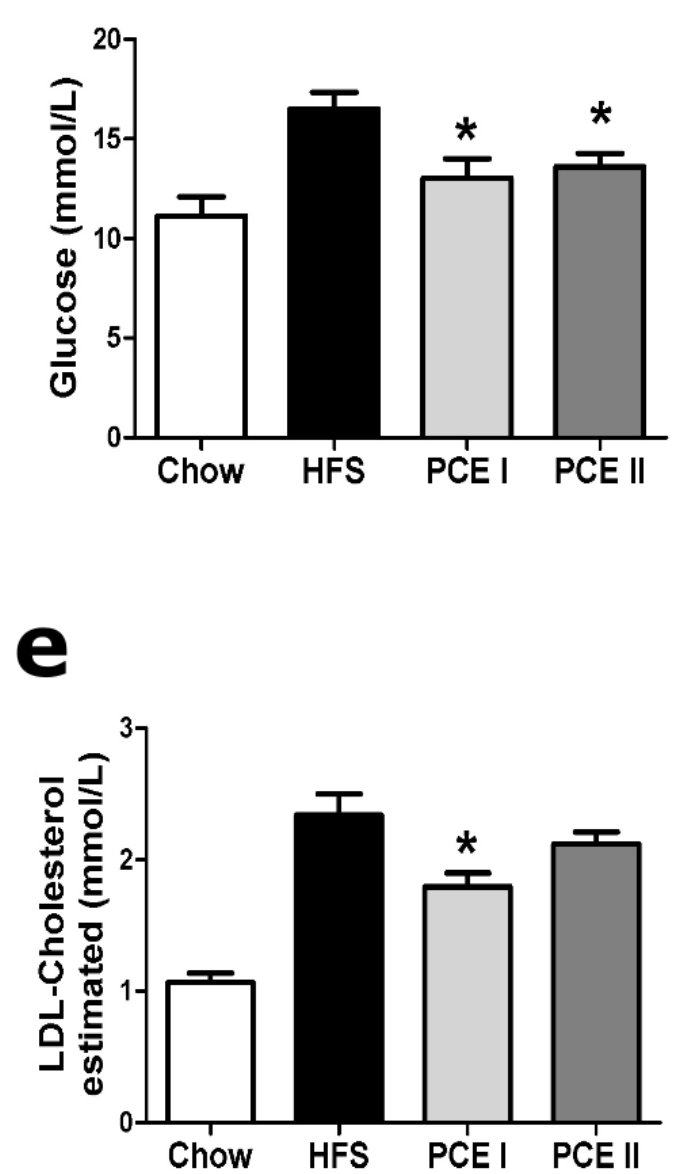

b
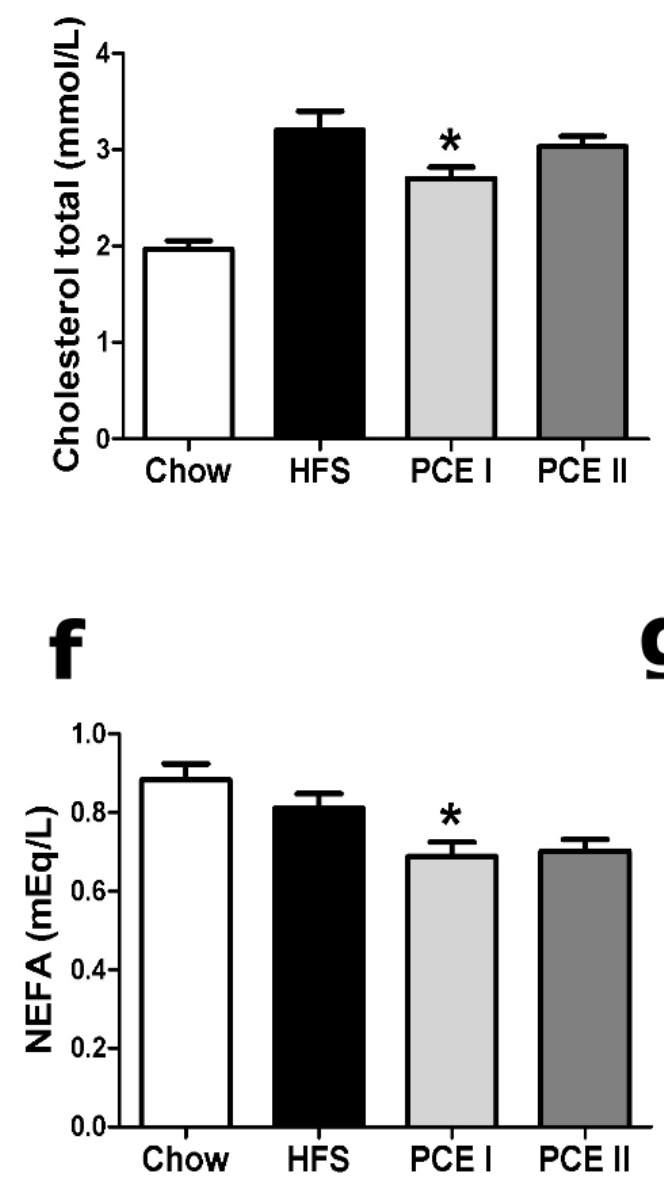

C
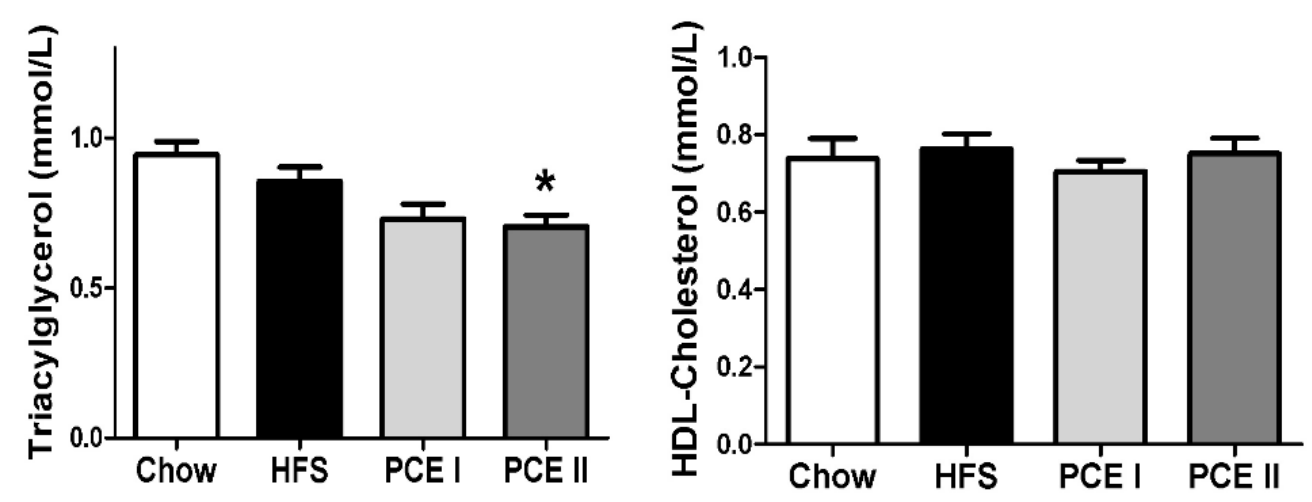

g

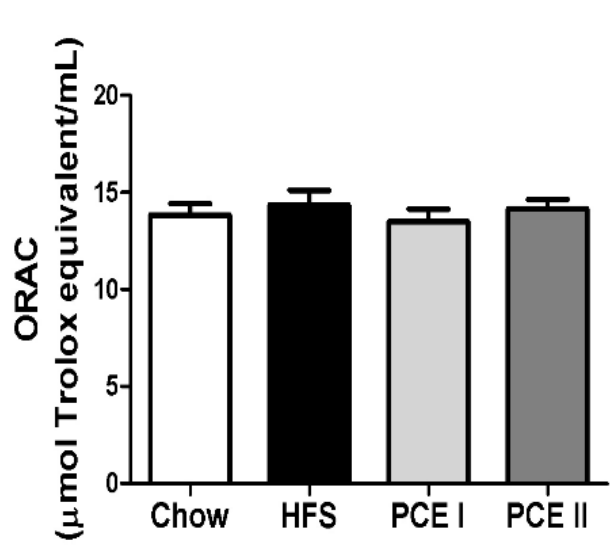

h

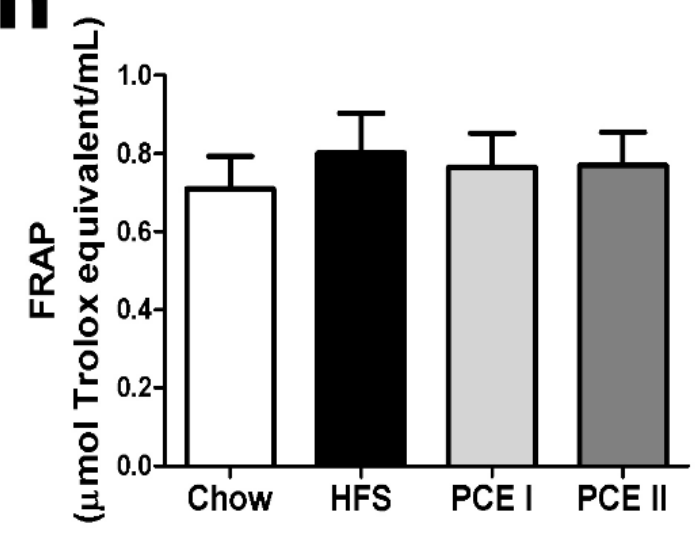

Figure 2 


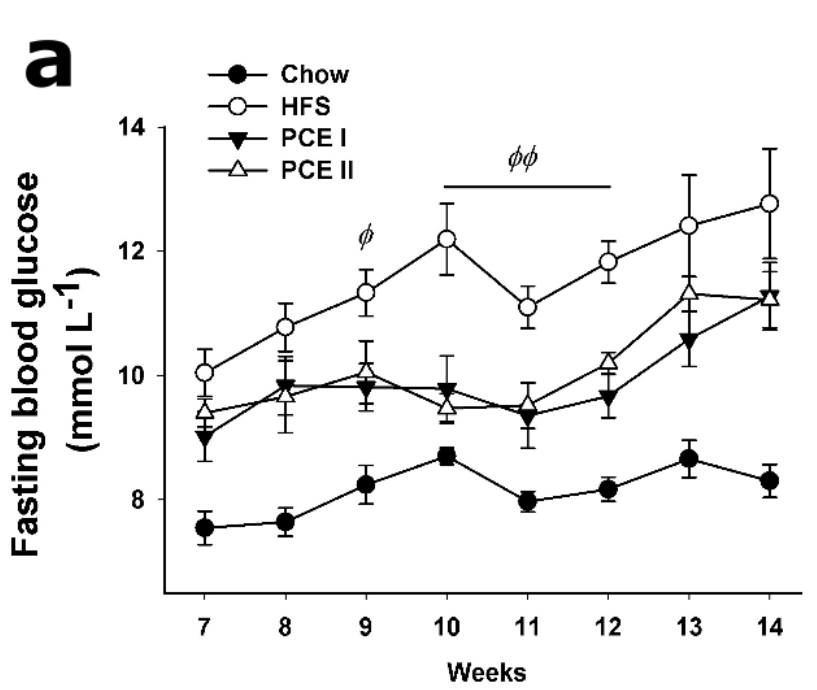

e

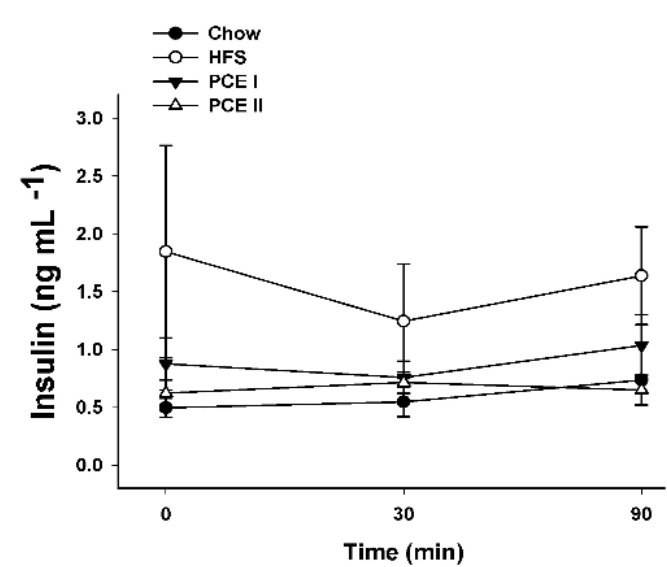

Figure 3

f

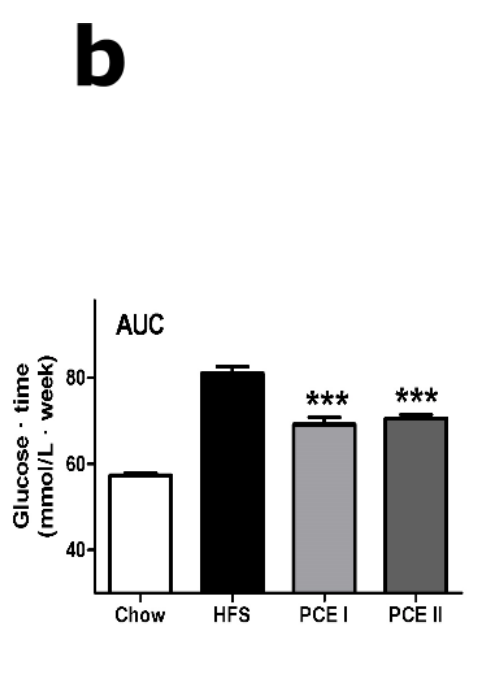

C

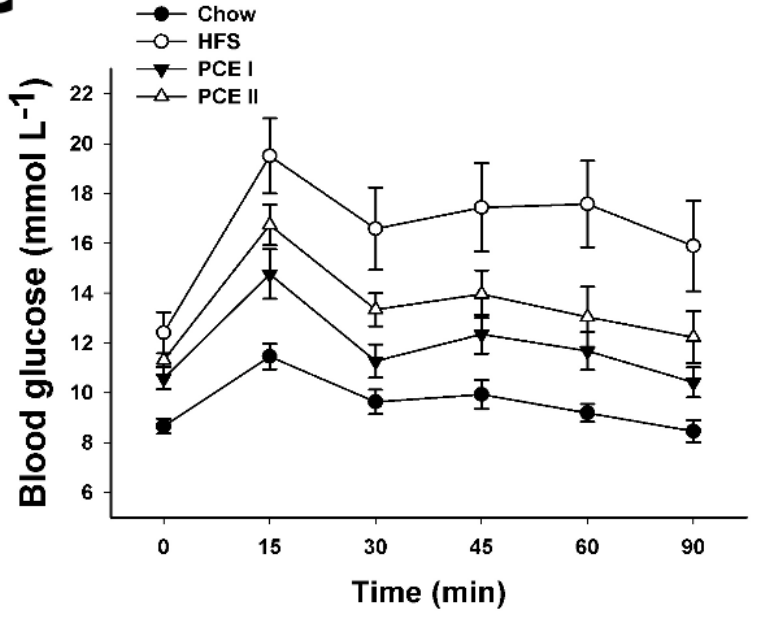

g d

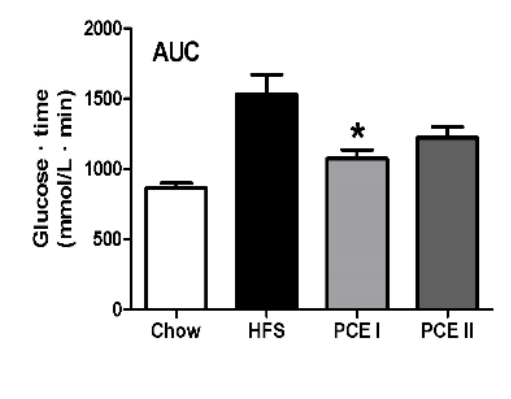

h
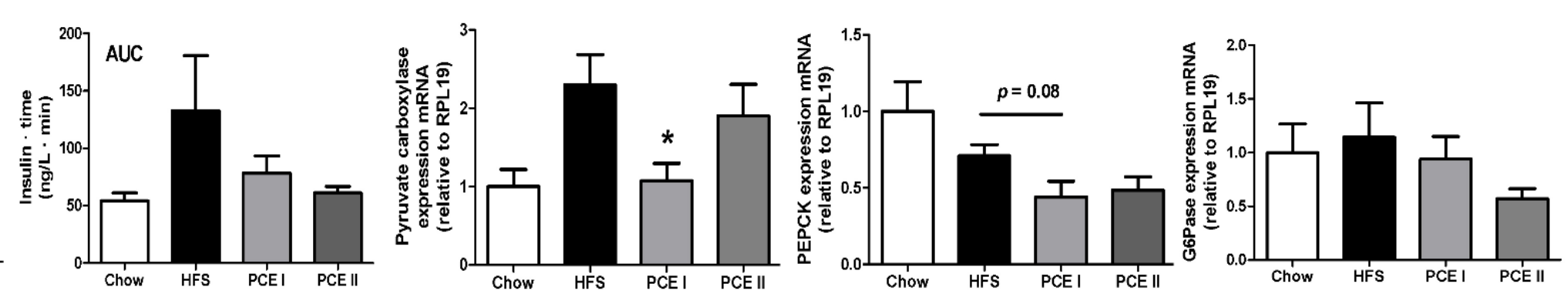
a

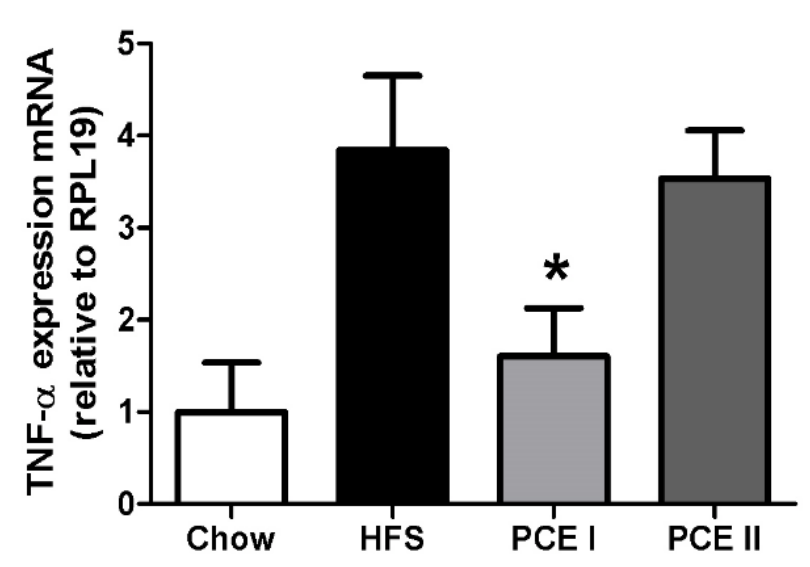

d

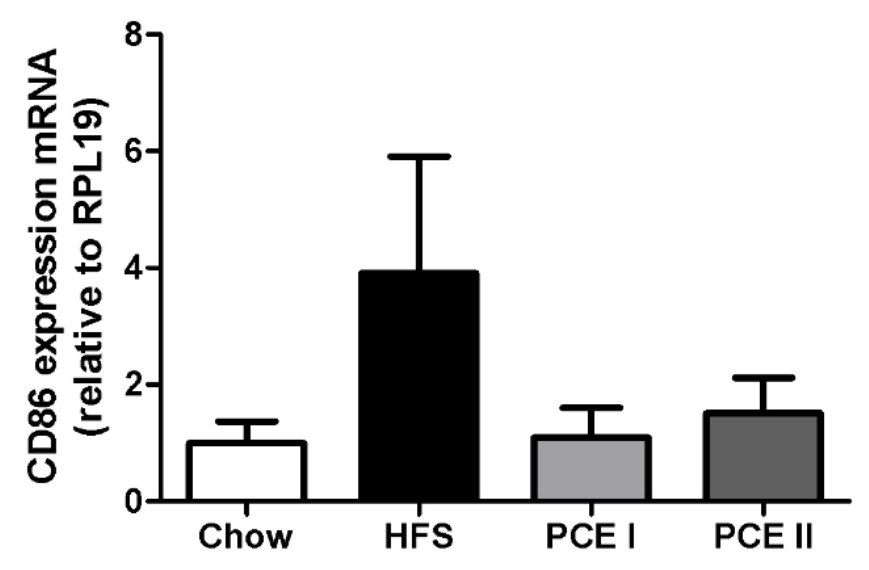

b

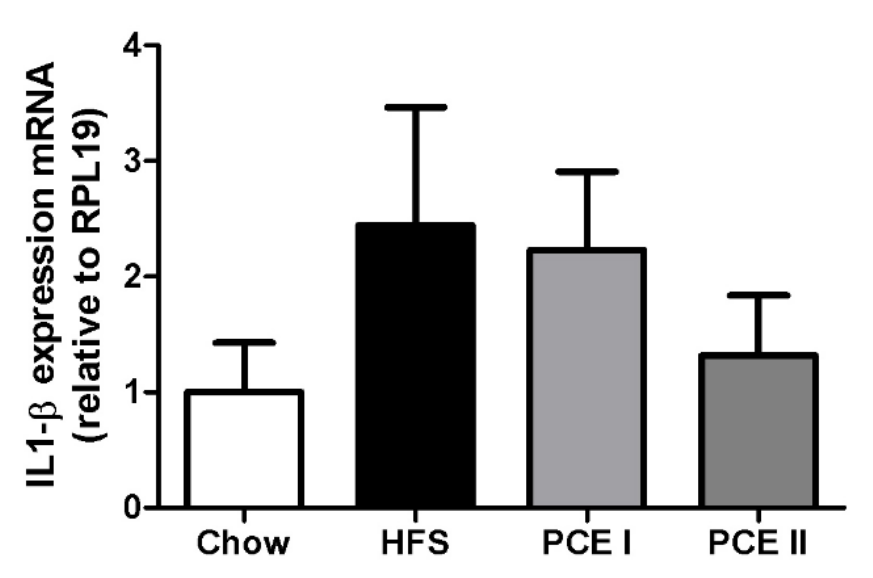

e
C

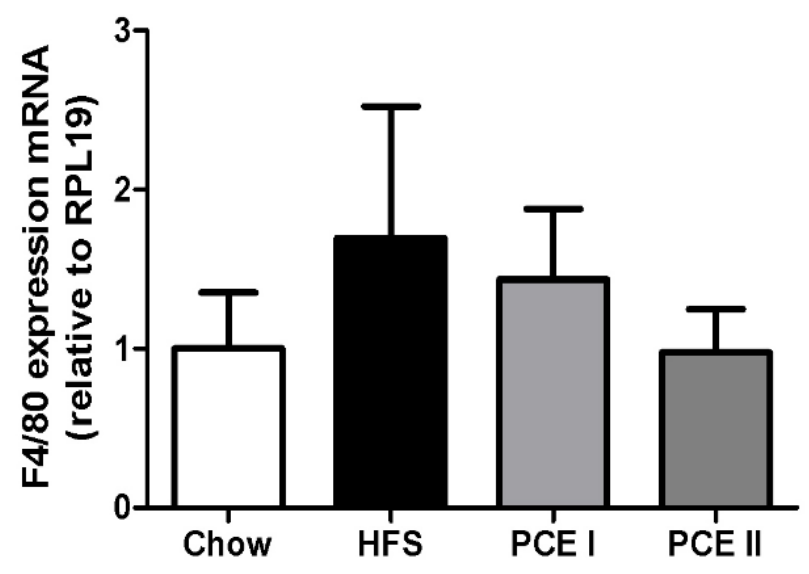

Figure 4

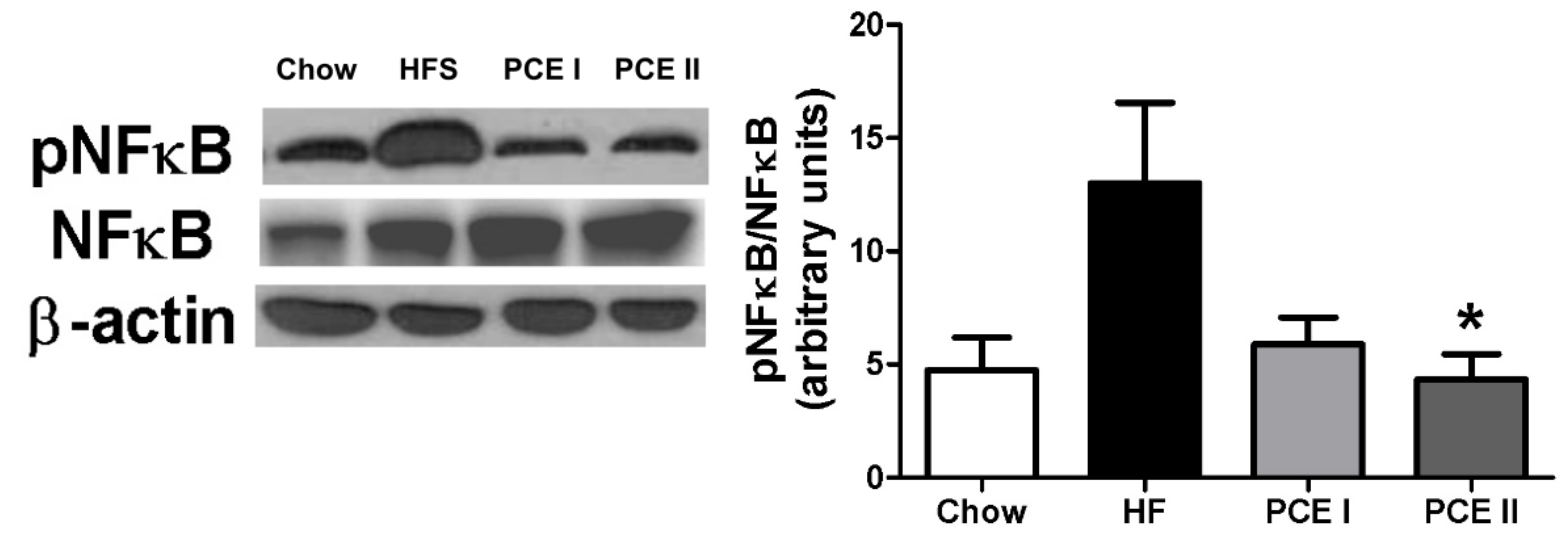




\section{CONCLUSIONS}

Polyphenols from cagaita and cambuci have a protective role in diet-induced obesity and their metabolic alterations:

- Extracts from both fruits showed a similar polyphenolic profile, being characterized by their high tannin contents, including proanthocyanidins and ellagitannins, and also flavonoids such as quercetin and kaempferol (only cagaita) derivatives, and phenolic acids such as ellagic acid as minor constituents.

- Polyphenols of both fruits improved glucose homeostasis as evidenced by reduced fasting hyperglycemia and enhanced glucose tolerance. These properties were observed in both preventive (cagaita and cambuci) and therapeutic (cagaita) protocols.

- Polyphenols from cagaita prevented body weight and fat mass gains induced by high-fat, high-sucrose diet, but did not reverse these parameters in an already developed obesity.

- Polyphenols from cambuci did not prevent body weight gain and adiposity, but protected against adipose tissue inflammation induced by high-fat, high-sucrose diet as evidenced by attenuated macrophage recruitment and expression of pro-inflammatory cytokines.

- Polyphenols of both fruits attenuated dyslipidemia induced by high-fat, high-sucrose diet in both preventive (cagaita and cambuci) and therapeutic (cagaita) protocols.

- Glucose homeostasis enhanced by polyphenols from cagaita in obese mice seems to be mediated, at least in part, through a reduction in hepatic inflammation, thereby attenuating gluconeogenesis.

- Further studies unraveling bioavailability from cagaita and cambuci polyphenols, actions upon gut microbiota and efficacy in humans should be performed to deepen our knowledge about possible usage of both fruits in the management of metabolic diseases. 


\section{REFERÊNCIAS}

ABE, L. T.; LAJOLO, F. M.; GENOVESE, M. I. Potential dietary sources of ellagic acid and other antioxidants among fruits consumed in Brazil: Jabuticaba (Myrciaria jaboticaba (Vell.) Berg). Journal of the Science of Food and Agriculture, v. 92, n. 8, p. 1679-1687, 2012.

ADATI, R. T. Estudo biofarmacognóstico Campomanesia phaea (O.Berg.) Landrum. Myrtaceae. 125 p. Dissertação (Mestrado em Fármacos e Medicamentos) - Universidade de São Paulo, 2001.

ARABBI, P. R.; GENOVESE, M. I.; LAJOLO, F. M. Flavonoids in vegetable foods commonly consumed in brazil and estimated ingestion by the Brazilian population. Journal of Agricultural and Food Chemistry, v. 52, p. 1124-1131, 2004.

AUNE, D.; CHAN, D. S. M.; VIEIRA, A. R.; ROSENBLATT, D. A. N.; VIEIRA, R.; GREENWOOD, D. C.; NORAT, T. Fruits, vegetables and breast cancer risk: A systematic review and meta-analysis of prospective studies. Breast Cancer Research and Treatment, v. 134, n. 2, p. 479-493, 2012.

AZEVEDO, M. C. S.; SILVA, R. R. E.; JACOMINO, A. P.; GENOVESE, M. I. Physicochemical variability of cambuci fruit (Campomanesia phaea) from a same orchard, from different locations and at different ripening stages. Journal of Food Science and Agriculture, v. 02139, n. Accepted Article, 2016.

BASTIANETTO, S.; QUIRION, R. Phytochemicals and the aging brain. In: MESKIN, M.S.; BIDLACK, W.R.; RANDOLPH, R.E. (Ed.). Phytochemicals: Aging and Health. Boca Raton: CRC Press, 2008. chap. 6, p. 107-117.

BAZZANO, L. A.; LI, T. Y.; JOSHIPURA, K. J.; HU, F. B. Intake of fruit, vegetables, and fruit juices and risk of diabetes in women. Diabetes Care, v. 31, p. 1311-1317, 2008.

BELCHIOR, T.; PASCHOAL, V. A.; MAGDALON, J.; CHIMIN, P.; FARIAS, T. M.; CHAVES-FILHO, A. B.; FESTUCCIA, W. Omega-3 fatty acids protect from diet-induced obesity, glucose intolerance, and adipose tissue inflammation through PPAR $\gamma$-dependent and PPAR $\gamma$-independent actions. Molecular Nutrition and Food Research, v. 59, p. 957-967, 2015.

BENZIE, I. F. F.; STRAIN, J. J. The ferric reducing ability of plasma (FRAP) as a measure of "antioxidant power": The FRAP assay. Analytical Biochemistry, v. 239, 70-76, 1996.

BIDEN, T. J.; BOSLEM, E.; CHU, K. J.; SUE, N. Lipotoxic endoplasmic reticulum stress, $\beta$ cell failure, and type 2 diabetes mellitus. Trends in Endocrinology and Metabolism: TEM, v. 25, n. 8 , p. $389-398,2014$.

BIGORNIA, S. J.; FARB, M. G.; MOTT, M. M.; HESS, D. T.; CARMINE, B.; FISCALE, A.; JOSEPH, L.; APOVIAN, C. M.; GOKCE, N. Relation of depot-specific adipose inflammation to insulin resistance in human obesity. Nutrition \& Diabetes, v. 2, n. 3, p. e30, 
2012.

BRAND-WILLIAMS, W.; CUVELIER, M. E.; BERSET, C. Use of a free radical method to evaluate antioxidant activity. LWT - Food Science and Technology, v. 28, p. 25-30, 1995.

BRAY, G. A. Obesity is a chronic, relapsing neurochemical disease. International Journal of Obesity, v. 28, p. 34-38, 2004.

BURTON-FREEMAN, B. M.; SANDHU, A. K.; EDIRISINGHE, I. Red raspberries and their bioactive polyphenols: cardiometabolic and neuronal health links. Advances in Nutrition: An International Review Journal, v. 7, n. 1, p. 44-65, 2016.

CABALLERO, B. The global epidemic of obesity: An overwiew. Epidemioligc Reviews, v. 29, p. 1-5, 2007.

CANCELLO, R.; CLÉMENT, K. Is obesity an inflammatory illness? Role of low-grade inflammation and macrophage infiltration in human white adipose tissue. BJOG: An International Journal of Obstetrics and Gynaecology, v. 113, n. 10, p. 1141-1147, 2006.

CARDOSO, L. M; MARTINO, H. S. D.; MOREIRA, A. V. B.; RIBEIRO, S. M. R.; PINHEIRO-SANT'ANA H. M. Cagaita (Eugenia dysenterica DC) of the Cerrado of Minas Gerais, Brazil: physical and chemical characterization, carotenoids and vitamins. Food Research International, v. 44, p. 2151-2154, 2011.

CARROLL, N. V.; LONGLEY, R. W.; ROE, J. H. The determination of glycogen in liver and muscle by use of anthrone reagent. Journal of Biological Chemistry, v. 220, p. 583-593, 1956.

CARTER, P.; GRAY, L. J.; TROUGHTON, J.; KHUNTI, K.; DAVIES, M. Fruit and vegetable intake and incidence of type 2 diabetes mellitus: systematic review and metaanalysis. British Medical Journal, v. 341, n. 7772, p. c4229, 2010.

CHERNIACK, E. P. Polyphenols: Planting the seeds of treatment for the metabolic syndrome. Nutrition, v. 27, n. 6, p. 617-623, 2011.

CLOVEGARDEN. Myrtles-Order Myrtales: Cagaita. URL
http://www.clovegarden.com/ingred/myrtle.html. Accesed 20.05.14.

CROZIER, A.; JAGANATH, I. B.; CLIFFORD, M. N. Dietary phenolics: chemistry, bioavailability and effects on health. Natural Product Reports, v. 26, n. 8, p. 1001-1043, 2009.

CYPESS, A. M.; KAHN, C. R. The role and importance of brown adipose tissue in energy homeostasis. Current Opinion in Pediatrics, v. 22, n. 4, p. 478-484, 2013.

DAI, J.; MUMPER, R. J. Plant phenolics: Extraction, analysis and their antioxidant and anticancer properties. Molecules, v. 15, n. 10, p. 7313-7352, 2010.

DÁVALOS, A.; GÓMEZ-CORDOVÉS, C.; BARTOLOMÉ, B. Extending applicability of the oxygen radical absorbance capacity (ORAC-fluorescein) assay. Journal of Agricultural 
and Food Chemistry, v. 52, p. 48-54, 2004.

DEFRONZO, R. A. Pharmacologic therapy for type 2 diabetes mellitus. Annals of Internal Medicine, v. 131, n. 4, p. 281-303, 1999.

DEVALARAJA, S.; JAIN, S.; YADAV, H. Exotic fruits as therapeutic complements for diabetes, obesity and metabolic syndrome. Food Research International, v. 44, n. 7, p. 1856-1865, 2011.

DONADO-PESTANA, C. M.; BELCHIOR, T.; GENOVESE, M. I. Phenolic compounds from cagaita (Eugenia dysenterica DC.) fruit prevent body weight and fat mass gain induced by a high-fat, high-sucrose diet. Food Research International, v. 77, p. 177-185, 2015.

EMANUELA, F.; GRAZIA, M.; MARCO, De R.; PAOLA, L. M.; GIORGIO, F.; MARCO. B. Inflammation as a link between obesity and metabolic syndrome. Journal of Nutrition and Metabolism, v. 2012, p. 1-7, 2012.

FANTUZZI, G. Adipose tissue, adipokines, and inflammation. Journal of Allergy and Clinical Immunology, v. 115, n. 5, p. 911-920, 2005.

FAOSTAT, Food and Agriculture Organization of the United Nations. FAOSTAT database (updated January 2016). URL http://faostat.fao.org/site/291/default.aspx. Accesed 05.04.16.

FESTUCCIA, W. T., OZTEZCAN, S.; LAPLANTE, M.; BERTHIAUME, M.; MICHEL, C., DOHGU, S., et al. Peroxisome proliferator-activated receptor-gamma-mediated positive energy balance in the rat is associated with reduced sympathetic drive to adipose tissues and thyroid status. Endocrinology, v. 149, p. 2121-2130, 2008.

FOLCH, J.; LEES, M.; STANLEY, G. H. S. A simple method for the isolation and purification of total lipides from animal tissues. Journal of Biological Chemistry, v. 226, p. 497-509, 1957.

FORD, E. S.; MOKDAD, A. H. Fruit and vegetable consumption and diabetes mellitus incidence among U.S. adults. Preventive Medicine, v. 32, n. 1, p. 33-39, 2001.

FRAYN, K. N.; FIELDING, B. A.; MACDONALD, I. A.; COPPACK, S. W. Integrative physiology of human adipose tissue. International Journal of Obesity, v. 27, n. 8, p. 875888, 2003.

FRIEDEWALD, W. T.; LEVY, R. I.; FREDRICKSON, D. S. Estimation of the concentration of low-density lipoprotein cholesterol in plasma, without use of the preparative ultracentrifuge. Clinical Chemistry, v. 18, p. 499-502, 1972.

FUHRMAN, B.; AVIRAM, M. Polyphenols and flavonoids protect LDL against atherogenic modifications. In: CADENAS, E.; PACKER, L. (Ed.). Handbook of Antioxidants. 2nd ed. New York: Marcel Dekker, 2002. chap. 16, p. 303-336.

GENOVESE, M. I.; PINTO, M. da S.; GONÇALVES, A. E. de S.; LAJOLO, F. M. Bioactive compounds and antioxidant capacity of exotic fruits and commercial frozen pulps from Brazil.

Food Science and Technology International, v. 14, p. 207-214, 2008. 
GONÇALVES, A. E. de S. S.; LAJOLO, F. M.; GENOVESE, M. I. Chemical composition and antioxidant/antidiabetic potential of Brazilian native fruits and commercial frozen pulps. Journal of Agricultural and Food Chemistry, v. 58, p. 4666-4674. 2010.

GORLACH, S.; FICHNA, J.; LEWANDOWSKA, U. Polyphenols as mitochondria-targeted anticancer drugs. Cancer Letters, v. 366, n. 2, p. 141-149, 2015.

HAMINIUK, C. W. I.; PLATA-OVIEDO, M. S.; GUEDES, A. R.; STAFUSSA, A. P.; BONA, E.; CARPES S. T. Chemical, antioxidant and antibacterial study of Brazilian fruits. International Journal of Food Science and Technology, v. 46, p. 1529-1537, 2011.

HANHIEVA, K.; TÖRROÖNEN， R.; BONDIA-PONS， I.; PEKKINEN， J.; KOLEHMAINEN, M.; MYKKÄNEN H.; POUTANEN, K. Impact of dietary polyphenols on carbohydrate metabolism. International Journal of Molecular Sciences, v. 11, p. 1365$1402,2010$.

HUANG, W.-Y.; CAI, Y.-Z.; ZHANG, Y. Natural phenolic compounds from medicinal herbs and dietary plants: potential use for cancer prevention. Nutrition and Cancer, v. 62, n. 1, p. $1-20,2010$.

ITOH, M.; SUGANAMI, T.; HACHIYA, R.; OGAWA, Y. Adipose tissue remodeling as homeostatic inflammation. International journal of inflammation, v. 2011, p. 720926, 2011.

KADL, A. et al. Identification of a novel macrophage phenotype that develops in response to atherogenic phospholipids via Nrf2. Circulation Research, v. 107, n. 6, p. 737-746, 2010.

KAWASAKI, M. L.; LANDRUM, L. R. A rare and potentially economic fruit of Brazil: cambuci, Campomanesia phaea (Myrtaceae). Economic Botany, v. 51, p. 403-407, 1997.

KOH, E.; MITCHELL, A. E. Trends in the analysis of phytochemicals. Flavonoids and Carotenoids. In: MESKIN, M. S.; BIDLACK, W. R.; RANDOLPH, R. E. (Ed.). Phytochemicals: Aging and Health. Boca Raton: CRC Press, 2008. chap. 3, p. 39-76.

KRIS-ETHERTON, P. M.; HECKER, K. D.; BONANOME, A.; COVAL, S. M.; BINKOSKI, A. E.; HILPERT, K. F.; GREL, A. E.; ETHERTON, T. D. Bioactive compounds in foods: their role in the prevention of cardiovascular disease and cancer. The American Journal of Medicine, v. 113, n. 9, Supplement 2, p. 71-88, 2002.

LEE, D. W.; GOULD, K. S. Anthocyanins in leaves and other vegetative organs: An introduction. In: GOULD, K. S.; LEE, D. W. Advances in botanical research: Anthocyanins in leaves, London: Academic Press, p. 2-12, 2002.

LEMIEUX, C.; PICARD, F.; LABRIE, F.; RICHARD, D.; DESHAIES, Y. The estrogen antagonist EM-652 and dehydroepiandrosterone prevent diet- and ovariectomy-induced obesity. Obesity Research, v. 11, p. 477-490, 2003.

LIMA, T. B.; SILVA, O. N.; SILVA, L. P.; ROCHA, T. L.; GROSSI-de-SÁ; M. F.; FRANCO, O. L.; LEONARDECZ, E. In vivo effects of cagaita (Eugenia dysenterica, DC.) 
leaf extracts on diarrhea treatment. Evidence-Based Complementary and Alternative Medicine, v. 2011, p. 1-10, 2011.

LIU, R. H. Health benefits of fruit and vegetables are from additive and synergistic combinaions of phytochemicals. The American Journal of Clinical Nutrition, v. 78, p. 3-6, 2003.

MARTINOTTO, C.; PAIVA, R.; SOARES, F. P.; SANTOS, B. R.; NOGUEIRA, R. C. Cagaiteira (Eugenia dysenterica DC.). Boletim Técnico Universidade Federal De Lavras, v. 1, n. 78, p. 1-21, 2008.

MONTONEN, J.; JÄRVINEN, R.; HELIÖVAARA, M.; REUNANEN, A.; AROMAA, A.; KNEKT, P. Food consumption and the incidence of type II diabetes mellitus. European Journal of Clinical Nutrition, v. 59, p. 441-448, 2005.

NAKAI, M.; FUKUI, Y.; ASAMI, S.; TOYODA-ONO, Y.; IWASHITA, T.; SHIBATA, H.; et al. Inhibitory effects of oolong tea polyphenols on pancreatic lipase in vitro. Journal of Agricultural and Food Chemistry, v. 53, p. 4593-4598, 2005.

NAKAMURA, K.; NAGATA, C.; OBA, S.; TAKATSUDA, N.; SHIMIZU, H. Fruit and vegetable intake and mortality from cardiovascular disease are inversely associated in Japanese women but not in men. Journal of Nutrition, v. 138, n. 6, p. 1129-1134, 2008.

NCD RISK FACTOR COLLABORATION. Trends in adult body-mass index in 200 countries from 1975 to 2014: a pooled analysis of 1698 population-based measurement studies with 19.2 million participants. Lancet, v. 387, p. 1377-1396, 2016.

NG, M. et al. Global, regional, and national prevalence of overweight and obesity in children and adults during 1980-2013: A systematic analysis for the Global Burden of Disease Study 2013. The Lancet, v. 384, n. 9945, p. 766-781, 2014.

OLIVEIRA, M. E. S.; PANTOJA, L.; DUARTE, W.F.; COLLELA, C. F.; VALARELLI, L. T.; SCHWAN, R. F.; DIAS, D. R. Fruit wine produced from cagaita (Eugenia dysenterica DC) by both free and immobilised yeast cell fermentation. Food Research International, v. 44, n. 7, p. 2391-2400, 2011.

OSBORN, O.; OLEFSKY, J. M. The cellular and signaling networks linking the immune system and metabolism in disease. Nature Medicine, v. 18, n. 3, p. 363-374, 2012.

OZKAN, G.; BAYDAR, H.; ERBAS, S. The influence of harvest time on essential oil composition, phenolic constituents and antioxidant properties of Turkish oregano (Origanum onites L.). Journal of the Science of Food and Agriculture, v. 90, n. 2, p. 205-209, 2010.

PAERATAKUL, S.; LOVEJOY, J. C.; BRAY, G. A. The relation of gender, race and socioeconomic status to obesity and obesity comorbidities in a sample of US adults. International Journal of Obesity, v. 26, n. 9, p. 1205-1210, 2002.

PATEL, P. S.; BURAS, E. D.; BALASUBRAMANYAM A. The role of the immune system in obesity and insulin resistance. Journal of Obesity, v. 2013, p. 1-9, 2013. 
PINTO, M. S.; LAJOLO, F. M.; GENOVESE, M. I. Bioactive compounds and quantification of total ellagic acid in strawberries (Fragaria $x$ ananassa Duch.). Food Chemistry, v. 107, p. 1629-1635, 2008.

PORTER, L. J.; HRSTICH, L. N.; CHAN, B. G. The conversion of procyanidins and prodelphinidins to cyanidin and delphinidin. Phytochemistry, v. 25, p. 223-230, 1985.

PRABHAKAR, P. K.; DOBLE, M. A target based therapeutic approach towards diabetes mellitus using medicinal plants. Current Diabetes Reviews, v. 4, n. 4, p. 291-308, 2008.

REYES, L. F.; CISNEROS-ZEVALLOS, L. Wounding stress increases the phenolic content and antioxidant capacity of purple-flesh potatoes (Solanum tuberosum L.). Journal of Agricultural and Food Chemistry, p. 5296-5300, 2003.

REYNERTSON, K. A.; YANG, H.; JIANG, B.; BASILE, M. J.; KENELLY, E. J. Quantitative analysis of antiradical phenolic constituents from fourteen edible Myrtaceae fruits. Food Chemistry, v. 109, n. 4, p. 883-890, 2008.

REYNERTSON, K. A.; BASILE, M. J.; KENNELLY, E. J. Antioxidant potential of seven Myrtaceous fruits. Ethnobotany Research \& Applications, v. 3, p. 25-35, 2005.

ROSSI, M.; BOSETTI, C.; NEGRI, E.; LAGIOU, P.; LA VECCHIA, C. Flavonoids, proanthocyanidins, and cancer risk: a network of case-control studies from Italy. Nutrition and Cancer, v. 62, n. 7, p. 871-877, 2010.

SAMMAN, S. Phytochemicals and the prevention of cardiovascular disease: Potential roles for selected fruits, herbs, and spices. In: BAO, Y.; FENWICK, R. (Ed.). Phytochemicals in Health and Disease. New York: Marcel Dekker, 2004. chap. 12, p. 241-255.

SCALBERT, A.; MANACH, C.; MORAND, C.; RÉMÉSY, C.; JIMÉNEZ, L. Dietary polyphenols and the prevention of diseases. Critical Reviews in Food Science and Nutrition, v. 45, n. 4, p. 287-306, 2005.

SHAHIDI, F.; NACZK, M. Phenolics in Food and Nutraceuticals. New York: CRC Press, 576 p., 2006.

SINGLETON, V. L.; ORTHOFER, R.; LAMUELA-RAVENTOS, R. M. Analysis of total phenols and other oxidation substrates and antioxidants by means of Folin-Ciocalteu reagent. Oxidants and Antioxidants, v. 299, p. 152-178, 1999.

SILVA, M. R.; LACERDA, D. B. C. L.; SANTOS, G. G.; MARTINS, D. M. O. Caracterização química de frutos nativos do cerrado. Ciência Rural, v. 38, n. 6, p. 17901793, 2008.

SUGANAMI, T.; OGAWA, Y. Adipose tissue macrophages: their role in adipose tissue remodeling. Journal of Leukocyte Biology, v. 88, n. 1, p. 33-39, 2010.

TURCONI, G.; CENA, H. Epidemiology of Obesity. In: BAGCHI, D.; PREUSS, H. G. (Ed). Obesity: Epidemiology, Pathophysiology, and Prevention. Boca Ratón: CRC Press, chap 1, p. 3-32, 2012. 
SAMMAN, S. Phytochemicals and the prevention of cardiovascular disease: Potential roles for selected fruits, herbs, and spices. In: BAO, Y.; FENWICK, R. (Ed.). Phytochemicals in Health and Disease. New York: Marcel Dekker, 2004. chap. 12, p. 241-255.

VALLILO, M. I.; GARBELOTTI, M. L.; OLIVEIRA, E. de; LAMARDO, L. C. A. Características físicas e químicas dos frutos do cambucizeiro (Campomanesia phaea). Revista Brasileira de Fruticultura, v. 27, p. 241-244, 2005.

WANG, S.; MOUSTAID-MOUSSA, N.; CHEN, L.; MO, H.; SHASTRI, A.; SU, R.; BAPAT, P.; KWUN, I.; SHEN, C-L. Novel insights of dietary polyphenols and obesity. Journal of Nutritional Biochemistry, v. 25, n. 1, p. 1-18, 2014.

WELLEN, K. E.; HOTAMISLIGIL, G. S. Obesity-induced inflamatory changes in adipose tissue. The Journal of Clinical Investigation, v. 112, n. 12, p. 1785-1788, 2003.

WENG, J.-K.; PHILIPPE, R. N.; NOEL, J. P. The rise of chemodiversity in plants. Science, v. 336, n. 6089, p. 1667-70, 2012.

WHITE, P. J.; MARETTE, A. Inflammation-induced insulin resistance in obesity: when immunity affects metabolic control. In: HAWLEY, J. A.; ZIERATH, J. R. (Ed.). Physical activity and type 2 diabetes: Therapeutic effects and mechanisms of action. Champaign, IL: Human Kinetics, p. 67-82, 2005.

WHITING, D. R.; GUARIGUATA, L.; WEIL, C.; SHAW, J. IDF Diabetes Atlas: Global estimates of the prevalence of diabetes for 2011 and 2030. Diabetes Research and Clinical Practice, v. 94, n. 3, p. 311-321, 2011.

WHO, World Health Organization of the United Nations. Obesity and overweight. URL http://www.who.int/mediacentre/factsheets/fs311/en/. Accesed 10.06.16.

WHO, World Health Organization of the United Nations. Diabetes. URL http://www.who.int/mediacentre/factsheets/fs312/en/. Accesed 10.06.16. 
ANEXOS 
ANEXO A - PARECER DO COMITÊ DE ÉTICA

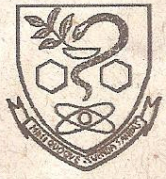

Ofício CEUAIFCF/97/2012
UNIVERSIDADE DE SÃO PAULO

FACULDADE DE CIÊNCIAS FARMACÊUTICAS

Comissão de Ética no Uso de Animais - CEUA

\section{CERTIFICADO}

A Comissão de Ética no Uso de Animais da Faculdade de Ciências Farmacêuticas da Universidade de São Paulo Certifica que o Projeto "Compostos fenólicos de cagaita (Eugenia dysenterica DC.) e cambuci (Campomanesia phaea, Berg.): seu potencial no tratamento e prevenção de obesidade e diabetes mellitus tipo 2" (Protocolo CEUA/FCF/378), de responsabilidade do pesquisador Carlos Mario Donado Pestana, sob a orientação da. Profa. Dra. Maria Inés Genovese, está de acordo com as normas do Conselho Nacional de Controle de Experimentação Animal - CONCEA e foi APROVADO em reunião de 01 de outubro de 2012.

São Paulo, 02 de outubro de 2012.

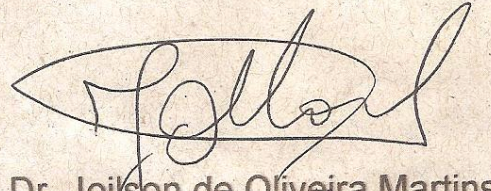

Prof. Dr. Joilson de Oliveira Martins

Coordenador da Comissão de Ética no Uso de Animais CEUAFCF/USP 
ANEXO B - PARECER DO COMITÊ DE ÉTICA

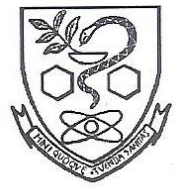

UNIVERSIDADE DE SÃO PAULO

FACULDADE DE CIÊNCIAS FARMACÊUTICAS

Comissão de Ética no Uso de Animais - CEUA

Ofício CEUA/FCF 112.2014-P378

São Paulo, 11 de novembro de 2014.

Prezado(a) Senhor(a),

Cumpre-nos informar que a Comissão de Ética no Uso de Animais, da Faculdade de Ciências Farmacêuticas da Universidade de São Paulo, em reunião realizada em 7 de novembro de 2014, APROVOU o relatório parcial, relativo ao projeto de pesquisa "Compostos fenólicos de cagaita (Eugenia dysenterica DC.) e cambuci (Campomanesia phaea, Berg.): seu potencial no tratamento e prevenção de obesidade e diabetes mellitus tipo 2' (Protocolo CEUA n० 378), apresentado por Vossa Senhoria.

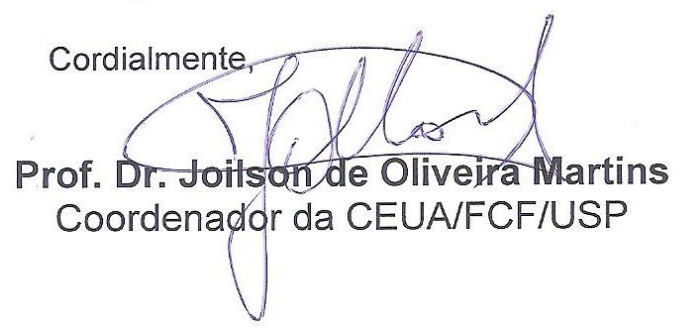

Ilmo(a). Sr(a). Carlos Mario Donado Pestana

Orientador(a): Profa. Dra. Maria Inés Genovese

FBA/FCF/USP 


\section{ANEXO C - PARECER DO COMITÊ DE ÉTICA}

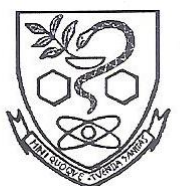

Ofício CEUA/FCF 113.2014-P378

UNIVERSIDADE DE SÃO PAULO

FACULDADE DE CIÊNCIAS FARMACÊUTICAS

Comissão de Ética no Uso de Animais - CEUA

São Paulo, 11 de novembro de 2014.

Prezado(a) Senhor(a),

A Comissão de Ética no Uso de Animais da Faculdade de Ciências Farmacêuticas da Universidade de São Paulo (CEUA/FCF/USP), em reunião realizada em 7 de novembro de 2014, aprovou as alterações propostas para o projeto de pesquisa "Compostos fenólicos de cagaita (Eugenia dysenterica DC.) e cambuci (Campomanesia phaea, Berg.): seu potencial no tratamento e prevenção de obesidade e diabetes mellitus tipo 2" (Protocolo CEUA $n^{\circ}$ 378), a saber: inclusão de mais 108 animais da linhagem C57BL/6, conforme constante nos documentos apresentados.

Cordialmente,

Prof. Dr. Joilson de Oliveira Martins

Coordenador da CEUA/FCF/USP

IImo(a). Sr(a).

Carlos Mario Donado Pestana

Orientador(a): Profa. Dra. Maria Inés Genovese

FBA/FCF/USP

Av. Prof. Lineu Prestes, 580 - Bloco 13 A - Cidade Universitária - CEP 05508-900 - São Paulo - SP Fone: (11) 3091-3622 / Fone/Fax: (11) 3091-3677 - e-mail: ceuafcf@usp.br 
ANEXO D - FICHA DO ALUNO

an U1S - Sistema Administrativo da Pós-Graduação

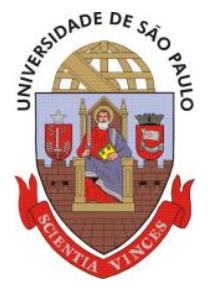

Universidade de São Paulo

Faculdade de Ciências Farmacêuticas

Documento sem validade oficial

FICHA DO ALUNO

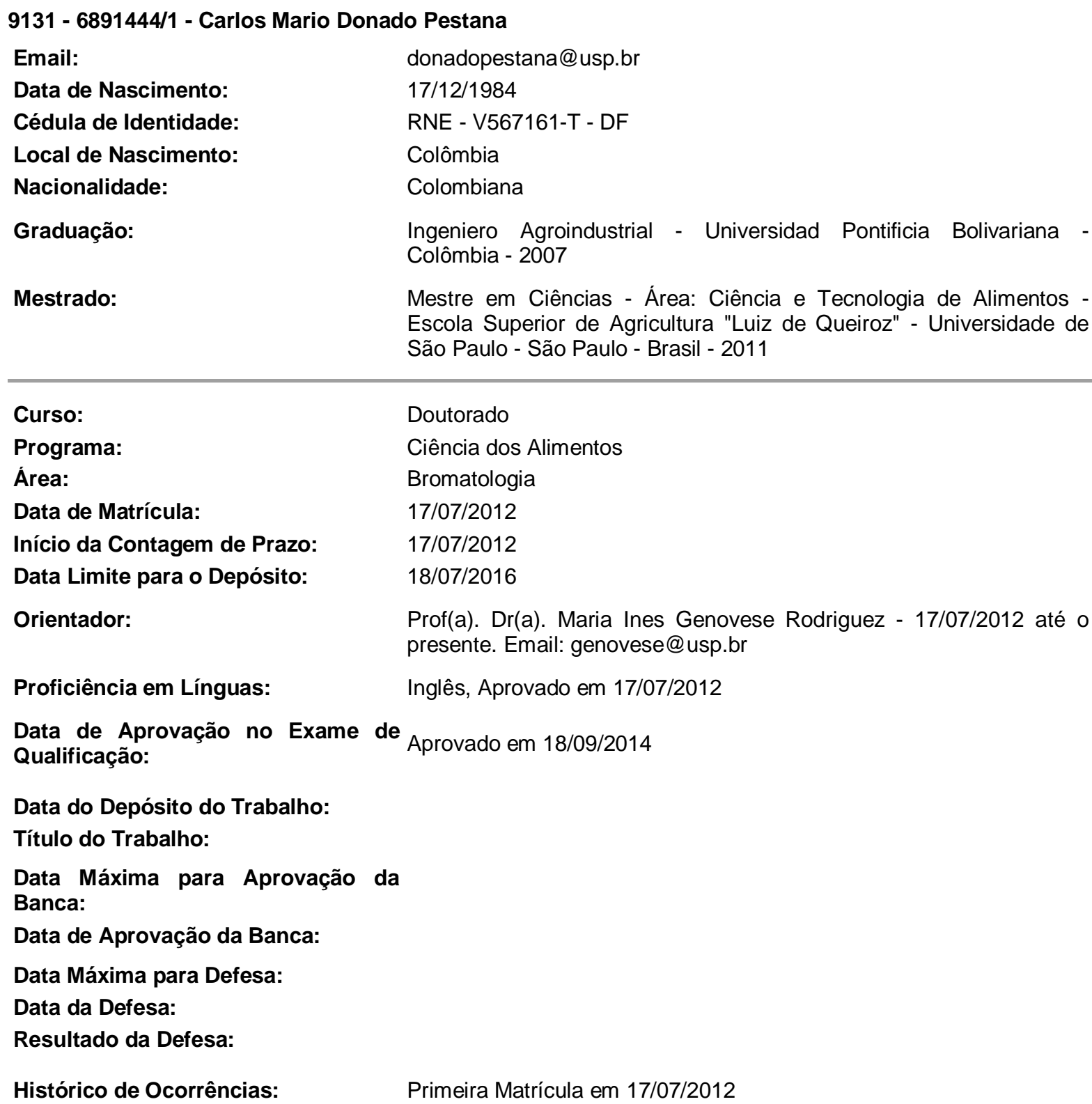

Curso:

Programa:

Área:

Data de Matrícula:

Início da Contagem de Prazo:

Data Limite para o Depósito:

Orientador:

Proficiência em Línguas:

Data de Aprovação no Exame de Qualificação:

Data do Depósito do Trabalho:

Título do Trabalho:

Data Máxima para Aprovação da

Banca:

Data de Aprovação da Banca:

Data Máxima para Defesa:

Data da Defesa:

Resultado da Defesa:

Histórico de Ocorrências:

Primeira Matrícula em 17/07/2012

Aluno matriculado no Regimento da Pós-Graduação USP (Resolução nº 5473 em vigor de 18/09/2008 até 19/04/2013).

Última ocorrência: Matrícula de Acompanhamento em 01/02/2016

Impresso em: 05/07/2016 16:40:57 


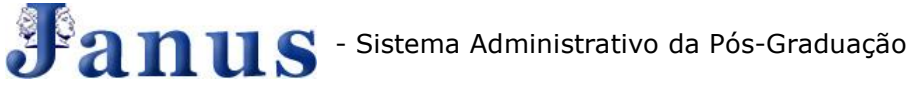

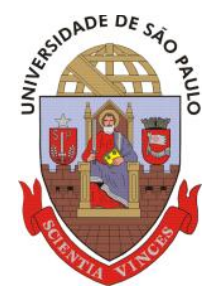

Universidade de São Paulo

Faculdade de Ciências Farmacêuticas

Documento sem validade oficial

FICHA DO ALUNO

9131 - 6891444/1 - Carlos Mario Donado Pestana

\begin{tabular}{|c|c|c|c|c|c|c|c|c|c|}
\hline Sigla & $\begin{array}{l}\text { Nome da } \\
\text { Disciplina }\end{array}$ & Início & Término & $\begin{array}{l}\text { Carga } \\
\text { Horária }\end{array}$ & Cred. & Freq. & Conc. & Exc. & Situação \\
\hline $\begin{array}{c}\text { MCM5716- } \\
5 / 4\end{array}$ & $\begin{array}{lrr}\text { Atualização } & \text { em } \\
\text { Diabetes } & \text { Mellitus } \\
\text { Tipo 1 e } & \text { e } \\
\text { Síndrome } & & \\
\text { Metabólica } & & \\
\text { (Faculdade } & & \text { de } \\
\text { Medicina } & - \\
\text { Universidade } & \text { de } \\
\text { São Paulo) } & \end{array}$ & $13 / 08 / 2012$ & $16 / 09 / 2012$ & 75 & 5 & 100 & A & $\mathrm{N}$ & Concluída \\
\hline $\begin{array}{c}\text { EDM5102- } \\
\quad 3 / 2\end{array}$ & $\begin{array}{lr}\text { Preparação } & \\
\text { Pedagógica } & \text { PAE } \\
\text { (Faculdade } & \text { de } \\
\text { Educação } & - \\
\text { Universidade } & \text { de } \\
\text { São Paulo) } & \end{array}$ & $16 / 08 / 2012$ & $26 / 09 / 2012$ & 60 & 0 & - & - & $\mathrm{N}$ & $\begin{array}{c}\text { Pré- } \\
\text { matrícula } \\
\text { indeferida }\end{array}$ \\
\hline $\begin{array}{l}\text { BMB5804- } \\
\quad 2 / 5\end{array}$ & $\begin{array}{lr}\text { O Órgão } & \text { Adiposo } \\
\text { como } & \text { Centro } \\
\text { Regulador } & \text { do } \\
\text { Metabolismo } & \\
\text { (Instituto } & \text { de } \\
\text { Ciências } & \\
\text { Biomédicas } & - \\
\text { Universidade } & \text { de } \\
\text { São Paulo) } & \end{array}$ & 22/10/2012 & 03/12/2012 & 60 & 4 & 90 & A & $\mathrm{N}$ & Concluída \\
\hline $\begin{array}{c}\text { EDM5102- } \\
3 / 3\end{array}$ & $\begin{array}{lr}\text { Preparação } & \\
\text { Pedagógica } & \text { PAE } \\
\text { (Faculdade } & \text { de } \\
\text { Educação } & - \\
\text { Universidade } & \text { de } \\
\text { São Paulo) } & \end{array}$ & $13 / 03 / 2013$ & $23 / 04 / 2013$ & 60 & 0 & - & - & $\mathrm{N}$ & $\begin{array}{c}\text { Pré- } \\
\text { matrícula } \\
\text { indeferida }\end{array}$ \\
\hline $\begin{array}{c}\text { QBQ5802- } \\
4 / 1\end{array}$ & $\begin{array}{lr}\text { Metodologias } & \text { em } \\
\text { Bioquímica } & \text { e } \\
\text { Biologia Molecular: } \\
\text { Conceitos } \\
\text { Aplicações (Instituto } \\
\text { de Química } \\
\text { Universidade } \\
\text { São Paulo) }\end{array}$ & $19 / 03 / 2013$ & $29 / 04 / 2013$ & 60 & 4 & 100 & A & $\mathrm{N}$ & Concluída \\
\hline $\begin{array}{c}\text { FBA5870- } \\
7 / 1\end{array}$ & $\begin{array}{l}\text { Tópicos em Ciência } \\
\text { dos Alimentos e } \\
\text { Nutrição I }\end{array}$ & 02/04/2013 & $10 / 06 / 2013$ & 30 & 2 & 100 & A & $\mathrm{N}$ & Concluída \\
\hline $\begin{array}{c}\text { FBF5764- } \\
3 / 3\end{array}$ & $\begin{array}{l}\text { Biossíntese } \\
\text { Metabólitos } \\
\text { Secundários } \\
\text { Vegetais }\end{array}$ & $11 / 04 / 2013$ & $22 / 05 / 2013$ & 60 & 4 & 100 & A & $N$ & Concluída \\
\hline RMAREQ1 7_ & Ficinnatnlnnis & 12/nQ/On12 & $17 / \cap a / O \cap 12$ & $a n$ & 1 & $1 \cap n$ & $\Delta$ & $\mathrm{N}$ & Conolinída \\
\hline
\end{tabular}




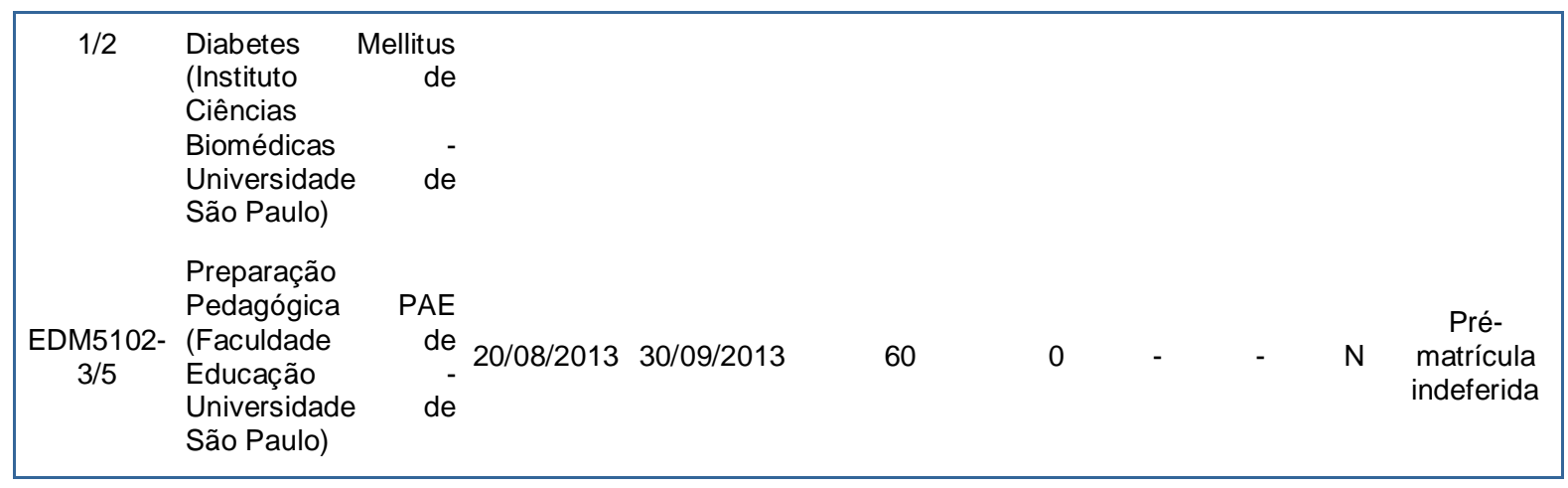

\begin{tabular}{|l|c|c|c|}
\hline & \multicolumn{2}{|c|}{ Créditos mínimos exigidos } & $\begin{array}{c}\text { Créditos } \\
\text { obtidos }\end{array}$ \\
\hline & $\begin{array}{c}\text { Para exame de } \\
\text { qualificação }\end{array}$ & Para depósito de tese & \\
\hline Disciplinas: & 0 & 20 & 23 \\
\hline Estágios: & 0 & & 23 \\
\hline Total: & 0 & 20 & \\
\hline
\end{tabular}

Créditos Atribuídos à Tese: 167

Conceito a partir de 02/01/1997:

A - Excelente, com direito a crédito; B - Bom, com direito a crédito; C - Regular, com direito a crédito; R Reprovado; T - Transferência.

Um(1) crédito equivale a 15 horas de atividade programada.

Última ocorrência: Matrícula de Acompanhamento em 01/02/2016

Impresso em: 05/07/2016 16:40:57 
ANEXO E - CURRICULO LATTES

\section{(9) Curriculo Lattes}

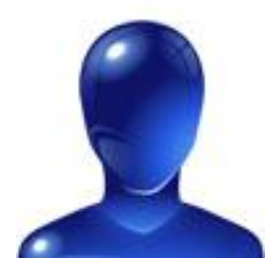

\section{Carlos Mario Donado Pestana}

Endereço para acessar este CV: http://lattes.cnpq.br/0207554760732103

Última atualização do currículo em 01/06/2016

Engenheiro agroindustrial (Universidad Pontificia Bolivariana - 2007) e mestre em Ciências na área de de concentração de Ciência e Tecnologia de Alimentos (Universidade de São Paulo - Escola Superior de Agricultura "Luiz de Queiroz", 2011). Atualmente realizo estudos de Pós-Graduação em nível de doutorado na área de Ciência dos Alimentos (Universidade de São Paulo). Possuo interesses na subárea de Alimentos Funcionais e Compostos Bioativos, principalmente em tópicos como fenólicos, carotenoides, fitoesteróis e suas bioatividades. (Texto informado pelo autor)

\section{Identificação}

Nome Carlos Mario Donado Pestana

Nome em citações bibliográficas Donado-Pestana, Carlos M.;Donado-Pestana CM;DONADOPESTANA, CM;DONADO-PESTANA, CARLOS MARIO

\section{Endereço}

\section{Endereço Profissional}

Universidade de São Paulo, Faculdade de Ciências Farmacêuticas, Departamento de Alimentos e Nutrição Experimental.

Av. Prof. Lineu Prestes, 580

Butantã - Cidade Universitária

05508-000 - Sao Paulo, SP - Brasil

Telefone: (11) 30913656

\section{Formação acadêmica/titulação}

\section{2}

Doutorado em andamento em Ciências dos Alimentos (Conceito CAPES 7).

Universidade de São Paulo, USP, Brasil.

Orientador: (9)Maria Inés Genovese.

Bolsista do(a): Coordenação de Aperfeiçoamento de Pessoal de Nível Superior, CAPES, Brasil. 
Mestrado em Ciência e Tecnologia de Alimentos.

Universidade de São Paulo, USP, Brasil.

Título: Efeitos do processamento sobre a disponibilidade de carotenóides, fenólicos totais e atividade antioxidante em quatro cultivares de batata doce (Ipomoea batatas L.) biofortificados,Ano de Obtenção: 2011.

Orientador: (9)]ocelem Mastrodi Salgado.

Bolsista do(a): Conselho Nacional de Desenvolvimento Científico e Tecnológico, CNPq, Brasil.

Palavras-chave: Alimento funcional; Bioatividade; Biofortificação; Tratamento térmico.

Grande área: Ciências Agrárias

Setores de atividade: Agricultura, Pecuária e Serviços Relacionados.

$2001-2007$

Graduação em Engenharia Agroindustrial.

Universidad Pontificia Bolivariana, UPB, Colômbia.

Título: Clones de yuca y batata con altos contenidos de vitamina A y variedades de maíz QPM: su potencial agroindustrial como fuente de alimentación de poblaciones humanas marginales del caribe colombiano.

Orientador: Antonio José López Montes.

Atuação Profissional

Universidade de São Paulo, USP, Brasil.

Vínculo institucional

2012 - Atual

Vínculo: Bolsista, Enquadramento Funcional: Estudante de Doutorado, Regime: Dedicação exclusiva.

Vínculo institucional

2009 - 2011

Vínculo: Estudante Pós-Graduação, Enquadramento Funcional: Estudante de Mestrado, Regime:

Dedicação exclusiva.

Corporación Colombiana de Investigación Agropecuaria, CORPOICA, Colômbia.

Vínculo institucional

2008 - 2008

Vínculo: Colaborador, Enquadramento Funcional: Pesquisador Colaborador, Carga horária: 20

\section{Vínculo institucional}

2005 - 2007

Vínculo: Iniciação Científica, Enquadramento Funcional: Estudante de Iniciação científica, Regime:

Dedicação exclusiva.

\section{Projetos de pesquisa}

2009 - 2011

Efeitos do processamento sobre a biodisponibilidade de provitamina A em batata doce

Situação: Concluído; Natureza: Pesquisa.

Integrantes: Carlos Mario Donado Pestana - Integrante / Salgado, Jocelem Mastrodi - Coordenador.

$2008-2010$

Desarrollo de sistemas de producción de raizes y parte aérea de la planta de yuca para ser utilizada como suplemento energético-protéico en la producción y mejora de la calidad de la carne bovina en la 
región de Córdoba

Situação: Concluído; Natureza: Pesquisa.

Integrantes: Carlos Mario Donado Pestana - Integrante / Antonio López Montes - Coordenador.

\section{5 - 2007}

Evaluación adaptativa de clones elite de yuca y btatata para la producción intensiva de harinas como material prima con mayor valor nutricional para la cadena avícola y porcícola

Situação: Concluído; Natureza: Pesquisa.

Integrantes: Carlos Mario Donado Pestana - Integrante / Antonio López Montes - Coordenador.

\section{Projetos de desenvolvimento}

\section{7 - 2007}

Planeamiento, construcción y operación de una planta piloto para la producción de alcohol carburante a partir de yuca, batata y otras fuentes de biomasa para la Región del Caribe Colombiano Situação: Concluído; Natureza: Desenvolvimento.

Integrantes: Carlos Mario Donado Pestana - Integrante / Antonio López Montes - Coordenador.

\section{Revisor de periódico}

2012 - Atual

Periódico: Journal of Medicinal Food

2015 - Atual

Periódico: Journal of Functional Foods

\section{Áreas de atuação}

1. Grande área: Ciências Agrárias / Área: Ciência e Tecnologia de Alimentos / Subárea: Alimentos Funcionais e Compostos Bioativos.

2. Grande área: Ciências Agrárias / Área: Ciência e Tecnologia de Alimentos / Subárea: Ciência de Alimentos.

3. Grande área: Ciências Agrárias / Área: Ciência e Tecnologia de Alimentos / Subárea: Ciência de Alimentos/Especialidade: Valor Nutritivo de Alimentos.

\section{Idiomas}

Espanhol Compreende Bem, Fala Bem, Lê Bem, Escreve Bem.

Inglês Compreende Pouco, Fala Pouco, Lê Bem, Escreve Razoavelmente.

Português Compreende Bem, Fala Razoavelmente, Lê Bem, Escreve Bem.

Prêmios e títulos

\section{6}

Segundo Mejor Examen de Calidad a la Educación Superior Institucional. Ingeniería Agroindusrial, Universidad Pontificia Bolivariana.

\section{0}

Mejor Bachiller Examen del Instituto Colombiano de Fomento a la Educación Superior, Colegio Seminario Juan XXIII. 


\section{Produções}

Produção bibliográfica

Artigos completos publicados em periódicos

1. Donado-Pestana, Carlos M.; BELCHIOR, THIAGO ; FESTUCCIA, WILLIAM T. ; GENOVESE, MARIA INES. Phenolic compounds from cambuci (Campomanesia phaea O. Berg) fruit attenuate glucose intolerance and adipose tissue inflammation induced by a high-fat, high-sucrose diet. Food Research International $^{\text {JCR }}$, v. 69, p. 170-178, 2015.

2. DOS SANTOS, PRISCILA ROBERTINA ; Donado-Pestana, Carlos M. ; FRANCISQUINE DELGADO, EDUARDO ; OSSAMU TANAKA, FRANCISCO ; CONTRERAS-CASTILLO, CARMEN J. . Tenderness and oxidative stability of Nellore bulls steaks packaged under vacuum or modified atmosphere during storage at $2^{\circ} \mathrm{C}$. Food Packaging and Shelf Life, v. 4, p. 10-18, 2015.

3. Donado-Pestana, Carlos M.; BELCHIOR, THIAGO;GENOVESE, MARIA INÉS. Phenolic compounds from cagaita (Eugenia dysenterica DC.) fruit prevent body weight and fat mass gain

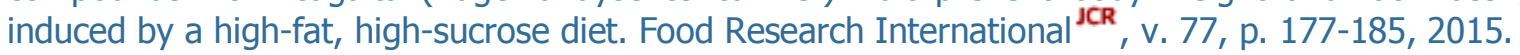

4. CARDOSO, GABRIELLE APARECIDA; Salgado, Jocelem Mastrodi ; CESAR, MARCELO DE CASTRO ; DONADO-PESTANA, CARLOS MARIO. The Effects of Green Tea Consumption and Resistance Training on Body Composition and Resting Metabolic Rate in Overweight or Obese Women. Journal of Medicinal Food ${ }^{\text {JCR }}$, v. 16, p. 120-127, 2013.

5. Salgado, Jocelem Mastrodi ; Ferreira, Tânia Rachel Baroni ; DONADO-PESTANA, CM ; de Almeida, O. C. ; das Neves, A. M ; Mansi, Débora Niero ; Dias, Carlos Tadeu dos Santos . Conjugated Linoleic Acid Combined with Physical Activity Reduces Body Fat Accumulation But Does Not Modify Lean Body Mass in Male and Female Wistar Rats. Journal of Medicinal Food ${ }^{\text {JcR }}$, v. 15, p. 406-412, 2012.

6. Donado-Pestana, Carlos M.; Salgado, Jocelem Mastrodi ; OLIVEIRA RIOS, ALESSANDRO ; SANTOS, PRISCILA ROBERTINA ; JABLONSKI, ANDRÉ . Stability of Carotenoids, Total Phenolics and In Vitro Antioxidant Capacity in the Thermal Processing of Orange-Fleshed Sweet Potato (Ipomoea batatas Lam.) Cultivars Grown in Brazil. Plant Foods for Human Nutrition (Dordrecht) ${ }^{\text {ICR }}$, v. 67, p. 262-270, 2012.

7. Salgado, Jocelem Mastrodi ; Rodrigues, Bruno Sanches ; DONADO-PESTANA, CM ; Dias, Carlos Tadeu dos Santos ; Morzelle, Maressa . Cupuassu (Theobroma grandiflorum) Peel as Potential Source of Dietary Fiber and Phytochemicals in Whole-Bread Preparations. Plant Foods for Human Nutrition (Dordrecht) ${ }^{\text {JCR }}$, v. 66, p. 384-390, 2011.

8. Salgado, Jocelem Mastrodi ; Mansi, Débora Niero ; Bastos, Candido Ricardo ; Donado-Pestana, Carlos M. ; Marcondes, Fernanda Klein ; de Oliveira, Anderson Giovanni Candido . The Role of Black Rice (. Journal of Medicinal Food ${ }^{\text {ICR }}$, v. 13, p. 1355-1362, 2010.

\section{Capítulos de livros publicados}

1. Salgado, J. ; DONADO-PESTANA, CM . Soy as a Functional Food. In: Hany El-Shemy. (Org.). Soybean and Nutrition. 1ed.Rijeka: Intech Publisher, 2011, v. 1, p. 21-44.

\section{Resumos expandidos publicados em anais de congressos}

1. Santos PR ; Contreras-Castillo CJ ; DONADO-PESTANA, CM ; Delgado, EF . Influência de Diferentes Sistemas de Embalagem na Maciez e Oxidação Protéica de Músculo Longissimus lumborum. 
In: VIII Congreso Iberoamericano de Ingeniería de Alimentos, 2011, Lima. CIBIA Llave de la Innovación. Lima: Facultad de Industrias Alimentarias UNALM, 2011. v. 1. p. PA-052-PA-052.

2. Santos PR ; Contreras-Castillo CJ ; DONADO-PESTANA, CM ; Feldmann V . Estabilidade oxidativa e índice de maciez de bifes de bovinos machos inteiros embalados em atmosferas modificadas ou vácuo durante estocagem refrigerada. In: VI Congresso Brasileiro de Ciência e Tecnologia de Carnes, 2011, Campinas. VI Congresso Brasileiro de Ciência e Tecnologia de Carnes, Anais - Resumos. Campinas: ITAL, 2011. v. 1. p. 1-4.

\section{Resumos publicados em anais de congressos}

1. DONADO-PESTANA, CM; BELCHIOR, THIAGO ; FESTUCCIA, WILLIAM T. ; GENOVESE, MARIA INES . Polyphenols from cambuci (Campomanesia phaea O. Berg) fruit attenuate glucose intolerance and adipose tissue infl ammation induced by a high-fat, high-sucrose diet. In: 7th International Conference on Polyphenols and Health, 2015, Tours, France. 7th International Conference on Polyphenols and Health, 2015.

2. DONADO-PESTANA, CM; BARROS, H. ; GENOVESE, M. I. . Phenolic compounds from cagaita (Eugenia dysenterica DC) fruit reduce body fat accumulation and inflammatory status in c57bl/6 mice fed a high-fat high-sucrose diet. In: VIII World Congress on Polyphenols Applications, 2014, Lisbon. International Society of Antioxidants in Nutrition and Health. 8th ISANH Congress on Polyphenols Applications, 2014.

3. DONADO-PESTANA, CM; ARAUJO, R. ; COLOMBO, K. ; DAZA, L. D. ; GENOVESE, M. I. . Polyphenols from cagaita (Eugenia dysenterica DC.) fruit and leaves and their in vitro antioxidant / antidiabetic / antiobesity functionality. In: VI International Conference on Polyphenols and Health, 2013, Buenos Aires. VI International Conference on Polyphenols and Health, 2013.

4. Santos PR ; Contreras-Castillo CJ ; DONADO-PESTANA, CM ; Delgado, EF ; Almeida, M. . Tenderness and oxidative stability of beef in modified atmospheres packaging and vacuum. In: 58th International Congress of Meat Science and Technology, 2012, Montreal. The Healthy World of Meat, 2012.

\section{Apresentações de Trabalho}

1. DONADO-PESTANA, CM; López-Montes, A ; Bautista, M. Exposición y muestra de productos biofortificados.. 2008. (Apresentação de Trabalho/Comunicação).

2. DONADO-PESTANA, CM; López-Montes, A . Alimentos Biofortificados. Socialización de los resultados de investigaciones agrícolas y pecuarios en el Centro de Investigación Turipaná. 2006. (Apresentação de Trabalho/Comunicação).

\section{Bancas}

Participação em bancas de trabalhos de conclusão

Trabalhos de conclusão de curso de graduação

1. DONADO-PESTANA, CM; Salgado, J.; Morzelle, M.. Participação em banca de Fúvia de Oliveira Biazotto.Elaboração de chá infusão a base de extrato seco de casca de romã (Punica granatum). 2011

- Universidade de São Paulo.

\section{Eventos}


1. Aplicações da Metabolômica na Pesquisa em Alimentos, Nutrição e Agriculturaura. 2013. (Simpósio).

2. Lactic Acid Bacteria, Dairy Proteins and Dairy Products: Structure-Function Relationships And Different Uses?e. 2013. (Seminário).

3. Uso de Animais na Experimentação. Biotério e Animais de Laboratório e Ética na Experimentação. 2013. (Simpósio).

4. International Workshop on Capillary Electrophoresis and Microchip Technology. 2010. (Outra).

5. Simpósio de Alimentos Funcionais. 2009. (Simpósio).

6. I Semana Nacional de la Ciencia, la Tecnología y la Innovación en Colombia.Alimentos Biofortificados. 2006. (Outra).

\section{Educação e Popularização de C \& T}

\section{Livros e capítulos}

1. Salgado, J. ; DONADO-PESTANA, CM . Soy as a Functional Food. In: Hany El-Shemy. (Org.). Soybean and Nutrition. 1ed.Rijeka: Intech Publisher, 2011, v. 1, p. 21-44. 

